TALITA RODRIGUES GOMES

O ERRO MÉDICO SOB O OLHAR DO JUDICIÁRIO: UMA ANÁLISE DAS DECISÕES DO TRIBUNAL DE JUSTIÇA DO DISTRITO FEDERAL E TERRITÓRIOS 


\author{
UNIVERSIDADE DE BRASÍLIA \\ FACULDADE DE CIÊNCIAS DA SAÚDE \\ PROGRAMA DE PÓS-GRADUAÇÃO EM SAÚDE COLETIVA
}

TALITA RODRIGUES GOMES

\title{
O ERRO MÉDICO SOB O OLHAR DO JUDICIÁRIO: UMA ANÁLISE DAS DECISÕES DO TRIBUNAL DE JUSTIÇA DO DISTRITO FEDERAL E TERRITÓRIOS
}

\footnotetext{
Dissertação apresentada como requisito parcial para obtenção do Título de Mestre em Saúde Coletiva pelo Programa de PósGraduação em Saúde Coletiva da Universidade de Brasília.

Orientadora: Profa. Dra.Maria Célia Delduque Pires de Sá
}

BRASÍLIA 


\title{
O ERRO MÉDICO SOB O OLHAR DO JUDICIÁRIO: UMA ANÁLISE DAS DECISÕES DO TRIBUNAL DE JUSTIÇA DO DISTRITO FEDERAL E TERRITÓRIOS
}

\author{
Dissertação apresentada como requisito parcial para obtenção \\ do Título de Mestre em Saúde Coletiva pelo Programa de Pós- \\ Graduação em Saúde Coletiva da Universidade de Brasília. \\ Orientadora: Profa. Dra. Maria Célia Delduque Nogueira Pires \\ de Sá
}

Aprovado em 20/02/2017

\section{BANCA EXAMINADORA}

Profa. Dra. Maria Célia Delduque Pires de Sá (Presidente)

Universidade de Brasília

Prof. Dr. Vitor Laerte Pinto Júnior

Universidade de Brasília

Profa. Dra. Silvia Badim Marques

Universidade de Brasília

Profa. Dra. Tania Cristina Morais Santa Barbara Rehem

Universidade de Brasília 
Aos meus pais Ricardo e Socorro pelo exemplo de vida e pelo amor incondicional.

Ao Lawrence pelo amor, carinho e compreensão durante essa caminhada.

Ao Edu por acreditar que tudo vai dar certo. 


\section{AGRADECIMENTOS}

Agradeço a Deus por todas as bênçãos derramadas sobre mim, pois sei que a Sua graça se fez presente em todos os momentos da minha vida, iluminando meu caminho e abrindo portas para novas conquistas.

Agradeço à minha família, meu marido e ao meu companheiro de patas Toquinho pelo carinho e apoio incondicional durante o processo de construção desse mestrado, respeitando minhas ausências e motivando-me sempre a realizar novos sonhos.

Agradeço imensamente à minha mentora, professora e orientadora Maria Célia Delduque Nogueira Pires de Sá, por todo o tempo e confiança investido em mim, com toda sua atenção, ensinando-me a ampliar e aperfeiçoar meus conhecimentos no decorrer dessa experiência. Em especial por ensinar-me a ser uma pesquisadora apaixonada pelo Direito Sanitário e as Políticas Públicas de Saúde.

Agradeço aos professores e à coordenação do Mestrado Profissional em Saúde Coletiva pelo carinhoso apoio, pela dedicação e por proporcionar o conhecimento durante esse processo de formação profissional. Vocês terão meus eternos agradecimentos.

Agradeço meus colegas de mestrado pela companhia, incentivo e experiências compartilhadas ao longo do mestrado. Em especial à Maíra pela amizade e parceria a cada semestre do curso, alegrando os intervalos de aula e os trabalhos de grupo.

Agradeço a equipe de trabalho junto ao Programa de Direito Sanitário da Fiocruz Brasília, Sandra, Ester, Anna Karina, Cássia, Ivan, Felipe, Luciana e Anna Paula pelo carinho e apoio motivacional de todos os dias.

Aos amigos que fazem parte da minha vida e fizeram parte da minha formação, e que me fortaleceram apesar de todas as dificuldades que enfrentamos juntos. 
"Our lives begin to end the day we become silent about things that matter."

(Martin Luther King Jr.)

I Have A Dream - Agosto, 1963. 


\section{RESUMO}

A ocorrência de erros médicos causam danos e sofrimento aos pacientes. A relação insatisfatória entre médicos, instituições de saúde e pacientes são motivos que desencadeiam grande parte das denúncias feitas nos conselhos regionais de medicina e nos tribunais, traduzidos em processos judiciais e indenizações. $O$ erro médico é entendido como o dano provocado no paciente pela ação ou omissão do profissional de saúde no exercício de sua profissão com ou sem a intenção de cometêlo podendo ser definido como imprudência, imperícia ou negligência. Este trabalho visa estudar as demandas de justiça relacionadas ao erro médico junto ao Tribunal de Justiça do Distrito Federal e Territórios disponíveis e publicadas em seu respectivo sitio eletrônico com a finalidade de conhecer o objeto material das ações propostas pelos pacientes; identificar a especialidade médica envolvida nos pleitos judicializados; analisar e qualificar os argumentos dos magistrados nas decisões relacionadas ao erro médico por meio de um levantamento bibliográfico sobre o tema, e com a utilização de diferentes metodologias de coleta e análise de dados para cada objetivo específico. Como resultado observou-se a partir da revisão de literatura que o estudo do tema erro médico no Brasil ainda está muito centrada na área da Enfermagem enquanto no exterior há uma ampla discussão que envolve diversas áreas da saúde, observou-se pela análise dos dados coletados no site do TJDFT durante os anos de 2013 a 2015 que a maioria dos pleitos tratam de indenizações por danos morais e materiais, $51 \%$ das sentenças tiveram o setor privado como polo passivo da ação, $44 \%$ o setor público, as especialidades com maior envolvimentos em ações relacionadas ao erro médico foram ginecologia-obstetrícia seguida de cirurgia geral e plástica, em relação a decisão judicial, 57\% foram consideradas improcedentes e $22 \%$ foram consideradas procedentes. Em vista aos dados qualitativos observamos pela análise do discurso dos magistrados que há um uso diferenciado da legislação para o julgamento de casos de erro médico de forma distinta para o setor público, baseada no arcabouço legal do direito a saúde enquanto frente ao setor privado elencam legislação referente a uma relação consumerista. É necessário haver uma visão sistêmica ao enfrentamento da questão do erro na prática médica assim como a aplicação de mecanismo de prevenção eficazes.

Palavras-chave: Erro médico. Segurança do Paciente. Políticas de Saúde. Judicialização. 


\section{ABSTRACT}

The occurrence of medical errors usually causes harm and suffering to patients. Unsuccessful relationship between doctors, health institutions and patients are the main reasons that trigger most of the complaints made in medical councils and through lawsuits in the courtroom. Medical error can be understood as the damage caused to the patient by the actions or omission of the health professional during his or her assignment with or without the intention of committing. They are defined as recklessness, malpractice or negligence. This study proposal looks forwards to study lawsuits related to medical error through the Federal District Court database, available and published in the electronic website; with the purpose of knowing the material object of the actions moved by the patients and their families. This work intent to identify the medical specialties involved on each litigation and intents to analyze and qualify the judge's arguments in decisions related to medical error through a bibliographical survey on the subject, and with the use of different methods of data collection and speech analysis method. As observed from the literature review, the study of the medical error topic in Brazil focuses on the nursing area even thou in other countries there is already a wide discussion involving other health areas. It was also observed by the data analysis in the TJDFT website regarding actions from 2013 to 2015, that, most lawsuits deal with repair of moral and material damages; $51 \%$ of the judgments had the private sector as a passive actor; $44 \%$ the public sector; specialties with most participations in lawsuits were gynecology-obstetrics followed by general and plastic surgery; sentences were denied in $57 \%$ and ruled in favor in $22 \%$. The qualitative data viewed that the judge's analysis have a distinguished use of legislation in cases were the public sector is involved using the legal framework of the right to health while when it involves the private sector they perceive as a consuming relation. There needs to be a systemic approach when addressing the medical error issue during practice as well as the application of effective prevention mechanisms.

Key-words: Medical error. Patient safety. Health Policies. Judicialization 


\section{LISTA DE ABREVIATURAS E SIGLAS}

ANVISA - Agência Nacional de Vigilância Sanitária

CFM - Conselho Federal de Medicina

CPOE - Computerized Provider Order Entry

CREMESP - Conselho Regional de Medicina do Estado de São Paulo

GM - Gabinete do Ministro

ICPS - Classificação Internacional de Segurança do Paciente

IOM - Instituto de Medicina

MS - Ministério da Saúde

NCQHSP - Núcleo Central de Qualidade Hospitalar e Segurança do Paciente

NOTIVISA - Sistema de Notificações em Vigilância Sanitária

OMS - Organização Mundial de Saúde

OPAS - Organização Pan-americana de Saúde

PNSP - Programa Nacional de Segurança do Paciente

RDC - Resolução da Diretoria Colegiada

SAS - Subsecretaria de Atenção à Saúde

SESDF - Secretaria de Saúde do Distrito Federal

SUS - Sistema Único de Saúde

TJDFT - Tribunal de Justiça do Distrito Federal e Territórios 


\section{LISTA DE FIGURAS}

Figura 1 Construída pelos autores com base na metodologia aplicada.

.43

Figura 1 Principais fatores que interferem na ocorrência de erros (Desenvolvido pelas autoras com base na figura descrita por Carvalho et. al.)

Figura 2 Classificação das ações cíveis e criminais sobre erro médico no TJDFT entre os anos de 2013-2015 (Fonte: TJDFT)

Figura 3 Tipo de danos reclamados nos processos judiciais entre 2013-2015 sobre erro médico no TJDFT (Fonte: TJDFT)

Figura 4 - Identificação do polo passivo das ações judiciais sobre erro médico no TJDFT no período entre 2013 e 2015. (Fonte: TJDFT)

Figura 5 Resultado das decisões nas ações sobre erro médico analisadas no TFDFT, no período entre 2013-2015 (Fonte: TJDFT)

Figura 1 Tipos de requeridos nos processos entre 2013-2015 no TJDFT sobre erro médico. (Fonte: TJDFT) 


\section{LISTA DE QUADROS E TABELAS}

Tabela 1 - Especialidades médicas/enfermagem/odontologia em número de processos de erro médico no TJDFT, entre os anos de 2013-2015

Tabela 1 - Análise dos Discursos inseridos nas Decisões Procedentes das Apelações Cíveis e Criminais com a Variável Normativa. .71

Tabela 2 - Análise dos Discursos inseridos nas Decisões Procedentes das Apelações Cíveis e Criminais com a Variável Processual.

Tabela 3 - Análise dos Discursos inseridos nas Decisões Procedentes das Apelações Cíveis e Criminais com a Variável Material (Fática).

Quadro 1 - Títulos dos artigos sobre erro médico e cuidados com pacientes em língua portuguesa encontrado nas bases BVS, LILACS e MEDLINE - 2014-2015, tipo de estudo, área de pesquisa e palavras-chave. 89

Quadro 2 - Títulos dos artigos sobre erro médico e cuidados com pacientes em língua inglesa encontrado nas bases BVS, LILACS e MEDLINE - 2014-2015, tipo de estudo, área de pesquisa e palavras-chave. 


\section{SUMÁRIO}

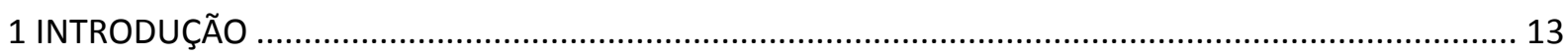

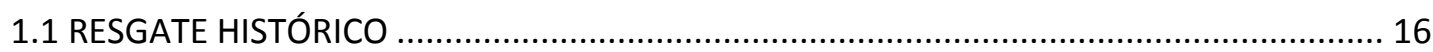

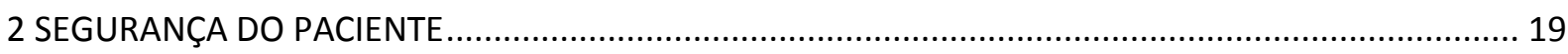

2.1 SEGURANÇA DO PACIENTE NO CUIDADO EM SAÚDE ................................................... 23

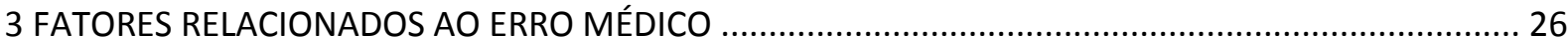

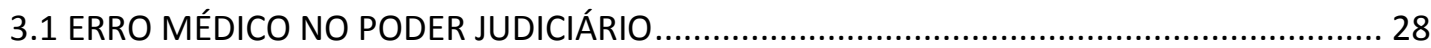

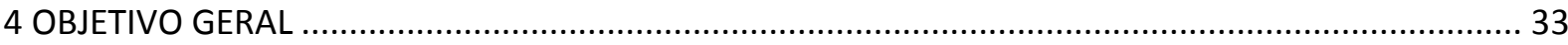

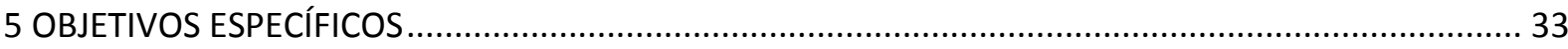

6 METODOLOGIA

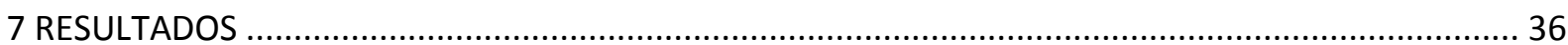

Artigo 1: A questão do erro médico no Brasil: uma revisão integrativa sobre segurança do paciente. -

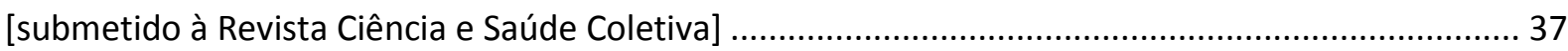

Artigo 2: O Erro médico sob o olhar do Judiciário: uma investigação no Tribunal de Justiça do Distrito

Federal e Territórios - [submetido aos Cadernos Ibero-Americanos de Direito Sanitário] .................. 52

Artigo 3: Análise Idiossincrática dos Discursos proferidos nas decisões judiciais sobre Erro Médico no

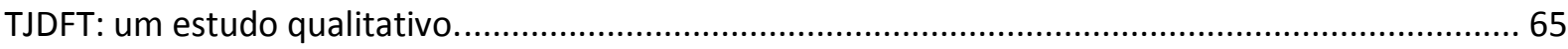

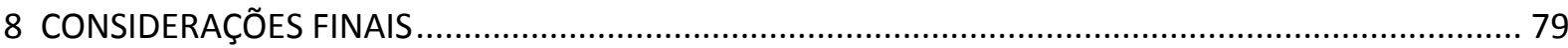

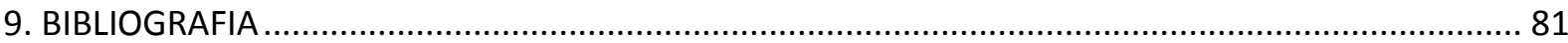

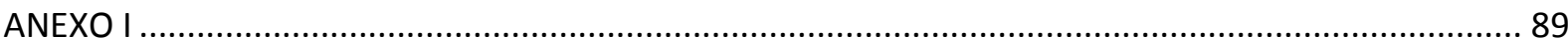

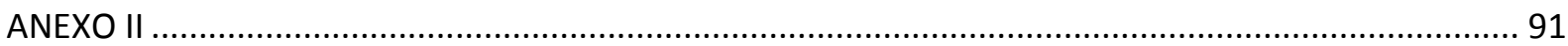




\section{INTRODUÇÃO}

Apesar de incontestáveis avanços na área da medicina, um problema continua ameaçando os profissionais de saúde e os pacientes: a ocorrência de erros. As questões relacionadas com a qualidade em saúde e segurança do paciente, em particular a ocorrência de erros e eventos adversos, têm constituído há tempos parte de uma crescente preocupação não só para as organizações de saúde como também para os atores políticos, gestores, profissionais de saúde, os pacientes e seus familiares.

Existem poucos estudos no Brasil que evidenciam a presença de iatrogenias decorrente de má prática profissional dentro das instituições de saúde, suas consequências e a gravidade do problema. Nesse contexto, um sistema desorganizado e complexo, associado a profissionais despreparados e com experiência insuficiente para lidar com a situação, induz ao erro. Este pensamento parece evidente, no entanto, foi ignorado durante séculos. Somente agora a partir do século XXI, que este assunto é refletido com maior atenção e importância.

Semelhante ao setor de saúde, outras atividades de risco elevado como a aviação civil, sugerem uma lógica de um sistema com ênfase nos processos que minimizem a ocorrência de eventos adversos e, assim, otimizem a segurança da atividade e do trabalhado. Ou seja, ao reconhecer que o fator humano é passível de falhas, evitáveis ou não, observa-se uma mudança na conformação e na maneira que o sistema funciona, de forma a prevenir os "quase erros" e reduzir as taxas de eventos adversos.

A ocorrência de um evento adverso não significa obrigatoriamente que houve erro no cuidado com o paciente. Pacientes podem sofrer danos inerentes ao cuidado de saúde que não podem ser evitados. O evento adverso evitável representa o dano ao paciente que está associado a uma falha ativa ou a uma condição latente, ou mesmo a uma violação de normas e padrões. James Reason, um psicólogo britânico autor de Human Error, uma série de relatos sobre a segurança do paciente, mostrou que a abordagem individualizada do problema é obsoleta e propõe a quebra deste paradigma. Ele demonstrou que a ocorrência de um erro é decorrente da falha de um sistema e deve ser enfrentada de forma sistêmica e não pontual. Através de suas observações ele propôs o Modelo do Queijo Suíço, onde um erro ativo (na ponta) é o 
resultado de uma sequência alinhada de erros latentes (no processo) que perpassam falhas nas barreiras (fatias de queijo).

O avanço do conhecimento e a melhora das práticas de segurança do paciente esbarram na grande proliferação de definições e terminologias. Para homogeneizar definições dos principais conceitos presentes na literatura sobre segurança do paciente, a Organização Mundial de Saúde (OMS), por meio do Patient Safety Program, desenvolveu a Classificação Internacional de Segurança do Paciente (ICPS), na qual incidente é definido como todo evento ou circunstância que poderia ter resultado, ou resultou, em dano desnecessário ao paciente. Nessa classificação, os incidentes com dano correspondem aos EAs. Entretanto, a ICPS é posterior e difere da maioria dos estudos sobre incidência de EA já consolidados na literatura.

O conceito de segurança do paciente implica que os profissionais envolvidos nos cuidados de saúde devem assegurar que os tratamentos e intervenções que os os pacientes recebem não Ihes causam danos, lesões ou complicações além das consequências naturais da evolução da sua própria doença e dos necessários e justificados para o diagnóstico e tratamento da mesma. A ocorrência crescente de casos documentados de eventos adversos no cuidado à saúde tem provocado um debate sobre a segurança do paciente em âmbito internacional. Reconhecer que a exposição ao sistema de saúde pode gerar danos, e não só proporcionar benefícios deve ser encarado como consequência inevitável que se paga pelos avanços tecnológicos e progressos da medicina.

Para os efeitos da análise do desvio de conduta médica, o Direito não leva em consideração se o mal foi praticado por erro ou por ignorância. Tanto incide em responsabilidade o médico que, no mau exercício da profissão, causa dano ao paciente por erro, quanto o profissional que compromete a vida ou a saúde do paciente por ignorância. O importante é o que se denomina "má prática" - uma expressão cunhada pelos americanos "malpractice" e que se aplica a todas as profissões da área da saúde. É a má prática que pode levar à responsabilidade legal do médico, podendo assumir aspectos: penal, civil ou administrativo.

Em vista essa relação da prática médica, a ocorrência do erro com consequentes danos materiais ou morais, acabam por desembocar no Poder Judiciário, que se vê na contingência de decidir sobre os aspectos da 
responsabilidade penal e cível dos profissionais de saúde, mais essencialmente, dos médicos.

Nos últimos anos, o Supremo Tribunal Federal tem desempenhado um papel ativo na vida institucional brasileira. A atuação da Corte na tomada de decisões sobre algumas das grandes questões nacionais tem gerado aplauso e crítica, e exigem uma reflexão cuidadosa. $O$ fenômeno da judicialização não é peculiaridade nossa pois em diferentes partes do mundo cortes constitucionais ou supremas cortes destacaram-se em determinadas ações históricas como protagonistas de decisões envolvendo questões de largo alcance político e implementação de políticas públicas em temas controversos na sociedade, o que demonstra a corrente fronteira entre a política e a justiça no mundo contemporâneo.

A judicialização pode ser compreendida como a atuação dos órgãos do Poder Judiciário em decidir frente algumas questões de larga repercussão política ou social no lugar das instâncias políticas tradicionais como o Congresso Nacional, o Poder Executivo e a Administração Pública em geral. A judicialização envolve uma transferência de poder para juízes e tribunais, com alterações significativas na linguagem, na argumentação e no modo de participação da sociedade. Um fenômeno de causas múltiplas que refletem uma tendência mundial.

No Brasil há poucos estudos que abordam o erro médico nos tribunais e investigações sobre as decisões judiciais, valores de indenizações, especialidades médicas mais judicializadas por erro, etc., mas é de importância crucial que se debruce sobre temas dessa envergadura a fim de conhecer e analisar esse aspecto da relação médico-paciente, especialmente na atualidade, em que escolas de medicina têm encontrado terreno fértil para sua proliferação no país.

Assim que se elegeu este tema para a pesquisa jurisprudencial no Tribunal de Justiça do Distrito Federal, como locus de investigação para o erro médico. O trabalho de pesquisa que dá ensejo a esta dissertação de Mestrado Profissional junto a Universidade de Brasília, Faculdade de Saúde, Departamento de Saúde Coletiva, foi levado à cabo durante os anos de 2015 e 2016, na esteira dos projetos de pesquisa sobre judicialização lato sensu desenvolvidos no Programa de Direito Sanitário da Fundação Oswaldo Cruz, em Brasília. Esta dissertação foi construída em forma de artigos: a revisão de literatura realizada está consubstanciada em um artigo já 
submetido à Revista Ciência e Saúde Coletiva, assim como os resultados obtidos estão apresentados em dois artigos distintos, sendo um com abordagem qualitativa e o outro com abordagem quantitativa.

Deste modo, este trabalho de investigação sobre a saúde nos tribunais dá maior ênfase às consequências da relação entre o exercício profissional da medicina e o dano ao paciente, o chamado Erro Médico.

\subsection{RESGATE HISTÓRICO}

$\mathrm{Na}$ antiguidade remota, o exercício da Medicina era um conglomerado de mitos, em que se curava por sonhos, em que se levava em conta somente a cura que, de tão raras, eram inscritas nas colunas dos templos (MORAES, 1996).

Dezenove séculos antes de Cristo, Hamurabi - fundador do império babilônico - inscreveu em seu famoso Código de Hamurabi, várias normas prevendo penas para os médicos incompetentes ou desastrosos. No curso do tempo, a disciplina legal da profissão médica foi ganhando vulto, atingindo sua maioridade com Hipócrates de Cós, que com seus discípulos escreveu 120 obras enfatizando o compromisso que o médico deve assumir de ser fiel às melhores tradições de sua profissão. Tais normas passaram a enriquecer o "juramento hipocrático" que realça a fidelidade nas graduações médicas.

Ainda na Grécia Antiga (460-351 a.C.) "o pai da medicina", instituiu o princípio da não maleficência Primum Non Nocere: "aos doentes, tenha por hábito duas coisas: ajudar ou, pelo menos, não produzir dano", de forma similar, no século 18 a.C., quando o Código de Hamurabi, que dispunha sobre regras e punições para eventos da vida cotidiana, "Olho por olho, Dente por dente", onde os médicos pagavam pelo erro com a perda das próprias mãos (CHEHUEN NETO et. al., 2011).

Entende-se o Estado neste período como a fonte e o fundamento único do direito; um sistema fechado de direito positivo onde restam cristalizados as visões de mundo e as prerrogativas de uma classe social interessada se manter vitoriosa. Corresponde a um sistema hermenêutico sem brechas, em que nada ficava ao arbítrio do juiz. Começa-se a cultivar a ideia de ordenamento jurídico, complexo de normas que traduzem preceitos declarativos, proibitivos e permitidos aos cidadãos (BOBBIO, 1994). 
Em Roma, as leis sobre o erro médico eram bastante severas, o que acabou por afastar da profissão os mais aptos e capazes, por receio das punições que poderiam sofrer (MORAES, 1996). O êxodo foi tão extremo que a partir de certa época apenas escravos curavam, enquanto os mais abastados passaram a importar médicos de Alexandria e da Grécia. Foi um período em que a Medicina perdeu sua dignidade no Império Romano, chegando ao extremo da produção de unguentos da simpatia, na Escola de Salerno.

A atividade médica durante o período romano caracterizava-se como forma de coerção contra o dano sofrido. Foi no direito romano que a responsabilidade civil (inclusive a responsabilidade médica) ganhou princípios genéricos que mais tarde seriam cristalinizados nas legislações ocidentais modernas. Neste período nascem as célebres Leis das 12 tábuas (Lex Duodecim Tabularum), legislação que reunia sistematicamente todo o direito que era praticado na época. (MOURA, 2009). Em Roma, o ato ilícito implicava na obrigação de indenizar a parte lesada e à condenação pecuniária. Surge no séc. III a.C. a Lei Anquilia de dammo que formula um conceito apurado de culpa, bem como a tipificação de alguns delitos que poderiam ser cometidos por médicos - os primeiros elementos da responsabilidade médica. Com a lei, nasce o que se entende por responsabilidade civil delitual ou extracontratual e concomitantemente, surge também, a responsabilidade subjetiva pautada na culpa do autor da conduta ilícita.

O Estado agora entendido como um ente de natureza política que deve servir à administração da própria política e dos negócios públicos, normatiza assuntos internos e variados no contexto social. O Estado moderno surge quando as forças do Estado Medieval estavam dissipadas por causa do crescimento das forças produtivas, o poder estava sem foco e descentralizado. Ele atua como mecanismo em que se agregam o político, o econômico e o jurídico. A organização política estava centrada na norma jurídica, na lei e a separação dos poderes permitia à sociedade política controlá-lo de forma mais eficaz, de modo suas manifestações não poderiam transbordar dos estritos limites estabelecidos pela lei.

Na França, no início do século XIX surge a teoria da irresponsabilidade médica, que baseada numa decisão da Academia de Medicina de Paris em 1829, consistia no entendimento de que só havia a responsabilidade moral dos profissionais da arte de curar, consagrando uma espécie de imunidade, pois para que houvesse 
responsabilidade médica, seria necessário provar-se falta grave, imprudência visível, manifesta imperícia. Defendia também que os juízes não estavam aptos a julgarem a conduta médica, e que as pretensões de ressarcimentos materiais deveriam ser consideradas tentativas de enriquecimento ilícito. Todavia, com a verdadeira revolução operada pela jurisprudência francesa, de $1832 \mathrm{em}$ diante, passou-se a conceber a tese da responsabilidade plena, quando verificada a culpa do profissional, inclusive do médico, pois não era mais admissível conceder privilégios a determinadas categorias. Este princípio (da responsabilidade plena) norteou e ainda norteia os ordenamentos jurídicos de todo o Ocidente (KFOURI NETO, 2003).

$\mathrm{Na}$ legislação francesa, a culpa foi inserida como pressuposto da responsabilidade civil aquiliana, influenciando diversas legislações, até mesmo o Código Civil Brasileiro.

Entretanto, esta teoria da culpa trazida pela legislação francesa não foi suficiente para regular todos os casos concretos ao longo do tempo, o que fez surgir outras teorias. Tais teorias são amparadas em várias legislações mundiais, sem, contudo, fazer desaparecer totalmente a teoria clássica da culpa, o que ocorreu inclusive com o Código Civil Brasileiro que reconhece, expressamente em seu art. 927, as duas espécies de responsabilidade, isto é, a responsabilidade subjetiva, com a devida comprovação da culpa e a responsabilidade objetiva, que existe independentemente de culpa.

Art. 927. Aquele que, por ato ilícito (Arts. 186 e 187), causar dano a outrem, fica obrigado a repará-lo.

Parágrafo único. Haverá obrigação de reparar o dano, independentemente de culpa, nos casos especificados em lei, ou quando a atividade normalmente desenvolvida pelo autor do dano implicar, por sua natureza, risco para os direitos de outrem.

Observa-se no caput do referido do artigo o tratamento da responsabilidade civil estribada na culpa, ou seja, a responsabilidade civil subjetiva, posto que a remissão ao artigo 186 como prática de ato ilícito revela que o mesmo é aquele causado por ação ou omissão voluntária, negligência ou imprudência, que são espécies do gênero culpa. Por outro lado, o parágrafo único do artigo supracitado 
revela a responsabilidade objetiva, na medida em que nos revela a expressão "independentemente de culpa".

Antigamente não se possuía uma assistência especializada e mesmo assim não era permissivo errar. À medida que ocorreram novos avanços no conhecimento e consequentemente a tecnologia foi evoluindo a complexidade assistencial e aumentase a probabilidade de sobreviver à erros também. Contrariamente a esse contexto, cada vez mais a conduta punitiva é adotada, de modo a identificar e apontar sempre o indivíduo responsável pelo engano, ou seja, leis restritivas foram paulatinamente dando lugar a uma prática indiscriminada e descontrolada da Medicina, gerando muitos erros.

\section{SEGURANÇA DO PACIENTE}

A segurança do paciente, uma importante dimensão da qualidade em saúde, se tornou foco de atenção a partir do relatório apresentado em 1998 pelo Instituto de Medicina (IOM) - To err is human -, que estimou a ocorrência de até 98.000 óbitos anualmente, em decorrência de erros médicos em hospitais dos EUA, apontando a alta frequência de eventos adversos resultantes do cuidado hospitalar, ou seja, incidentes que resultavam em dano para o paciente, e que mais da metade dos casos eram evitáveis. Este relatório revolucionou a abordagem sobre a segurança e qualidade da atuação médica, estimulando organizações e agências de saúde a desenvolverem dispositivos para a melhoria da segurança do paciente e à elaboração de estratégias voltadas para a melhoria da qualidade do cuidado à saúde e consequente minimização dos riscos. A partir de então, a segurança do paciente entra na agenda dos pesquisadores de vários países e passa a ser internacionalmente reconhecida como uma dimensão da qualidade em saúde.

Em 2002, durante a 55ª Assembleia Mundial da Organização Mundial de Saúde (OMS) foi aprovada a Resolução WHA 55.18 com o tema "Qualidade da Atenção: Segurança do Paciente" pela qual urge à OMS e a seus Estados Membros a conceder a maior atenção possível à segurança do paciente. Em 2004, cria-se a Aliança Mundial para a Segurança do Paciente voltada para elevar a consciência e o compromisso político com a melhoria da segurança dos cuidados e para facilitar o desenvolvimento de políticas e práticas seguras na atenção sanitária. Como uma das primeiras 
propostas centrais dos Desafios Globais para a Segurança do Paciente, formulado com a ajuda de mais de 100 especialistas internacionais e que foi implementada em diferentes partes do mundo, a OMS, em 2005, publicou diretrizes sobre uma medida básica para reduzir as infecções: a higienização das mãos. O desafio "Mãos limpas são mãos mais seguras" concentrou-se na melhoria dos padrões e práticas de higienização das mãos na assistência à saúde ajudando a implantar intervenções bem-sucedidas.

No Brasil, o reflexo das iniciativas da OMS tornou-se mais evidente a partir de 2006, com o I Fórum de Segurança do Paciente: Erros de Medicação. Nesse evento, conferencistas discutiram diversos conceitos na área de segurança do paciente e erros de medicação, apresentaram um panorama histórico nacional e internacional, bem como experiências e estratégias em prevenção de erros no ambiente ambulatorial e hospitalar.

Pode-se citar exemplos de ações específicas no campo da segurança do paciente no Brasil antes da concretização de uma política específica relacionada ao tema. Para atender a necessidade de informações qualificadas e para retroalimentação dos processos de revalidação de registros, a Anvisa desenvolveu um projeto de ações de vigilância sanitária em hospitais que visa favorecer a organização de gerências de risco sanitário hospitalar, chamada Rede Sentinela. Essa rede compõe-se de instituições que, desde 2002, trabalham com gerenciamento de risco sobre três pilares: busca ativa de eventos adversos; notificação de eventos adversos e uso racional das tecnologias em saúde, monitorando um conjunto de eventos adversos no atendimento aos pacientes.

Em 2009, instituiu-se por meio da Portaria do Ministério da Saúde MS/GM no 1.660, o Sistema de Notificação e Investigação em Vigilância Sanitária (NOTIVISA), no âmbito do Sistema Nacional de Vigilância Sanitária, como parte integrante do Sistema Único de Saúde (SUS). Uma das premissas do NOTIVISA é a necessidade de promover a identificação precoce de problemas relacionados com os serviços e produtos sob vigilância sanitária, a fim de eliminar ou minimizar os riscos decorrentes do seu uso.

Em 2011, com a RDC n63, a Anvisa, visando estabelecer fundamentos na qualificação, na humanização da atenção e gestão, e na redução e controle de riscos 
aos usuários e ao meio ambiente, estabeleceu requisitos de boas práticas de funcionamento de serviços de saúde.

Em 2013, instituído por meio da Portaria do Ministério da Saúde MS/GM nํ529, com o objetivo geral de contribuir para a qualificação do cuidado em saúde em todos os estabelecimentos de Saúde do território nacional, públicos e privados, criou-se o Programa Nacional de Segurança do Paciente (PNSP) que lista no seu art. $3^{\circ}$ os seguintes objetivos:

a) Promover e apoiar a implementação de iniciativas voltadas à segurança do paciente em diferentes áreas da atenção;

b) Organização e gestão de serviços de saúde, por meio da implantação da gestão de risco e de Núcleos de Segurança do Paciente nos estabelecimentos de saúde;

c) Envolver os pacientes e familiares nas ações de segurança do paciente;

d) Ampliar o acesso da sociedade às informações relativas à segurança do paciente;

e) Produzir, sistematizar e difundir conhecimentos sobre segurança do paciente; e

f) Fomentar a inclusão do tema segurança do paciente no ensino técnico e de graduação e pós-graduação na área da saúde.

Ainda no mesmo ano, a Diretoria Colegiada da Agência Nacional de Vigilância Sanitária institui ações para a segurança do paciente em serviços de saúde por meio da Resolução da Diretoria Colegiada - RDC nํ 36 que adota no seu art. $3^{\circ}$ as seguintes definições de segurança do paciente:

I - Boas práticas de funcionamento do serviço de saúde: componentes da garantia da qualidade que asseguram que os serviços são ofertados com padrões de qualidade adequados;

II - Cultura da segurança: conjunto de valores, atitudes, competências e comportamentos que determinam o comprometimento com a gestão da saúde e da segurança, substituindo a culpa e a punição pela oportunidade de aprender com as falhas e melhorar a atenção à saúde;

III - Dano: comprometimento da estrutura ou função do corpo e/ou qualquer efeito dele oriundo, incluindo doenças, lesão, sofrimento, morte, incapacidade ou disfunção, podendo, assim, ser físico, social ou psicológico;

IV - Evento adverso: incidente que resulta em dano à saúde;

V - Garantia da qualidade: totalidade das ações sistemáticas necessárias para garantir que os serviços prestados estejam dentro dos padrões de qualidade exigidos para os fins a que se propõem;

VI - Gestão de risco: aplicação sistêmica e contínua de políticas, procedimentos, condutas e recursos na identificação, análise, avaliação, comunicação e controle de riscos e eventos adversos que afetam a segurança, a saúde humana, a integridade profissional, o meio ambiente e a imagem institucional; 
VII - Incidente: evento ou circunstância que poderia ter resultado, ou resultou, em dano desnecessário à saúde;

VIII - Núcleo de Segurança do Paciente (NSP): instância do serviço de saúde criada para promover e apoiar a implementação de ações voltadas à segurança do paciente;

IX - Plano de segurança do paciente em serviços de saúde: documento que aponta situações de risco e descreve as estratégias e ações definidas pelo serviço de saúde para a gestão de risco visando a prevenção e a mitigação dos incidentes, desde a admissão até a transferência, a alta ou o óbito do paciente no serviço de saúde;

X - Segurança do paciente: redução, a um mínimo aceitável, do risco de dano desnecessário associado à atenção à saúde;

$X I$ - Serviço de saúde: estabelecimento destinado ao desenvolvimento de ações relacionadas à promoção, proteção, manutenção e recuperação da saúde, qualquer que seja o seu nível de complexidade, em regime de internação ou não, incluindo a atenção realizada em consultórios, domicílios e unidades móveis;

XII - Tecnologias em saúde: conjunto de equipamentos, medicamentos, insumos e procedimentos utilizados na atenção à saúde, bem como os processos de trabalho, a infraestrutura e a organização do serviço de saúde.

Também no nível do Distrito Federal ações foram tomadas sobre a segurança do paciente. Em decorrência do PNSP, em 2013, considerando a necessidade de se desenvolver estratégias, produtos e ações direcionadas aos gestores, profissionais e usuários da saúde sobre segurança do paciente que possibilitem a promoção da mitigação da ocorrência de evento adverso na atenção à saúde, institui-se no Distrito Federal, com a Portaria da Secretaria de Saúde SES/DF no 332, o Núcleo Central de Qualidade Hospitalar e Segurança do Paciente da Sub-secretaria de Atenção à Saúde/SAS/SES/DF - NCQHSP.

Cabe ao núcleo:

a) Definir diretrizes e estratégias de apoio às unidades hospitalares de forma a aperfeiçoar os processos de certificação, acreditação e qualidade hospitalar;

b) Apoiar a instituição do Núcleo de Qualidade Hospitalar e Segurança do Paciente, ou estrutura similar, no âmbito dos Hospitais da Rede SES/DF;

c) Instituir diretrizes e estratégias gerais, no âmbito da SAS, para os Núcleos Hospitalares de Segurança do Paciente; auxiliar na elaboração, implementação, monitoramento e avaliação dos Planos de Segurança do Paciente em Serviços de Saúde dos Hospitais da Rede SES/DF; e

d) Contribuir para a articulação e integração de áreas correlatas na disseminação da cultura de qualidade e segurança.

O desenvolvimento de estratégias para a segurança do paciente no país depende do conhecimento e do cumprimento do conjunto de normas e regulamentos que regem o funcionamento dos estabelecimentos de Saúde. $O$ caráter multidimensional e pluridisciplinar que caracteriza essas áreas - qualidade em saúde 
e segurança do paciente - requer abordagens sistêmicas e integradas de forma ajudar a conhecer, interpretar e compreender os fenômenos em causa desde a definição de políticas e estratégias de saúde no âmbito de um pais, região organização ou serviço.

\subsection{SEGURANÇA DO PACIENTE NO CUIDADO EM SAÚDE}

De acordo com Nascimento; Travassos (2010), a segurança do paciente é definida pela Classificação Internacional de Segurança do Paciente (ICPS - sigla em inglês) da Organização Mundial de Saúde (OMS), sendo considerada um incidente, um evento ou circunstância que poderia ter resultado ou resultou em dano desnecessário ao paciente, advindo de atos não intencionais ou intencionais. $O$ incidente pode atingir ou não o paciente. Quando atinge, pode ou não causar um dano. Quando não causa dano é chamado de incidente sem dano e quando causa o dano é chamado de evento adverso. A segurança do paciente é definida como a redução, a um mínimo aceitável, do risco de dano desnecessário associado ao cuidado de saúde.

O entendimento do conceito de segurança do paciente é importante para o dimensionamento do problema e compreensão dos diversos fatores envolvidos. Estudos sobre agravos causados pelo cuidado à saúde já vêm sendo divulgados há alguns anos. A utilização de boas práticas e a redução dos erros decorrentes da assistência em saúde são fundamentais para a garantia da segurança do paciente em ambientes de cuidado (REIS; MARTINS; LAGUARDIA, 2013).

Uma das explicações de Maskens et. al. (2014) para um grande número de erros observados na prática médica é justamente a ausência de mecanismos que diminuam a sua ocorrência, ou que interceptem o erro antes de chegar ao paciente, pois parte-se do equivocado pressuposto de que um profissional de saúde não comete erros e, portanto, não se criam mecanismos de prevenção e correção.

A partir da aceitação de que errar é humano, acredita-se que uma postura mais sistêmica, uma visão mais ampliada das situações ou do conjunto de falhas que permitem a eclosão do erro, seja a maneira mais eficiente de preveni-lo e evitá-lo. Através de mecanismos que facilitem o trabalho humano, da utilização de tecnologia apropriada e da criação e manutenção de mecanismos de reconhecimento e reparação de situações que geram erros, pode-se tornar a prática médica mais segura para pacientes e profissionais de saúde (CARVALHO; VIEIRA, 2002). 
Barini (2001) pontua que, evidências vindas de estudos realizados com grupos de pacientes ajudam a tomar as decisões mais acertadas, mas não podem ser desvinculadas da experiência clínica. Neste contexto, é importante investir na prevenção dos erros, sendo necessário estimular, desde a graduação em Medicina, Enfermagem e todas a áreas da saúde, discussões que visem formar profissionais mais comprometidos com a prática médica e menos sujeitos a episódios de imperícia, negligência e imprudência.

Em um estudo transversal realizado por Atoof et. al. (2015), pacientes e familiares que são treinados em cuidados seguros diminuem significativamente a incidência de erros de medicação. Propõe-se como principal passo o envolvimento dos pacientes e do público em questões de segurança, comunicação mutua, ensino e compartilhamento de lições de segurança e implementação de soluções para prevenir danos, como por exemplo, uma rede internacional de pacientes e cuidadores que promova a participação dos pacientes em iniciativas de segurança.

A educação médica tem dois papéis, o de informador e o de formador. Enquanto o primeiro tem a função de fornecer ao estudante conhecimentos científicos e de natureza técnica essenciais ao exercício da futura profissão, o segundo é responsável pelo amadurecimento de uma personalidade adulta e equilibrada, capaz de entender a complexa estrutura biopsicossocial do paciente. (CHEHUEN NETO et. al., 2011)

Faz-se necessário uma mudança mais efetiva que vai além dos aspectos legais e éticos da clínica para a capacidade de integrar o conhecimento científico com a experiência clínica. Sabemos que a prática clínica deve ser sempre o resultado da experiência, da responsabilidade, da competência e do respeito à dignidade do paciente, mas limitar-se a esta concepção que reflete apenas experiências individuais, negligencia os avanços da ciência com potencial de ampliar e melhorar a atenção no cuidado em saúde (GOULART; CHIARI, 2010). Os profissionais de saúde devem ser capazes de se comunicar de forma eficaz com colegas, pacientes e cuidadores para garantir a confiança e a capacidade de alcançar a compreensão recíproca e construir uma relação de apoio e envolvimento nas decisões de cuidado (CUSHING et. al., 2014). 
Para Ginsburg et. al. (2014) o cuidado em saúde deve adotar abordagens sistemáticas que absorvam e eliminem erros. Capacitação técnica não é a chave, e sim um sistema reorganizado que vise a melhoria do atendimento de qualidade como objetivo principal. Se os erros não forem reduzidos a zero, o sistema deve pelo menos entender como objetivo a redução da ocorrência de erro prejudiciais ao paciente. Por isso o profissional deve atentar para o significado da relação médico-paciente como o estabelecimento de um modelo de medicina mais humanística, visando o respeito e a dignidade do paciente, proporcionando uma efetiva prevenção contra denúncias de erro profissional médico, evitando, portanto, uma série de incômodos e aborrecimentos.

$\mathrm{Na}$ literatura científica norte americana há muitos estudos de coorte, observacionais (CARAYON; XIE; KIANFAR (2014), TAMBLYN et. al. (2014), RUDDY et. al. (2015), ATOOF et. al. (2015), SINGH; MEYER; THOMAS (2014)), pesquisas de avaliação de qualidade (NOLAND; CARMACK (2015), SOUTHWICK; CRANLEY; HALLISY (2015)), evidências observadas na da prática clínica (KROMBACH et. al. (2015), MASKENS et. al. (2014), PERREGAARD et. al., (2015), GHOBRIAL et. al. (2015), MCCRORY; LAGRANGE; HALLBECK (2014)), estudos de aplicabilidade de tecnologias em saúde em prol da melhoria da segurança do paciente (CHO et. al. (2014), SINGH; SITTIG (2015), HRON et. al. (2015), LI et. al. (2014), UY; KURY; FONTELO (2015)), revisões sistemáticas (BUBALO et. al. (2014), TREADWELL; LUCAS; TSOU (2014), HARRIS et. al. (2015)) e análises da responsabilidade legal dos profissionais de saúde frente a casos que chegam a justiça (SVIDER et. al. (2014), MONTGOMERY (2015)), ademais, os estudos (YU et. al. (2014), GINSBURG et. al. (2014), JEFFS et. al. (2014), MASIC; IZETBEGOVIC (2014), CASTEL et. al., (2015)) também discutem os esforços para a criação de uma rede de segurança do paciente dentro das organizações de prática clínica, uma consolidação da cultura de segurança do paciente, comunicação interpessoal e com o paciente no ambiente hospitalar e a notificação de casos.

No Brasil, a questão do erro médico ainda está muito centrada na área da Enfermagem, enquanto no exterior há uma ampla discussão que envolve diversas áreas da saúde, o que indica que o problema seria desencadeado por múltiplos fatores e que merece a atenção de diferentes profissionais de saúde. A maioria dos trabalhos é proveniente da área da Enfermagem (SALVADOR et. al. (2014), MELLO; BARBOSA 
(2013), SOUZA; IZABEL; SOUZA (2015), DE PAIVA et. al. (2014), PARANAGUÁ et. al. (2014), NUNES et. al. (2014), REIS; MARTINS; LAGUARDIA (2013), DUARTE et. al. (2015)), o que evidencia a necessidade de expansão da discussão deste tema com outras áreas da saúde que também são personagens deste contexto e devem atuar visando enfrentamento da questão. Independentemente do tipo de erro médico a ser considerado (medicamentoso, operacional, clínico, dentre outros) cabe a discussão dos fatores relacionados à ocorrência do evento.

O enfrentamento da questão do erro médico deve estar centrado nas recomendações da OMS, como falhas de comunicação entre o profissional e 0 paciente, sistema de notificação de incidentes eficaz e fortalecimento da cultura de segurança entre os profissionais.

\section{FATORES RELACIONADOS AO ERRO MÉDICO}

Como elemento fundamental da promoção da cultura de segurança do paciente, é necessário identificar os fatores que atuam no contexto do erro médico. Nessa linha, os fatores que atuam no contexto do erro médico seriam as falhas estruturais ou pontuais, má-prática ou descuido dos profissionais de saúde, falhas de comunicação interpessoais e entre equipes de trabalho. Mecanismos de notificação eficientes previnem a ocorrência dos eventos adversos e promovem a segurança do paciente. Em contrapartida, a subnotificação dos erros impede sua análise e dificulta apontar as causas de origem, assim como o planejamento de ações para evitar a ocorrência dessas situações.

Carayon; Xie; Kianfar (2014) visaram entender o processo da ocorrência de um erro médico a partir da análise do contexto no qual está inserido e suas conexões temporais (sequência de eventos), a partir da coleta de dados detalhados sobre os fatores contextuais de um ambiente de trabalho, permitindo então uma compreensão mais precisa e específica, assim como a tipificação de erros frente a segurança farmacêutica de UTIs, abordando a complexidade do evento de erro medicamentoso e/ou evento adverso ao longo do processo de manejo medicamentoso dos pacientes.

Avaliando os erros e considerando que eles se propagam em todo o processo de manejo/gestão/dispensa/administração/controle de um medicamento, a falha pode 
ocorrer na prescrição ou na administração decorrente, por exemplo, de superdosagem, inadequação terapêutica, reações farmacológicas indesejadas ou demora em administrar o medicamento - utilizar tecnologias reduz, mas não elimina o potencial de erro. À medida que novas tecnologias em saúde são implementadas, é importante avaliar criticamente a sua eficácia na melhoria da segurança do paciente (BUBALO et. al., 2014).

Para o enfrentamento desse tipo de evento potencial já se discute intervenções tecnológicas para dirimir sua ocorrência por meio de instrumentos como programas Computerized Provider Order Entry (CPOE) ou CPOE with Clinical Decision Support. Essa ferramenta aplicada à prescrição de medicamento e à prescrição auxiliada de suporte clínico e outras tecnologias, como código de barras nas administrações terapêuticas e bombas de infusão inteligentes, também foram propostas para a redução de erros medicamentosos na fase de administração (LI et. al., 2014).

Em se tratando da subnotificação dos eventos adversos, Paranaguá et.al. (2014) discute a falta de uma política de capacitação dos profissionais da equipe de saúde para a notificação dos incidentes, o que dificulta seu monitoramento. É um problema presente no setor saúde com diversas implicações para a qualidade da assistência. De Paiva et al. (2014) e Jeffs et. al. (2014) tratam a questão da subnotificação de casos relacionada a uma cultura da retaliação no ambiente de trabalho indicando fragilidade em relação à comunicação de erros, ou seja, uma abordagem que acaba interferindo na identificação das falhas, impedindo que sejam efetuadas mudanças em busca de melhorias da qualidade no processo de trabalho.

Em se tratando da assistência à saúde nos hospitais brasileiros, acredita-se que os erros e suas consequências são consideravelmente maiores, devido à precariedade dos serviços prestados, à falta de dimensionamento adequado de pessoal, à carga horária excessiva e à má remuneração dos profissionais (OLIVEIRA et. al., 2014).

A respeito da sobrecarga de trabalho do profissional médico, Harris et. al. (2015) realizou uma revisão sistemática que demonstrou evidências de melhoria na qualidade de vida dos residentes e da fadiga, mas evidências insuficientes que suportam a restrição do horário de serviço para melhorar a segurança do paciente e treinamento cirúrgico. Controvérsias envolvendo a restrição de horas de serviço e 
supervisão dos residentes foram inconclusivas para a melhoria ou não da educação dos residentes e da segurança dos pacientes. Para McRory; Lagrange; Hallbeck ( 2014) muitos dos erros podem ser atribuídos à incompatibilidade entre o sistema de trabalho e as capacidades e limitações do operador humano. Estas interfaces cirurgião-paciente e cirurgião-tecnologia produzem um nível significativo de estresse físico e cognitivo contribuindo para erros cirúrgicos.

\subsection{ERRO MÉDICO NO PODER JUDICIÁRIO}

Incidentes relacionados a erros médicos vêm ganhando grande destaque, sendo discutidos frequentemente nos jornais, como tópico preferido da mídia, que desencadeiam forte pressão para que se investiguem e punam o profissional responsável e a causa do erro (CARVALHO; VIEIRA, 2002). Nos Estados Unidos os litígios relacionados a negligência médica aumentaram significativamente nas últimas décadas, contribuindo para o aumento dos custos de assistência médica em decorrência dos seguros médicos e indenizações de litígios, que podem custar de US\$ 6 a US $\$ 10$ bilhões (SVIDER et. al., 2014).

As vítimas de atos danosos no âmbito da saúde - erro médico - acabam recorrendo ao Poder Judiciário com ações em âmbito penal e cível. Assim é que se constata um crescimento das demandas judiciais por erro médico (BONETTI et. al., 2016). Elas podem recorrer em ações contra um profissional médico negligente de diversas formas: por meio de ação compensatória em busca de compensação monetária perante os tribunais civis, leis de contrato e proteção ao consumidor; ação punitiva representada por meio de queixa criminal contra o médico sob o código penal; assim como via ação disciplinar junto ao conselho profissional em busca de medidas disciplinares contra o prestador de cuidados de saúde (RAVEESH; NAYAK; KUMBAR, 2016).

O fenômeno da judicialização trata-se de uma tendência mundial por meio do qual questões políticas, sociais e morais relevantes são determinadas pelo Poder Judiciário ao invés de serem solucionadas pelo poder competente, seja este o Executivo ou o Legislativo. Cabe ao Poder Judiciário resolver os conflitos existentes, usando como arma a legislação que tem a seu dispor. Mas a falta de legitimidade é um argumento recorrente dos que defendem a atuação mínima do Judiciário. 
Para Bobbio (1992) em seu dicionário de política, a legitimidade possui dois significados. O primeiro conceito é genérico, no sentido de justiça ou de racionalidade (fala-se na Legitimidade de uma decisão, de uma atitude, etc). O segundo é específico. É aquele que aparece na linguagem política (poder constituinte). O que nos interessa, aqui, é a preocupação com o significado especifico. Os atos governamentais praticados de acordo com essa constituição são atos legítimos, mas quando fogem da orientação traçado por ela, há a necessidade de sua revisão.

A conjuntura brasileira é essencial para a concretização da judicialização da política, de acordo com sua estrutura e a circunstância de que o Supremo Tribunal Federal supervisiona a maioria das incompatibilidades judiciais, por meio da legitimidade originária e dos trâmites de recursos. A judicialização da política no Brasil alega estar sob a prevalência de uma democracia de direitos, o sistema de justiça passou a amparar cada esfera e de certa forma comprometeu a competência do ato administrativo, intervindo nas políticas públicas. Tal contexto aponta uma evidente prevalência do Poder Judiciário, ou seja, do sistema de justiça sobre os poderes políticos, quebrando o sistema de freios e contrapesos proveniente da separação dos poderes.

A judicialização da saúde pode ser entendida como o a ausência de efetividades do sistema de saúde no país a contento o Direito à Saúde, conforme previsão da Constituição Federal. Sendo assim, muitas vezes o Judiciário acaba sendo a última alternativa de muitos pacientes para obtenção de um medicamento ou tratamento e, se este fenômeno não for tratado da maneira adequada, poderá gerar prejuízos, não só aos cidadãos, como também ao Estado, em razão da desestruturação do orçamento público e, até mesmo, diante da possibilidade de um colapso do sistema público de saúde.

Apesar da judicialização da prática médica já ser um fenômeno consolidado na conjuntura americana ainda é insipiente e pouco discutida no contexto brasileiro. Ela reflete um movimento em busca da efetivação de uma política pública que vise a segurança da prática médica.

Campos; Camargo; Neves (2016) revelam que os maus resultados ocorridos não deveriam ser imputados exclusivamente ao profissional médico que diretamente 
atuaram no caso. Os autores questionam se a responsabilização deveria ser solidária em relação a outros profissionais envolvidos nas condutas.

Os estudos de Svider et. al. (2014) apontam que conhecer os fatores e caracterizar a responsabilidade médica e o processo de consentimento esclarecido do paciente, pode potencialmente ajudar os cirurgiões minimizar a responsabilidade legal, bem como melhorar a segurança do paciente. Para o estudo, o mero reconhecimento de que as ações de um médico resultaram em uma complicação não é suficiente para atender a definição legal de negligência. Os júris são instruídos de que várias condições devem ser cumpridas para caracterizar o dano, incluindo, 0 dever de agir, não promover o padrão de cuidado, danos e a produção direta da causa. Mesmo para os casos que chegam a julgamento, as decisões foram favoráveis ao médico em dois terços dos processos.

No Brasil, o desenvolvimento de políticas públicas sociais se conceitua como um processo de fortalecimento da cidadania, reforço dos instrumentos e órgãos de defesa do consumidor e assunção pelos indivíduos sobre seus direitos, aliada à drástica mudança na relação entre médico e paciente, decorrente dos modelos de atenção valorizados no atual sistema de saúde, que minimiza a comunicação entre as partes e diluem o respeito e a admiração que eram devidos ao médico em momentos históricos anteriores (FUJITA; SANTOS (1992), RAVEESH; NAYAK; KUMBAR (2016)). O profissional de saúde deve transmitir ao paciente uma informação adaptada ao indivíduo e à situação, considerando o grau de escolaridade, as especificidades culturais e linguísticas, bem como o grau de desenvolvimento cognitivo. A comunicação efetiva acarreta benefícios à relação profissional de saúde-paciente, sendo um fator que influencia na adesão ao tratamento. A informação aos pacientes deve ser clara e escrita sempre que possível, encorajando e capacitando-os a contribuir com a sua própria segurança e explicar-lhes a prescrição.

No processo de melhoria da comunicação entre o profissional e o paciente, a abordagem centrada no paciente deve ser valorizada respeitando o paciente como um elemento ativo no seu processo de cuidado, permitindo que este ajude a gerenciar o seu cuidado, inclusive um possível evento adverso. A melhor compreensão por parte dos pacientes com relação ao erro médico contribuiu para que o tema fosse discutido pela sociedade em vista que a principal causa do litígio rotulado de erro médico se dá devido a uma relação médico-paciente insatisfatória, fruto da incapacidade do 
profissional de prover adequada comunicação interpessoal e desinteresse por um atendimento de boa qualidade (PARANAGUÁ et. al. (2014); CHEHUEN NETO et. al. (2011);CARAYON; XIE; KIANFAR (2014)).

A medicina é uma atividade de risco. Cuida da saúde do ser humano, e isso envolve não só o tratamento de moléstias, como as expectativas do paciente. 0 médico é um profissional tecnicamente preparado para se defrontar com enfermidades, desenvolvendo-se entre ele e o paciente, em uma relação de confiança e esperança de resultado positivo (AGUIAR JÚNIOR, 2000).

Sendo assim, o médico está sujeito às consequências do exercício da sua atividade, tais como: a deformidade, a restrição da capacidade física ou mental do paciente, e até sua morte. Essas externalidades negativas advindas da prática médica no trato de seu paciente constituem os denominados erros médicos.

Os erros médicos são tratados no direito penal como crimes culposos entendendo-se como crime culposo aquele em que o agente deu causa ao resultado por imprudência, negligência ou imperícia. Os crimes dolosos, contrariamente, são assim classificados quando o agente tem a intenção de produzir o resultado (dolo direto), ou apesar de não pretender o resultado, assume o risco de vir a produzi-lo (dolo eventual)(BRASIL, 1940).

A imprudência é uma atitude em que o agente atua com precipitação, inconsideração, com afoiteza, sem cautelas, não usando de seus poderes inibidores. A negligência é a inércia psíquica, a indiferença do agente que, podendo tomar as cautelas exigíveis, não o faz por displicência ou preguiça mental. A imperícia é a incapacidade, a falta de conhecimentos técnicos no exercício da arte ou profissão, não tomando o agente em consideração o que sabe ou deve saber (JULIO FABBRINI MIRABETE, 2015).

Para Moraes (1996), se o médico, em sua atividade profissional, determina a morte do paciente ou o comprometimento de sua integridade física ou de sua saúde, por conduta culposa, deve responder pelo seu ato. O parâmetro para a conduta culposa é a previsibilidade. Se o médico não prevê o que deveria prever e causa dano, age culposamente, seja por imprudência, seja por negligência, seja por imperícia. 0 cirurgião, por exemplo, que opera em condições adversas de assepsia conhecendo essa deficiência é um imprudente; o clínico que prescreve um medicamento de graves 
efeitos colaterais, sem os levar em consideração, age com imprudência. Ou mesmo, o ortopedista que, por pressa ou desídia, avalia mal uma radiografia, e não detecta uma fratura que pode ter consequências danosas no ato cirúrgico, age com negligência. É imperito um cirurgião que, inadvertidamente, secciona, sem necessidade, uma determinada estrutura, ou quanto um clínico sem as cautelas devidas, prescreve um anticoagulante para seu paciente.

O Conselho Federal de Medicina do Brasil, na exposição de motivos da Resolução n 1.627/2001, enuncia que a expressão "erro médico" é uma contração da expressão correta "erro profissional de médico", afirmando ainda que embora contenha a expressão "médico" não é restrita a esses profissionais e pode abarcar outros da área de saúde (RIBEIRO; JULIO, 2011). A ocorrência de eventos adversos não está restrita a classe médica e afeta muitas outras áreas da saúde.

As terminologias relacionadas a segurança do paciente possuem conceitos similares e ainda não estão plenamente consolidadas na literatura científica. O termo segurança do paciente se aplica as iniciativas para evitar, prevenir e reduzir resultados adversos ocorridos a partir do cuidado à saúde. Segundo a OMS incidentes são eventos ou circunstâncias não esperadas, decorrentes do cuidado prestado, não associadas à doença de base, que pode resultar ou resultam em dano desnecessário ao paciente e são classificadas como incidente sem dano, circunstância notificável, evento adveros e quase-erro.

Existem autores que equiparam o conceito de erro médico à atuação do médico propriamente dito e o evento adverso à pratica das demais especialidades de saúde. Apesar da imprecisão conceitual dos termos utilizados para denominar o erro médico, a terminologia que será utilizada neste trabalho como erro médico está associada a ao entendimento do conselho federal de medicina que trata como um evento associado ao profissional da área da saúde e não ao estritamente ao profissional médico. Taxonomias derivadas das práticas em saúde como acidentes medicamentosos, reações adversas e acidentes de diagnóstico não serão abordadas neste trabalho. 


\section{OBJETIVO GERAL}

O objetivo geral deste trabalho foi o de qualificar e quantificar os processos judiciais relacionados à saúde, que versem sobre erro médico, em $2^{\underline{a}}$ instância, no Tribunal de Justiça do Distrito Federal e Territórios (TJDFT), durante o período de 2013 e 2015.

\section{OBJETIVOS ESPECÍFICOS}

- Conhecer o objeto material das ações propostas pelos pacientes;

- Identificar a especialidade médica envolvida nos pleitos judicializados

- Conhecer e analisar os argumentos dos julgadores para decidir sobre o Erro Médico 


\section{METODOLOGIA}

Este trabalho foi circunscrito em uma pesquisa exploratória, documental, descritivo-analítica e quali-quantitativa, em que a unidade de análise foi o processo judicial oriundo do TJDFT, tramitando em $2^{\underline{a}}$ instância. Tratou-se de uma pesquisa jurisprudencial sobre o erro médico.

A coleta de dados foi realizada entre abril e maio de 2016 no sítio eletrônico do TJDFT (www.tjdft.gov.br), privilegiando-se as Apelações Cíveis e Apelações Criminais julgadas em $2^{\mathrm{a}}$ instância, nos anos 2013 a 2015. Os dados são de acesso livre e desembaraçado. A palavra-chave utilizada para a busca de processos judiciais foi "ERRO MÉDICO".

Para a inclusão do julgado na análise de inteiro teor foi considerada a demanda diretamente relacionada à casos de erro médico classificados conforme referencial teórico deste trabalho. Como critério de inclusão foram selecionados os processos que continham a palavra-chave "erro médico", fossem apelações cíveis ou criminais e contivessem o inteiro teor das decisões disponível no sítio do tribunal. Como critério de exclusão, não foram considerados os processos que apesar de conter a expressão erro médico, continham objeto material distinto do objetivo da pesquisa. Igualmente os processos em segredo de justiça foram afastados da pesquisa.

Os dados coletados foram sistematizados em planilha eletrônica Microsoft Excel - versão 2013 e classificados quanto ao número de processos por ano, tipos de ação, especialidade médica envolvida na ação, tipos de decisão, etc. Em uma abordagem qualitativa, foi analisado o discurso emitido nos acórdãos a fim de conhecer os argumentos utilizados pelo órgão decisão. Para tanto, foi utilizada análise do discurso com a técnica de análise idiossincrática (MAEDA; POLLAK; MARTINS, 2009).

Foi ainda realizada uma revisão de literatura a partir da busca de artigos em base de dados científica. Foram considerados as publicações durante o período de 2014 e 2015 que contemplavam os objetivos estabelecidos nos idiomas português e inglês, nas seguintes bases de dados: Biblioteca Virtual em Saúde - BVS, LILACS e MEDLINE a partir dos descritores: "segurança do paciente AND direito do paciente", "segurança do paciente AND erro médico", "patient safety AND patient rights", "patient safety AND malpractice ", no qual o critério de inclusão foi o acesso livre do inteiro teor 
dos artigos e revisões sistemáticas encontradas nas bases pesquisadas, assim como critérios de exclusão: teses de monografias e artigos de acesso limitado ou indisponíveis.

Esta dissertação procurou elucidar a judicialização dos erros médicos no TJDFT a partir de três pressupostos descritos nos artigos a seguir.

O primeiro artigo descreveu o panorama das publicações relacionadas ao tema no último ano com a finalidade de caracterizar os marcos teóricos de interesse neste momento que relacionem a segurança do paciente à uma gestão em saúde baseada em evidências científicas. Após esta constatação, entrou-se em outra discussão: quais são os fatos que sustentam as provas científicas da ocorrência de erros médicos?

Com o campo tradicional e positivo dos fatos realizou-se uma pesquisa jusrisprudencial descrita pelo segundo artigo que visava quantificar as ações que tramitaram em segunda instância no tribunal de justiça com a finalidade de descrever a celeuma acerca da segurança do paciente e a consequência legal ainda que este não reflita a totalidade de casos de eventos adversos que ocorreram na prática médica.

Em vista da riqueza dos dados coletados considerou-se caracterizar por meio da metodologia da análise idiossincrática do discurso presentes nas sentenças com a finalidade de traçar as teorias e ideologias entendidas pela magistratura que foram descritas no terceiro e último artigo desta dissertação. 


\section{RESULTADOS}

Esta dissertação foi construída em formato de artigos sendo, 1 deles uma revisão de literatura, 1 com os resultados quantitativos e o último com os resultados qualitativos. Os dois primeiros foram submetidos a periódicos científicos sem ainda receber resposta dos editores. São eles revista Ciência e Saúde Coletiva e Cadernos Ibero-Americanos de Direito Sanitário. 


\section{Artigo 1: A questão do erro médico no Brasil: uma revisão integrativa sobre segurança do paciente. - [submetido à Revista Ciência e Saúde Coletiva]}

Título: A questão do erro médico no Brasil: uma revisão narrativa sobre segurança do paciente.

Autores: Talita Gomes e Maria Célia Delduque

Resumo: Organizações e agências internacionais de saúde têm evidenciado a necessidade de desenvolver dispositivos para a melhoria da segurança do paciente. Ao compreender melhor a prática de efetivar a evidência científica na atuação da clínica médica se faz necessário uma reflexão teórica a respeito do enfrentamento da incidência de erros médicos na rotina da clínica. Com a finalidade de trazer elementos sobre a segurança do paciente e a conduta negligente, imperita e imprudente do profissional médico este é um estudo descritivo-exploratório de busca de literatura relacionada ao tema em questão. Destaca-se trabalhos que versam sobre mudanças na prática clínica reduzindo riscos e eventos adversos do cuidado em saúde e a influência da medicina baseada em evidências na prevenção de erros médicos.

Palavras-chave: erro médico, segurança do paciente, serviços de saúde

Title: Medical Errors in Brazil: a narrative review regarding patient safety.

Abstract: International health organizations have been focusing on developing mechanisms to improve patient safety. In order to carry out the scientific evidence into the medical practice, a theoretical reflection regarding the incidence of medical errors is necessary. Element such as patient safety and negligent conduct, inexpert and reckless professional procedures were gathered in this descriptive exploratory study develop through a literature review related to this topic. Results describe changes in clinical practice that reduced risks and adverse events in health care and the influence of evidence-based medicine in the prevention of medical errors.

Key-words: malpractice, patient safety, healthcare

\section{Introdução:}

Organizações e agências de saúde têm evidenciado a necessidade de desenvolver dispositivos para a melhoria da segurança do paciente. Com isso desenvolveram estratégias voltadas para a melhora da qualidade do cuidado à saúde e, consequente minimização dos riscos. A segurança do paciente, uma importante dimensão da qualidade em saúde, tornou-se foco de atenção a partir de estudos que apontam a alta frequência de eventos adversos resultantes do cuidado 
hospitalar, ou seja, incidentes que resultaram em dano para o paciente(1)A ausência de acidentes deve ser vista como sinônimo de bom desempenho de segurança e saúde. (2)

Destarte, a integração da experiência clínica com a capacidade de analisar e aplicar a informação científica ao cuidado com o paciente contribui para a melhoria da qualidade da assistência médica que é ofertada.

Nos últimos vinte anos, as organizações e agências internacionais de saúde têm evidenciado a necessidade de desenvolver dispositivos para a melhoria da segurança do paciente. Ao longo desse período, desenvolveram um número significativo de estratégias voltadas para melhorar a qualidade do cuidado à saúde e, consequentemente, minorar os riscos inerentes a esses cuidados de saúde oferecidos (3). Reconhecer a importância e conhecer os fatores relacionados aos erros médicos é fundamental para formular medidas no sentido de evitar a má prática profissional (4).

Segundo Barini (5) define-se Medicina Baseada em Evidências (MBE) como o emprego consciencioso, explícito e judicioso da melhor evidência disponível na tomada de decisões sobre os cuidados de saúde de um paciente. A MBE requer a integração da melhor evidência com a competência clínica e os valores e as circunstâncias do paciente. No processo de praticar MBE, que vai da identificação do problema à escolha da alternativa a ser adotada, não se pode esquecer que cada pessoa que procura cuidados médicos é um ser único, apesar de possuir características similares a diversos outros pacientes. Evidências que vêm de estudos realizados com grupos de pacientes ajudam a tomar as decisões mais acertadas, mas não podem ser desvinculadas da experiência clínica individual (6)

No contexto da MBE, a descrição do problema deve ter como foco o paciente. Dependendo de cada situação, existem determinadas características do paciente que devem ser levadas em 
consideração na descrição do problema, de forma a facilitar a localização das informações necessárias (5).

A filosofia da MBE é condizente com a ideia de que a boa prática médica requer integração da ciência e da arte. A introdução nas escolas médicas de métodos didáticos que estimulem o auto aprendizado, bem como de cursos de Epidemiologia Aplicada aos Problemas Clínicos e de Análise Crítica de Trabalhos Científicos, contribui para a formação de profissionais capazes de selecionar adequadamente a fonte do conhecimento e de avaliar criteriosamente como se transferir a informação para a prática médica (5)(6)

Erros médicos causam dano e sofrimento aos pacientes, aliado a uma relação médico-paciente insatisfatória(4). Deslizes cometidos por profissionais de outras áreas podem não acarretar maiores consequências, mas os erros dos médicos, frequentemente, provocam resultados indesejados e, muitas vezes, sequelas irreversíveis (1)

O erro médico pode ser classificado de três maneiras: imperícia, quando o médico realiza procedimento para o qual não é habilitado, o que corresponde a um despreparo teórico e/ou prático por insuficiência de conhecimento; imprudência, quando o médico assume riscos para o paciente sem respaldo científico para o seu procedimento, agindo sem a cautela necessária; e negligência, quando não oferece os cuidados necessários ao paciente, sugerindo inação, passividade ou um ato omissivo (4)

Esses conceitos advêm do Código Penal Brasileiro (7) em que determina que o crime pode-se dar de duas maneiras: a primeira forma de cometimento de crime é quando há a vontade do agente em praticar o ato. A esta categoria, chama-se crime doloso, previsto no art. 18, I do Decreto-lei 28948/40. Ao revés, denomina-se crime culposo quando o agente que deu causa ao resultado agiu por imprudência, negligência ou imperícia, previsto no art. 18, II, do mesmo 
Decreto. Isto é, a vontade de praticar o ato está ausente, mas o resultado acaba sendo alcançado em virtude dessas três categorizações. (8)

De acordo com Nascimento e Travassos (3), a segurança do paciente, definida pela Organização Mundial de Saúde (OMS) é a ausência de dano potencial ou desnecessário para o paciente associado aos cuidados em saúde, e a capacidade de adaptação das instituições de saúde em relação aos riscos humanos e operacionais inerentes ao processo de trabalho inseguro.

Aprofundando a questão, Barini (5) pontua que, evidências vindas de estudos realizados com grupos de pacientes ajudam a tomar as decisões mais acertadas, mas não podem ser desvinculadas da experiência clínica. Neste contexto, é importante investir na prevenção dos erros, sendo necessário estimular, desde a graduação em Medicina, discussões que visem formar profissionais mais comprometidos com a prática médica e menos sujeitos a episódios de imperícia, negligência e imprudência. A educação médica tem dois papéis, o de informador e o de formador. Enquanto o primeiro tem a função de fornecer ao estudante conhecimentos científicos e de natureza técnica essenciais ao exercício da futura profissão, o segundo é responsável pelo amadurecimento de uma personalidade adulta e equilibrada, capaz de entender a complexa estrutura biopsicossocial do paciente (9)

Ao compreender melhor a prática de efetivar a evidência científica na atuação da clínica médica se faz necessário uma reflexão teórica a respeito do enfrentamento da incidência de erros médicos na rotina da clínica. Faz-se necessário também uma mudança mais efetiva que vai além dos aspectos legais e éticos da clínica médica para a capacidade de integrar o conhecimento científico com a experiência clínica. Sabemos que a prática médica deve ser sempre o resultado da experiência, da responsabilidade, da competência e do respeito à dignidade do paciente, mas limitar-se a esta concepção que reflete apenas experiências individuais, negligencia os avanços da ciência com potencial de ampliar e melhorar a atenção no cuidado em saúde. 
O objetivo deste trabalho é trazer elementos sobre a segurança do paciente e a conduta negligente, imperita e imprudente do profissional médico.

\section{Metodologia:}

Tratou-se de um estudo descritivo-exploratório a partir da busca de artigos em base de dados científicas onde a revisão integrativa emerge como uma metodologia que proporciona a síntese do conhecimento e a incorporação da aplicabilidade de resultados de estudos significativos na prática. (Souza, Carvalho)

A metodologia adotada na organização lógica presente no trabalho é uma adaptação da metodologia PICO (Paciente, Intervenção, Comparação e Outcomes), realizada pela equipe da Organização Pan-americana de Saúde (OPAS); trata-se de lógica para busca de evidências após observação da realidade e identificação de uma situação-problema, seguidas da busca de evidências em literatura e avaliação da evidência encontrada.

A questão norteadora proposta para o estudo foi a seguinte: qual é o arcabouço científicoacadêmico relacionado direito do paciente e o erro médico que permite a gestão em saúde voltada para segurança do paciente. Como desfecho esperado tem-se a sistematização dos exemplos de práticas de saúde descritas pela literatura científica indexada na Biblioteca Virtual de Saúde - BVS.

A revisão integrativa de literatura foi estabelecida em fases descritos como: elaboração da questão; estabelecimento da estratégia de busca na literatura; seleção de estudos com base nos critérios de inclusão; leitura crítica e avaliação do conteúdo; análise e interpretação dos resultados. 
Realizou-se uma revisão nos idiomas português e inglês, nas seguintes bases de dados: Biblioteca Virtual em Saúde - BVS, LILACS e MEDLINE a partir dos descritores: "segurança do paciente AND direito do paciente", "segurança do paciente AND erro médico", "patient safety AND patient rights", "patient safety AND malpractice ", durante o período de 20142015. Como critério de inclusão utilizou-se a disponibilidade do inteiro teor dos artigos e revisões sistemáticas encontrados nas bases pesquisadas e como critério de exclusão teses de monografias e artigos de acesso limitado ou indisponíveis.

Realizou-se uma triagem inicial pela leitura de títulos e resumos. Nesse sentido, foram considerados as publicações que contemplavam os objetivos estabelecidos neste artigo. Na sequência foi realizada a leitura do inteiro teor dos manuscritos sobre o erro médico e fichamento dos dados de acordo com a metodologia de estudo utilizada, área de pesquisa e palavras-chave. Os artigos foram agrupados por título/idioma e apresentados em forma de gráficos.

\section{Resultados:}

Ao total foram encontrados 157 artigos. Após a leitura dos títulos e resumos dos artigos destacam-se os trabalhos que versam sobre mudanças na prática clínica reduzindo riscos e eventos adversos do cuidado em saúde e como fator de influência na prática voltada para a prevenção de erros médicos. Foram 12 trabalhos encontrados na literatura em português e 73 na literatura em inglês. Dentre os trabalhos disponíveis em inteiro teor, foram selecionados 9 artigos em português e 40 artigos em inglês. 


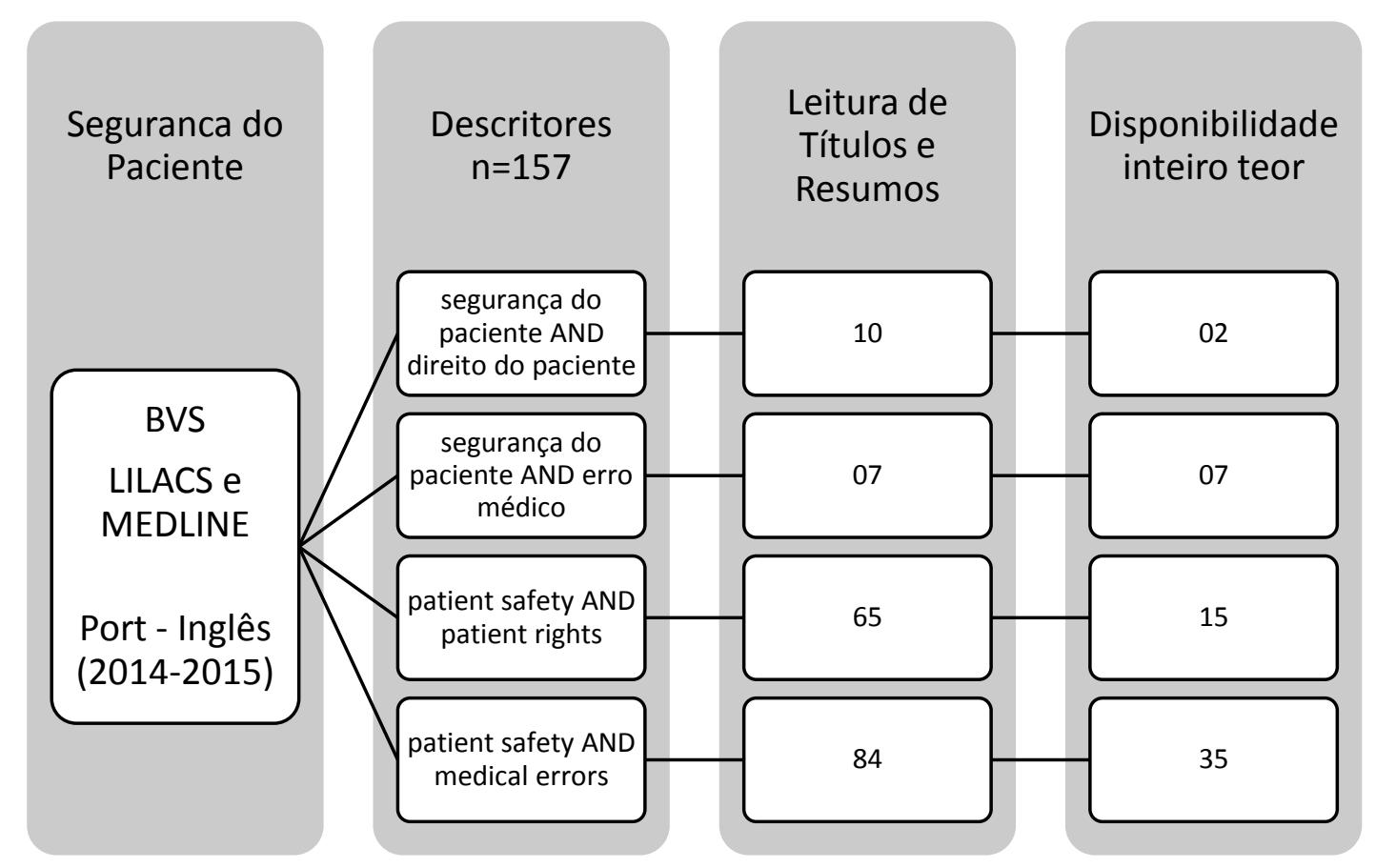

Figura 1 Construída pelos autores com base na metodologia aplicada.

Os trabalhos científicos analisados em Português constituem um total de 9 artigos, sendo 6 artigos (66\%) relacionados a área de Enfermagem, 2 artigos (22\%) da área de saúde pública e 1 artigo referente a comunicação em saúde. Os tipos de artigos analisados tratam de pesquisas quantitativas ( 3 artigos), pesquisas qualitativas ( 3 artigos), revisões de literatura ( 2 artigos) e 1 estudo observacional. Dentre as palavras-chave utilizadas nos trabalhos, $77 \%$ (7 artigos) citam segurança do paciente, 66\% (6 artigos) citam enfermagem e 44\% (4 artigos) citam erro médico. Em vista os trabalhos científicos analisados em Inglês um total de 40 artigos foram relacionados, 72\% (18 artigos) da área médica/medicine, 17\% (7 artigos) sobre assistência médica/healthcare, 12\% (5 artigos) sobre informação em saúde/health information, 7\% (3 artigos) da área de Enfermagem/Nursing, 7\% (3 artigos) da área de Farmácia/Pharmacy, 7\% (3 artigos) sobre direito e políticas públicas/law policy e 2\% (1 artigo) sobre educação em saúde/health education. 
Dentre os tipos de artigos analisados em inglês tratam de pesquisas quantitativas (14 artigos), pesquisas qualitativas (10 artigos), revisões de literatura (8 artigos), estudos observacionais (4 artigos), estudos de coorte (2 artigos), 1 relato de caso e estudo experimental. As palavras-chave utilizadas foram patient safety/segurança do paciente em $33 \%$ dos artigos, healthcare quality/qualidade do cuidado em saúde em $20 \%$ dos artigos, medical error/erro médico em 10\% dos artigos e safety culture/cultura de segurança em 5\% dos artigos.

\section{Discussão:}

Apesar da escassez de estudos na literatura em Português tanto na forma de discussão teórica/crítica das definições quanto em estudos exploratórios que abordem a questão do erro médico, observamos dentre os textos analisados que todos citaram o relatório To err is human: building a safer health care system de 1999 do Instituto de Medicina dos EUA (um marco do movimento para a segurança do paciente), assim como abordam também os esforços da Organização Mundial de Saúde (OMS) com a criação da Aliança Mundial para a Segurança do Paciente em 2004.

Todos os estudos caracterizaram erro médico segundo as definições sobre segurança do paciente da Classificação Internacional de Segurança do Paciente (ICPS - sigla em inglês) da OMS. No ICPS considera-se um incidente um evento ou circunstância que poderia ter resultado, ou resultou em dano desnecessário ao paciente, advindo de atos não intencionais ou intencionais. O incidente pode atingir ou não o paciente. Quando atinge pode ou não causar um dano. Quando não causa dano é chamado de incidente sem dano e quando causa o dano é chamado de evento adverso. Segurança do Paciente é definido como a redução, a um mínimo aceitável, do risco de dano desnecessário associado ao cuidado de saúde. 
Os estudos ainda abordam a questão do erro médico centrada em fatores relacionado as recomendações da OMS como falhas de comunicação entre o profissional e o paciente, sistema de notificação de incidentes e fortalecimento da cultura de segurança entre os profissionais. Destaca-se que a maioria dos trabalhos é proveniente da área da Enfermagem o que evidencia a necessidade de expansão da discussão deste tema com outras áreas da saúde que também são personagens deste contexto e devem atuar visando enfrentamento da questão. A falta de uma política de capacitação dos profissionais da equipe de saúde para a notificação dos incidentes dificulta seu monitoramento e é um problema presente no setor saúde com diversas implicações para a qualidade da assistência $(13)(14)(16)(17)(29)(37)$.

Diversos trabalhos tratam a questão da subnotificação de casos relacionada a uma cultura da retaliação no ambiente de trabalho indicando fragilidade em relação à comunicação de erros, ou seja, uma abordagem que acaba interferindo na identificação das falhas, impedindo que sejam efetuadas mudanças em busca de melhorias da qualidade no processo de trabalho (23).

Em grande maioria, os estudos em língua inglesa abordam a questão do erro medicamentoso, (o tipo de maior incidência nos EUA) e discutem mecanismos que enfrentamento aos eventos adversos como informatização de prontuários e receitas, ferramentas de monitoramento de dosagens medicamentosas, influência da sobrecarga de trabalho da concentração do profissional de saúde e tecnologias que possam auxiliar no treinamento de equipes de saúde na prevenção da ocorrência do erro médico $(21)(3)(32)(35)$.

Dentre os achados da literatura em inglês observamos muitos estudos de coorte (34)(52), observacionais (20)(26)(40)(44), pesquisas de avaliação de qualidade, evidências observadas na da prática clínica e estudos de aplicabilidade de tecnologias em saúde em prol da melhoria da segurança do paciente (42), revisões sistemáticas (37) (58) e análises da responsabilidade legal dos profissionais de saúde frente a casos que chegam a justiça (22)(29)(41). Muitos dos estudos abordam o processo da ocorrência de um erro médico propriamente dito - o contexto 
no qual está inserido e suas conexões temporais. Ademais, os estudos também discutem os esforços para a criação de uma rede de segurança do paciente dentro das organizações de prática clínica, uma consolidação da cultura de segurança do paciente, comunicação interpessoal e com o paciente no ambiente hospitalar e a notificação de casos(32)(33)(53).

\section{Conclusão:}

Novas abordagem vem sendo desenvolvidas em vista as questões que envolvem a segurança do paciente, tais como a criação da Portaria n529/2013 pelo Ministério da Saúde que institui a criação do Programa Nacional de Segurança do Paciente (PNSP). No Brasil a questão do erro médico ainda está muito centrada na área da Enfermagem enquanto no exterior percebemos uma ampla discussão que envolve diversas áreas da saúde, o que indica que o problema seria desencadeado por múltiplos fatores e que merece a atenção de diferentes profissionais de saúde.

Como elemento fundamental da promoção da cultura de segurança do paciente, conclui-se pela leitura dos artigos que seriam as falhas estruturais ou pontuais, má-prática ou descuido dos profissionais de saúde, falhas de comunicação interpessoais e entre equipes de trabalho, sistemas de informatização dos prontuários e receituários são fatores que atuam no contexto do erro médico.

Mecanismos de notificação eficientes previnem a ocorrência dos eventos adversos e promovem a segurança do paciente, em contrapartida, a subnotificação dos erros impede sua análise e dificulta apontar as causas de origem assim como o planejamento de ações para evitam a ocorrência dessas situações.

\section{Bibliografia:}

1. Reis CT, Martins M, Laguardia J. A segurança do paciente como dimensão da qualidade 
do cuidado de saúde: um olhar sobre a literatura. Cien Saude Colet. 2013 Jul;18(7):2029_ 36.

2. Paese F, Sasso GTMD. Cultura da segurança do paciente na atenção primária à saúde. Texto Context - Enferm. 2013;22(2):302-10.

3. Nascimento NB do, Travassos CM de R. O erro médico e a violação às normas e prescrições em saúde: uma discussão teórica na área de segurança do paciente. Physis Rev Saúde Coletiva [Internet]. 2010 [cited 2016 Oct 28];20(2):625-51. Available from: http://www.scielo.br/scielo.php?script=sci_arttext\&pid=S0103$73312010000200016 \& \operatorname{lng}=\mathrm{en} \& \mathrm{nrm}=\mathrm{iso} \& \operatorname{tn} \mathrm{l}=\mathrm{pt}$

4. Bitencourt AGV, Neves NMBC, Neves FBCS, Brasil ISP de S, Santos LSC dos. Análise do erro médico em processos ético-profissionais: implicações na educação médica. Rev Bras Educ Med. 2007 Dec;31(3).

5. Barini O. Medicina baseada em evidências. Rev Assoc Med Bras. 2001;47(4):294-294.

6. Ziv A, Ben-David S, Ziv M. Simulation Based Medical Education: an opportunity to learn from errors. Med Teach. 2005 May;27(3):193-9.

7. Brasil. Código Penal - Decreto-lei $n^{\circ}$ 2.848, 7/12/1940 [Internet]. Código Penal Decreto-lei $\quad \mathrm{n}^{\circ} \quad 2.848, \quad 7 / 12 / 1940 \quad 1940 . \quad$ Available from: http://www.planalto.gov.br/ccivil_03/decreto-lei/del2848compilado.htm

8. Moraes NC de. Erro médico: aspectos jurídicos. Rev Bras Cir Cardiovasc. 1996 Jun;11(2).

9. Lester H, Tritter JQ. Medical error: a discussion of the medical construction of error and suggestions for reforms of medical education to decrease error. Med Educ. 2001 Sep;35(9):855-61.

10. Salvador PTC de O, Martins CCF, Alves KYA, Costa TD da, Santos VEP. Analysis of Youtube Videos About Adverse Health Events. REME Rev Min Enferm. 2014;18(4):830-7.

11. Tomazoni, A.; Rocha, P.K.; Kusahara, D. M.; Souza, A.I.J; Macedo, T.R. Avaliação da cultura de segurança do paciente em terapia intensiva neonatal. Texto \& Contexto. v.24, n.1, p.161-169, 2015.

12. Marchon SG, Mendes Junior WV, Pavão ALB. Characteristics of adverse events in primary health care in Brazil. Cad Saude Publica. 2015;31(11):2313-30.

13. Souza S De, Izabel A, Souza J De. Identificação Da Criança Na Pediatria : Percepções Dos Profissionais De Enfermagem Identification of the Child in Pediatrics : Perceptions of Nursing Professionals Identificación Del Niño En Pediatría : Percepciones De Los 
Profesionales De. 2015;5-11.

14. de Paiva MCM da S, Popim RC, Melleiro MM, Tronchim DMR, Lima SAM, Juliani CMCM. The reasons of the nursing staff to notify adverse events. Rev Lat Am Enfermagem. 2014;22(5):747-54.

15. Marinho S, Ruão T, Lopes F, Fernandes L. O erro médico na imprensa portuguesa: Quando os pacientes fazem parte da notícia. Saude e Soc. 2015;24(4):1362-76.

16. Paranaguá TTDB, Bezerra ALQ, Dos Santos ALM, Silva AEBDC. Prevalence and factors associated with incidents related to medication in surgical patients. Rev da Esc Enferm. 2014;48(1):41-7.

17. Nunes F, Barros L, Azevedo R, Paiva S. Patient safety: how nursing is contributing to the issue? Rev Pesqui Cuid é Fundam Online. 2014;6(2):841-7.

18. Diniz SG, Salgado H de O, Andrezzo HF de A, de Carvalho PGC, Carvalho PCA, Aguiar C de A, et al. Violência obstétrica como questão para a saúde pública no brasil: origens, definições, tipologia, impactos sobre a saúde materna, e propostas para sua prevenção. $\mathbf{J}$ Hum Growth Dev. 2015;25(3):377-82.

19. Southwick FS, Cranley NM, Hallisy JA. A patient-initiated voluntary online survey of adverse medical events: the perspective of 696 injured patients and families. BMJ Qual Saf. 2015;(March 2010):bmjqs - 2015-003980 - .

20. Cho I, Lee JH, Choi SK, Choi JW, Hwang H, Bates DW. Acceptability and feasibility of the Leapfrog computerized physician order entry evaluation tool for hospitals outside the United States. Int J Med Inform. 2014;84(9):694-701.

21. Singh H, Sittig DF. Advancing the science of measurement of diagnostic errors in healthcare: the Safer Dx framework. BMJ Qual Saf. 2015;24(2):103-10.

22. Svider PF, Vidal G-P, Zumba O, Mauro AC, Haser PB, Graham A, et al. Adverse events in carotid endarterectomy from a medicolegal perspective. Vasc Endovascular Surg. 2014;48(5-6):425-9.

23. Lipshutz AKM, Caldwell JE, Robinowitz DL, Gropper M a. An analysis of near misses identified by anesthesia providers in the intensive care unit. BMC Anesthesiol. 2015;15(1):93.

24. Dudas RA, Barone MA. Can medical students identify a potentially serious acetaminophen dosing error in a simulated encounter? a case control study. BMC Med Educ. 2015;15(1):288.

25. Bonrath EM, Gordon LE, Grantcharov TP. Characterising "near miss" events in complex laparoscopic surgery through video analysis. BMJ Qual Saf. 2015;24(8):516-21. 
26. Cabello CM, Bair WB, Lamore SD, Ley S, Alexandra S, Azimian S, et al. NIH Public Access. 2010;46(2):220-31.

27. Krombach JW, Edwards WA, Marks JD, Radke OC. Checklists and Other Cognitive Aids For Emergency And Routine Anesthesia Care-A Survey on the Perception of Anesthesia Providers From a Large Academic US Institution. Anesthesiol pain Med. 2015;5(4):e26300.

28. Ratwani RM, Fong A. "Connecting the dots": leveraging visual analytics to make sense of patient safety event reports. J Am Med Inform Assoc. 2015;22(2):312-7.

29. Montgomery J. Conscientious objection: Personal and professional ethics in the public square. Med Law Rev. 2015;23(2):200-20.

30. Bubalo J, Warden BA, Wiegel JJ, Nishida T, Handel E, Svoboda LM, et al. Does applying technology throughout the medication use process improve patient safety with antineoplastics? J Oncol Pharm Pract. 2014;20(6):445-60.

31. Allison GM, Weigel B, Holcroft C. Does electronic medication reconciliation at hospital discharge decrease prescription medication errors? Int J Health Care Qual Assur. 2012;28(6):564-73.

32. Hron JD, Manzi S, Dionne R, Chiang VW, Brostoff M, Altavilla SA, et al. Electronic medication reconciliation and medication errors. Int J Qual Heal Care. 2015;27(4):3149.

33. Tamblyn R, Poissant L, Huang A, Winslade N, Rochefort CM, Moraga T, et al. Estimating the information gap between emergency department records of community medication compared to on-line access to the community-based pharmacy records. J Am Med Informatics Assoc. 2014;21:391-8.

34. Maskens C, Downie H, Wendt A, Lima A, Merkley L, Lin Y, et al. Hospital-based transfusion error tracking from 2005 to 2010: Identifying the key errors threatening patient transfusion safety. Transfusion. 2014;54(1):66-73.

35. Polisena J, Gagliardi A, Clifford T. How can we improve the recognition, reporting and resolution of medical device-related incidents in hospitals? A qualitative study of physicians and registered nurses. BMC Health Serv Res. 2015;15:220.

36. Yu H, Hu Z, Zhang X, Li B, Zhou S. How to overcome violence against healthcare professionals, reduce medical disputes and ensure patient safety. Pakistan J Med Sci. 2014;31(1):4-8.

37. Carayon P, Xie A, Kianfar S. Human factors and ergonomics as a patient safety practice. BMJ Qual Saf. 2014;23(3):196-205. 
38. Perregaard H, Aronson JK, Dalhoff K, Hellebek A. Medication errors detected in nontraditional databases: Types of errors in methotrexate dosing as listed in four different Danish registers. Eur J Clin Pharmacol. 2015;71(11):1375-9.

39. Noland CM, Carmack HJ. Narrativizing nursing students' experiences with medical errors during clinicals. Qual Health Res. 2015;25(10):1423-34.

40. Ruddy RM, Chamberlain JM, Mahajan P V, Funai T, O’Connell KJ, Blumberg S, et al. Near misses and unsafe conditions reported in a Pediatric Emergency Research Network. BMJ Open. 2015;5(9):e007541.

41. Ginsburg LR, Tregunno D, Norton PG, Mitchell JI, Howley H. "Not another safety culture survey": using the Canadian patient safety climate survey (Can-PSCS) to measure provider perceptions of PSC across health settings. BMJ Qual Saf. 2014;23(2):162-70.

42. Cushing AM, Ker JS, Kinnersley P, McKeown P, Silverman J, Patterson J, et al. Patient safety and communication: A new assessment for doctors trained in countries where language differs from that of the host country: Results of a pilot using a domain-based assessment. Patient Educ Couns. 2014;95(3):332-9.

43. Reznek MA, Kotkowski KA, Arce MW, Jepson ZK, Bird SB, Darling CE. Patient safety incident capture resulting from incident reports: a comparative observational analysis. BMC Emerg Med. 2015;15(1):6.

44. Atoof F, Eshraghian MR, Mahmoodi M, Mohammad K, Rangraz Jeddi F, Abootalebi F. Patients and Public Involvement in Patient Safety and Treatment Process in Hospitals Affiliated to Kashan University of Medical Sciences, Iran, 2013. Nurs midwifery Stud. 2015;4(2):e24755.

45. Li Q, Melton K, Lingren T, Kirkendall ES, Hall E, Zhai H, et al. Phenotyping for patient safety: algorithm development for electronic health record based automated adverse event and medical error detection in neonatal intensive care. J Am Med Inform Assoc. 2014;776-84.

46. Caine K, Tierney WM. Point and Counterpoint: Patient Control of Access to Data in Their Electronic Health Records. J Gen Intern Med. 2015;30(1):38-41.

47. McCrory B, LaGrange CA, Hallbeck M. Quality and safety of minimally invasive surgery: past, present, and future. Biomed Eng Comput Biol. 2014;6:1-11.

48. Ferreira R, Marques A, Mendes A, da Silva JA. Rheumatology telephone advice line experience of a Portuguese department. Acta Reum Port. 2015;40(2):163-8.

49. Treadwell JR, Lucas S, Tsou AY. Surgical checklists: a systematic review of impacts 
and implementation. BMJ Qual Saf. 2014;23(4):299-318.

50. Bohomol E, Cunha IC. Teaching patient safety in the medical undergraduate program at the Universidade Federal de Sao Paulo. Einstein. 2015;13(55 11):7-13.

51. Ghobrial GM, Hamade YJ, Bendok BR, Harrop JS. Technology and simulation to improve patient safety. Neurosurg Clin N Am. 2015;26(2):239-43.

52. Jeffs L, Hayes C, Smith O, Mamdani M, Nisenbaum R, Bell CM, et al. The effect of an organizational network for patient safety on safety event reporting. Eval Health Prof. 2014;37(3):366-78.

53. Singh H, Meyer AND, Thomas EJ. The frequency of diagnostic errors in outpatient care: estimations from three large observational studies involving US adult populations. BMJ Qual Saf. 2014;(May):1-5.

54. Masic I, Izetbegovic S. The role of medical staff in providing patients rights. Med Arh. 2014;68(1):61-4.

55. Uy RCY, Kury FP, Fontelo PA. The State and Trends of Barcode, RFID, Biometric and Pharmacy Automation Technologies in US Hospitals. AMIA Annu Symp Proc. 2015;2015:1242-51.

56. Castel ES, Ginsburg LR, Zaheer S, Tamim H. Understanding nurses' and physicians' fear of repercussions for reporting errors: clinician characteristics, organization demographics, or leadership factors? BMC Health Serv Res. 2015;15:326.

57. Eibling D. We're Not There Yet. Otolaryngol -- Head Neck Surg. 2014;150(5):785-6.

58. Harris JD, Staheli G, LeClere L, Andersone D, McCormick F. What Effects Have Resident Work-hour Changes Had on Education, Quality of Life, and Safety? A Systematic Review. Clin Orthop Relat Res. 2015;473(5):1600-8. 


\section{Artigo 2: O Erro médico sob o olhar do Judiciário: uma investigação no Tribunal de Justiça do Distrito Federal e Territórios - [submetido aos Cadernos Ibero-Americanos de Direito Sanitário]}

\section{O Erro médico sob o olhar do Judiciário: uma investigação no Tribunal de Justiça do Distrito Federal e Territórios}

The medical error under the eyes of the Judiciary: an investigation at the Court of Justice of Federal District and Territories.

Talita Gomes ${ }^{1}$

Maria Célia Delduque ${ }^{2}$

\section{RESUMO:}

A atividade do profissional da área médica pode suscitar em morte do paciente ou o comprometimento de sua integridade física ou de sua saúde, por conduta culposa (negligência, imperícia ou imprudência). Esses atos geram ações de responsabilidade civil levando-o a ressarcir os danos produzidos ao paciente ou ações de responsabilidade penal trazendo consequências criminais agente. Este artigo realizou uma pesquisa jurisprudencial a partir do levantamento de dados dos acórdãos em segunda instância disponível no site do TJDFT no período de 2013 a 2015, utilizando os termos "erro médico" no campo disponibilizado para pesquisa resultando um total de 204 processos. Desta analise $97 \%$ dos processos foram julgados pela justiça comum e 3\% por juizados especiais; $1 \%$ tratavam de dano material, $46 \%$ sobre danos morais e $53 \%$ relacionados a danos morais e materiais; as especialidades de menor participação nos pleitos de erro médico foram endocrinologia, dermatologia, fisioterapia, pneumologia, proctologia e erros provenientes da farmácia enquanto as com maior número de processos foram gineco-obstetrícia, cirurgia geral e plástica; encontramos ações cujo o réu foi o setor privado em $51 \%$, o setor público $44 \%$ e individual em $5 \%$ dos processos analisados; as sentenças foram improcedentes em $57 \%$, procedentes em $22 \%$ parcialmente procedentes em $19 \%$ e extintos em $2 \%$ dos processos analisados.

\section{Palavras-Chave:}

\section{Judicialização; Erro médico; Direito à Saúde; Saúde Pública}

\section{ABSTRACT:}

Actions related to health professionals can end in death of the patient or impairment of his or her physical integrity and health, through misconduct (negligence, malpractice or recklessness). These actions can lead to civil liability towards compensating damages towards the patient or criminal liability actions towards criminal charges. This article performed a jurisprudential research with data collected from second instance judgments available on the TJDFT website throughout 2013 to 2015, using the terms "medical error" in the research field involving 204 cases. From this analysis $97 \%$ of the cases were judged by the common justice and $3 \%$ by special courts; $1 \%$ dealt with material damage, $46 \%$ about moral damages and

\footnotetext{
${ }^{1}$ Mestranda em Saúde Coletiva pela Universidade de Brasília

2 Professora Colaboradora da Universidade de Brasília, Faculdade de Ciências da Saúde. Pesquisadora de Direito Sanitário da Fundação Oswaldo Cruz Brasília.
} 
$53 \%$ on moral and material damages. Specialties with fewer participation in medical error lawsuits were endocrinology, dermatology, physiotherapy, pneumology, proctology and errors from the pharmacy, whereas lawsuits with most cases were gynecological-obstetrics, general and plastic surgery. We found actions whose defendant was the private sector in $51 \%$, the public sector in $44 \%$ and individual in $5 \%$ of the analyzed cases. The sentences were dismissed in $57 \%$, ruled in favor of the plaintiff $22 \%$ partially in favor $19 \%$ and extinguished in $2 \%$ of the lawsuits analyzed.

\section{Keywords: Judicialization, Medical Error, Health Law, Public Health}

Introdução

A literatura voltada para estudos dos erros na área de saúde tem crescido nos últimos anos, porém ainda não há uma significativa oferta de estudos publicados sobre como o erro médico enfrentado pelos tribunais, especialmente no Brasil.

Erros relacionado às técnicas e procedimentos médicos podem resultar em tragédia para pacientes e suas famílias, prolongar o tempo de internação e aumentar consideravelmente os custos hospitalares. Para o médico canadense, ícone da medicina moderna, Sir William Osler Medicine is a science of uncertainty and an art of probability $^{3}$ as atividades médicas implicam em interação entre pessoas, logo, assume-se que a boa prática médica se caracteriza pelo equilíbrio entre 0 conhecimento científico, a tecnologia disponível e o relacionamento entre médico e paciente. Porém, nem sempre o insucesso terapêutico está ligado à conduta do médico, devendo-se buscar o nexo de causalidade entre os eventos e identificar as possíveis causas associadas (1).

Um paciente em unidade de terapia intensiva recebe em média 178 intervenções por dia e o risco de erro ou evento adverso aumenta em $6 \%$ a cada dia de internação (2). Os erros mais frequentes são os erros de prescrição e os de administração, sendo que as drogas mais relacionadas a esses erros são: analgésicos, antibióticos, sedativos, quimioterápicos, drogas de ação cardiovascular e anticoagulantes (3) (4).

Explica-se o número de erros observados na prática médica pela ausência de mecanismos que diminuam a sua ocorrência, ou que interceptem o erro antes de chegar ao consumidor final - o paciente. Infelizmente, no país, trabalha-se com a premissa de que o profissional de saúde não comete erros e, portanto, não se criam mecanismos de prevenção e correção.

\footnotetext{
${ }^{3}$ Medicina é a ciência da incerteza e uma arte de probabilidade (tradução livre da autora).
} 
Segundo Carvalho et. al. (2) são fatores ambientais, psicológicos e fisiológicos combinados que propiciam o erro na prática da medicina. A figura 1 apresenta os principais fatores que interferem na ocorrência de erros.

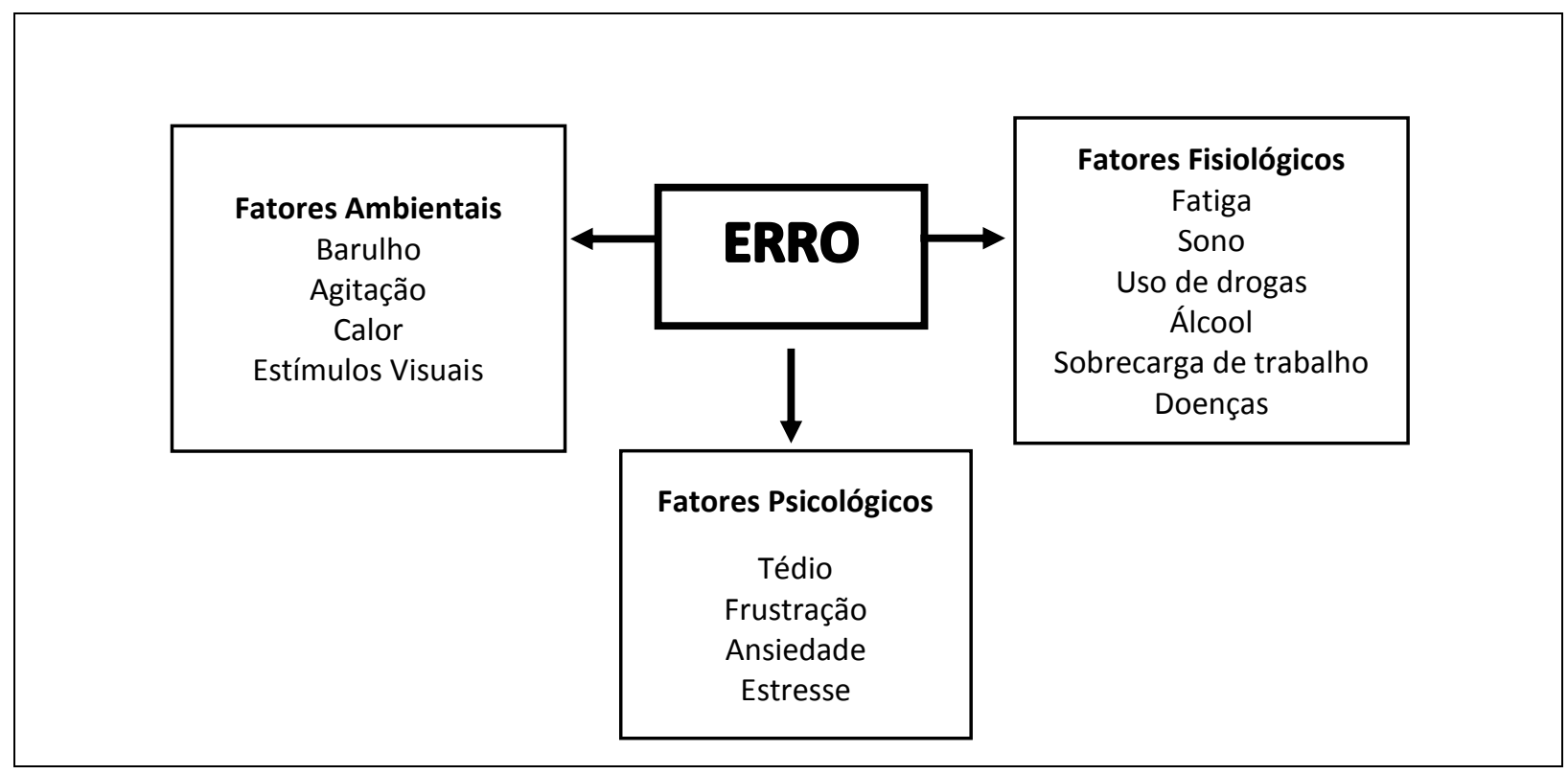

Figura 1 Principais fatores que interferem na ocorrência de erros (Desenvolvido pelas autoras com base na figura descrita por Carvalho et. al.)

Mas, o erro, seja qual for, consiste em um agir ou em um não-agir, ou seja, uma ação ou uma omissão. Esses estão envoltos na noção clássica de imperícia, negligência ou imprudência, elementos da culpa. A conduta culposa é um conceito dos mais controversos no campo jurídico, porque se refere ao resultado danoso advindo de uma ação ou omissão, havendo nexo causal entre a ação e o resultado, porém o agente não teve a intenção de produzir o resultado. Diferentemente, o dolo é a intenção de produzir um ato danoso ao sujeito destinatário da ação.

Assim, se o médico, em sua atividade profissional, determina a morte do paciente ou o comprometimento de sua integridade física ou de sua saúde, por conduta culposa - negligência, imperícia ou imprudência - responderá pelo seu ato.

Esses atos podem gerar ações de responsabilidade civil ao profissional da Medicina, fazendo-o ressarcir os danos produzidos no paciente, e ações de responsabilidade penal, trazendo consequências criminais ao médico. Tais ações são julgadas pelo Poder Judiciário, locus de resolução de conflitos intersubjetivos. São nos tribunais que o erro médico se torna visível aos olhos da sociedade, tratando-se no processo judicial as causas produzidas pelo ato comissivo ou omissivo do 
profissional, os danos produzidos, o nexo causal e a consequente sentença de reparação.

O Tribunal de Justiça do Distrito Federal e Territórios - TJDFT processa e julga ações cíveis e criminais para a reparação de erros médicos ocorridos sob sua jurisdição, por isso, este estudo privilegiou essa instância judiciária da Capital da República, a fim de conhecer as decisões judiciais de $2^{\underline{a}}$ instância sobre o erro médico.

\section{Metodologia}

Tratou-se de uma investigação retrospectiva de caráter documental baseada nas decisões judiciais proferidas em sede de Apelação cível ou Apelação criminal, no TJDFT, nos anos entre 2013 e 2015.

Foi feito um levantamento de dados online dos acórdãos em segunda instância, através de pesquisa jurisprudencial disponível no site do Tribunal de Justiça do Distrito Federal e Territórios (TJDFT) no período de 01/01/2013 e 01/01/2016, utilizando os termos "erro médico" juntos no campo disponibilizado para pesquisa específica.

Com o intuito de dar embasamento científico para a discussão, foi realizado levantamento bibliográfico nas bases de dados Pubmed/Medline e Biblioteca Virtual da Saúde utilizando os descritores Erro médico/Medical errors/Mala praxis. Foram incluídos no estudo os acórdãos em segunda instância em que o autor ou reclamante era o paciente e os casos em que o réu era o médico assistente e/ou a instituição médica pública ou privada em que o paciente havia sido atendido (clínica, hospital ou plano de saúde). Tratou-se de uma pesquisa essencialmente quantitativa, em que os dados numéricos foram analisados a partir da inserção das informações em planilha eletrônica Excel versão.2013.

Por se tratar de pesquisa documental em base pública, com acesso livre e desembaraçado aos dados, o projeto de pesquisa não foi submetido ao Conselho de Ética em Pesquisa.

\section{Resultados e Discussão}

Foram coletados um total de 427 processos no lapso temporal determinado para a pesquisa, sendo que 223 não cumpriram com os critérios de inclusão, apresentandose ações em segredo de justiça, outras ações que não versavam sobre o erro médico e foram desconsideradas na pesquisa. A amostra final resultou em 202 processos cíveis e criminais sobre erro médico entre 2013 e 2015, no TJDFT. 
Do total de 202 processos, no ano de 2013 foram encontrados 86 processos contendo ações judiciais, havendo um pico de aumento das ações sobre erros médicos no ano relatado. Nos anos subsequentes houve um decréscimo de ações judiciais sendo que foram 70 em 2014 e 47 em 2015.

Em 2015, o jornal o Estado de São Paulo (5) publicou extensa matéria sobre o erro médico no Superior Tribunal de Justiça-STJ, chamando a atenção para o acréscimo de $160 \%$ do número de ações em relação aos anos anteriores. E em Curitiba, o jornal A Tribuna (6), trouxe a informação de que no Brasil, nos 10 anos anteriores houve um aumento de $1600 \%$ de ações judiciais por erro médico e que as condenações de profissionais da medicina estavam em $180 \%$ aumentados em relação aos anos anteriores.

Em um estudo recente, erros médicos são apontados como a terceira maior causa de morte nos Estados Unidos num estudo que analisa os dados de mortalidade no país por oito anos, onde constataram que mais de 250 mil mortes por ano são atribuídas a erros (7).

Fujita e Santos (1), em sua investigação junto ao Conselho de Medicina de Goiás, igualmente verificou um aumento de processos por erro médico entre $2000 \mathrm{e}$ 2006, confirmando-se que o número de ações demandadas por pacientes tem aumentado, significativamente.

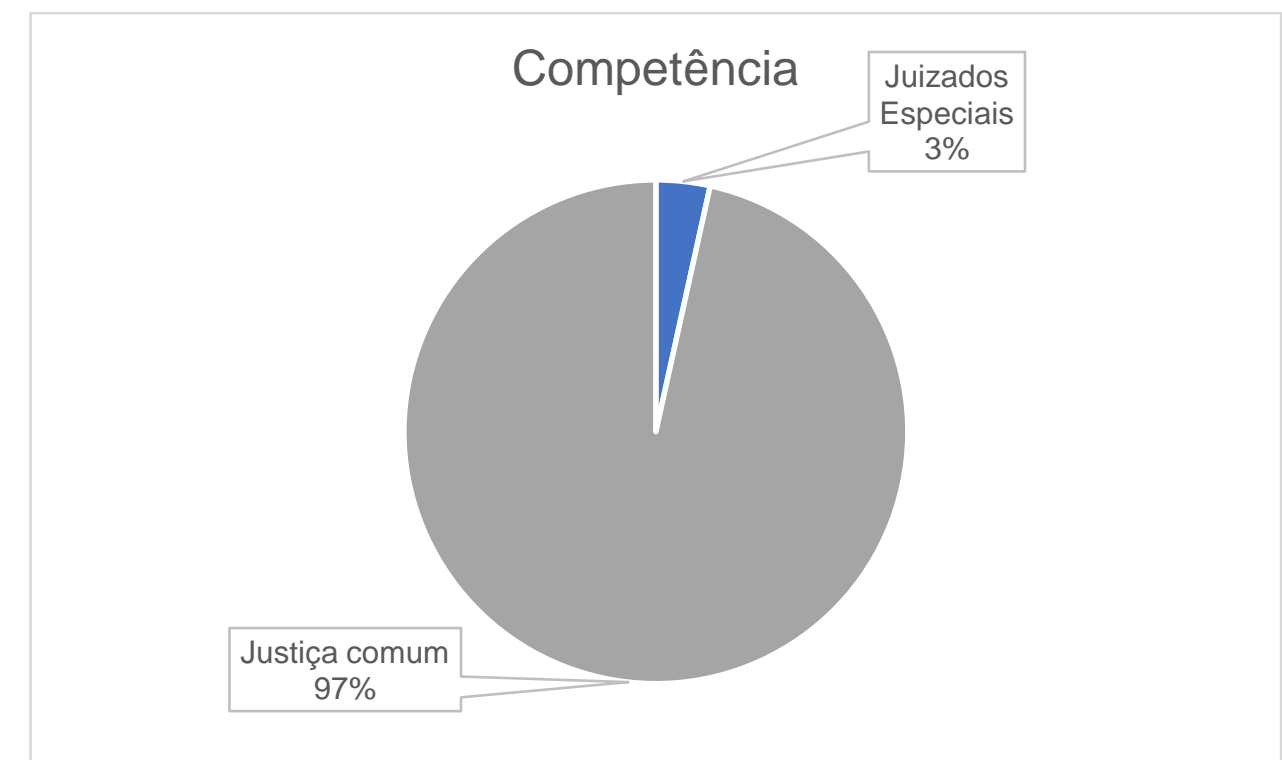

Figura 2 Classificação das ações cíveis e criminais sobre erro médico no TJDFT entre os anos de 2013-2015 (Fonte: TJDFT) 
Do total de processos coletados e analisados, incluindo-se a esfera cível e criminal, verificou-se, conforme figura 1, que um número muito reduzido de processos foi proposto nos Juizados Especiais, tendo a maioria sido proposta junto à Justiça Comum.

As vítimas podem recorrer ao Poder Judiciário com ações em âmbito penal, cível e via ação disciplinar junto ao conselho profissional em busca de medidas disciplinares contra o prestador de cuidados de saúde. Antes, porém, é possível a solução do litígio por meio da conciliação onde as partes, vítima e médico, venham a acordar a eventual reparação dos danos havidos, com a consequente homologação pelo juiz. A conciliação implica na renúncia ao direito de queixa ou representação (8).

Os Juizados Especiais são um importante meio de acesso à justiça, pois permitem que cidadãos busquem soluções para seus conflitos cotidianos de forma rápida, eficiente e gratuita. Eles são órgãos do Poder Judiciário, disciplinados pela Lei 9.099/95 (8). Os Juizados Especiais Cíveis servem para conciliar, julgar e executar causas de menor complexidade, que não exceda 40 salários mínimos e os criminais conciliam, julgam e executam infrações penais de menor potencial ofensivo. Nos processos criminais, autor é sempre o Ministério Público.

Os dados demonstram que, sendo mais volumoso os processos da justiça comum, é porque as ações indenizatórias foram superiores a 40 salários mínimos.

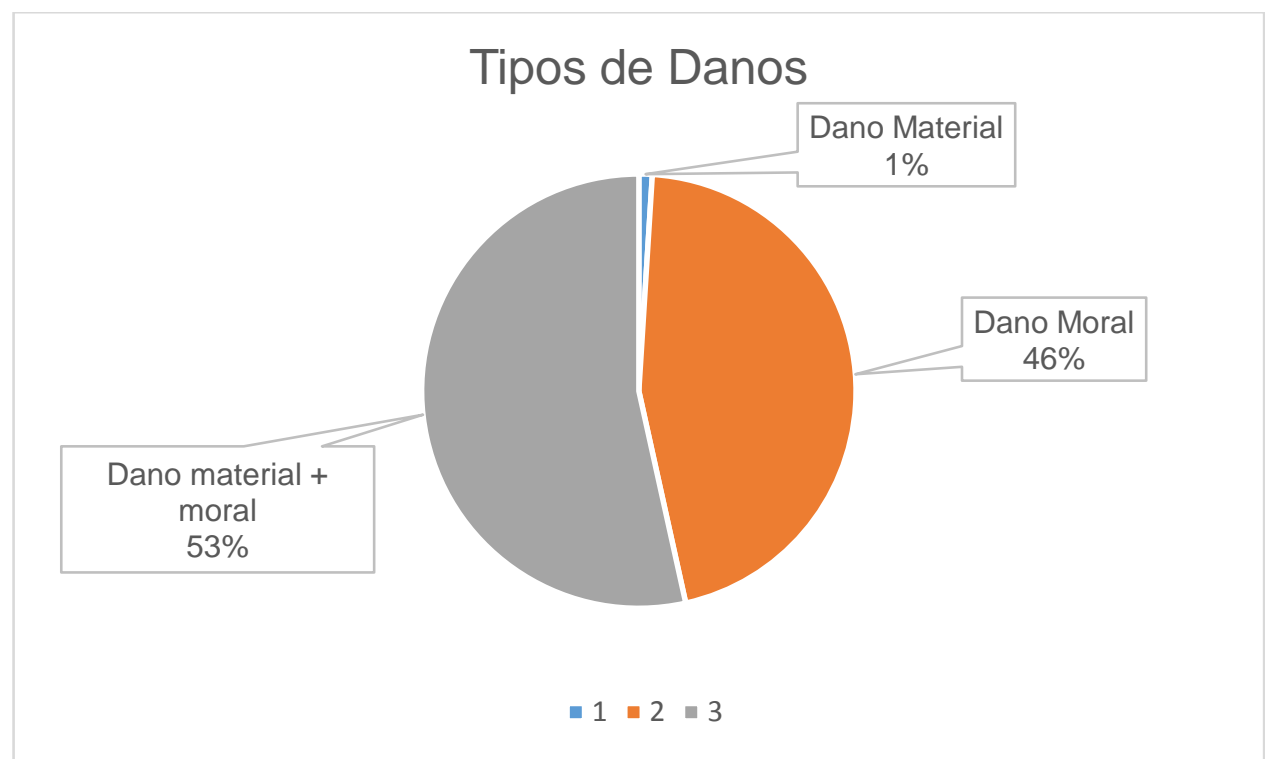

Figura 3 Tipo de danos reclamados nos processos judiciais entre 2013-2015 sobre erro médico no TJDFT (Fonte: TJDFT)

Quanto ao tipo de danos, 3 tipos foram identificados na amostra: dano material e morais; dano material; dano moral. O dano material é compreendido como os danos físicos ou estéticos produzidos no paciente, enquanto que o dano moral alcança $o$ 
psicológico e/ou a honra subjetiva do paciente. Verifica-se que a quantidade de processos por dano material foram muito reduzidos, prevalecendo o pedido de indenização associando o dano material e moral.

Os danos morais não são reparáveis, mas sim compensáveis e servem para estabelecer o quantum necessário para compensar os constrangimentos, transtornos e dissabores experimentados em decorrência de ato danoso produzido pelo médico. A indenização por dano moral tem como origem o "caráter punitivo" para que o causador do dano, pelo fato da condenação, se veja castigado pela ofensa que praticou; "caráter compensatório" para a vítima que receberá uma soma que the proporcione prazeres como contrapartida do mal sofrido, ante $\mathrm{o}$ ato gravoso praticado pelo autor.

Um dos danos materiais refere-se ao único caso de óbito do paciente por erro médico, não tendo a pesquisa encontrado outras ações em âmbito penal por lesão corporal ou crime menos grave.

Fujita e Santos (1), em um estudo que agrupou 2.293 denúncias ao órgão de classe dos médicos em Goiás, entre 2000 e 2006 encontrou pelo menos 29,4\% de processos cuja denúncia foi a morte do paciente. A julgar que seu estudo teve 6 anos de apuração, constata-se que as ações judiciais criminais encontradas neste estudo com óbito do paciente foram muito mais reduzidas.

As especialidades médicas objeto das ações judiciais analisadas envolvem erros decorrentes de procedimentos de exames de diagnósticos como: sangue, biópsias, ecografias, videolaparoscopias, entre outros. A especialidade de menor número de processos com judicialização de erro médico é a endocrinologia, dermatologia, fisioterapia, pneumologia, proctologia e erros provenientes da farmácia (Tabela 1)

As especialidades com maior número de processos por erro médico são: ginecoobstetrícia, ortopedia, cirurgia plástica e cirurgia geral.

Yamauti e Zerbini (9), ao analisarem as decisões judiciais por erro médico na especialidade da oftalmologia, contataram que os erros são mais frequentes em atos cirúrgicos em detrimento dos atos clínicos e que embora não tenha encontrado nenhum óbito durante sua pesquisa, os danos produzidos foram graves, com perda de visão total ou parcial.

$\mathrm{Na}$ investigação empreendida por Fujita e Santos (1), a especialidade médica com menor número de denúncias junto ao Conselho Regional de Medicina de Goiás é a hematologia, sendo a gineco-obstetrícia a especialidade com maior número de 
reclamações, seguida da cardiologia e semelhante aos achados de Jena et. al. (10) que descreve em seu estudo $46,7 \%$ para reclamações contra anestesiologistas a $62,6 \%$ para reclamações contra obstetras e ginecologistas e aos achados de Koeche et.al. (11) que cita a ginecologia/obstetrícia como a especialidade com maior número de médicos denunciados junto ao Conselho Regional de Medicina do Estado de Santa Catarina, seguida pela anestesiologia, ortopedia/traumatologia e outras especialidades. Esta modalidade também teve participação relevante nos resultados encontrados seja atuando em partos ou cirurgias como histerectomias.

Tabela 1 - Especialidades médicas/enfermagem/odontologia em número de processos de erro médico no TJDFT, entre os anos de 2013-2015

\begin{tabular}{|c|c|c|}
\hline GINECO-OBSTETRÍCIA & 45 & $22,28 \%$ \\
\hline CIRURGIA GERAL & 39 & $19,31 \%$ \\
\hline CIRURGIA PLÁSTICA & 24 & $11,88 \%$ \\
\hline ORTOPEDIA & 21 & $10,40 \%$ \\
\hline ONCOLOGIA & 15 & $7,43 \%$ \\
\hline NEUROCIRURGIA & 10 & $4,95 \%$ \\
\hline OFTALMOLOGIA & 10 & $4,95 \%$ \\
\hline ODONTOLGIA & 7 & $3,47 \%$ \\
\hline CARDIOLOGIA & 6 & $2,97 \%$ \\
\hline UROLOGIA & 5 & $2,48 \%$ \\
\hline ANESTESIA & 3 & $1,49 \%$ \\
\hline ENFERMAGEM & 3 & $1,49 \%$ \\
\hline HEMATOLOGIA & 2 & $0,99 \%$ \\
\hline INFECTOLOGIA & 2 & $0,99 \%$ \\
\hline RADIOLOGIA & 2 & $0,99 \%$ \\
\hline REPRODUÇÃO ASSISTIDA & 2 & $0,99 \%$ \\
\hline DERMATOLOGIA & 1 & $0,50 \%$ \\
\hline ENDOCRINOLOGIA & 1 & $0,50 \%$ \\
\hline FARMACIA & 1 & $0,50 \%$ \\
\hline FISIOTERAPIA & 1 & $0,50 \%$ \\
\hline PNEUMOLOGIA & 1 & $0,50 \%$ \\
\hline PROCTOLOGIA & 1 & $0,50 \%$ \\
\hline
\end{tabular}

Fonte: TJDFT

O TJDFT trata como erro médico atos praticados indistintamente da especialidade clínica propriamente dita como casos provenientes de tratamento odontológico ou cirurgia odontológica, não diferenciando o médico do dentista. 0 mesmo se diz do fisioterapeuta, que se trata de uma profissão distinta da Medicina. 
Nota-se a ausência de especialidades como pediatria, geriatria e outras, não significando, todavia que tais especialidades não cometam erros, mas constata-se que no período estudado e no tribunal escolhido tais especialidades não apareceram.

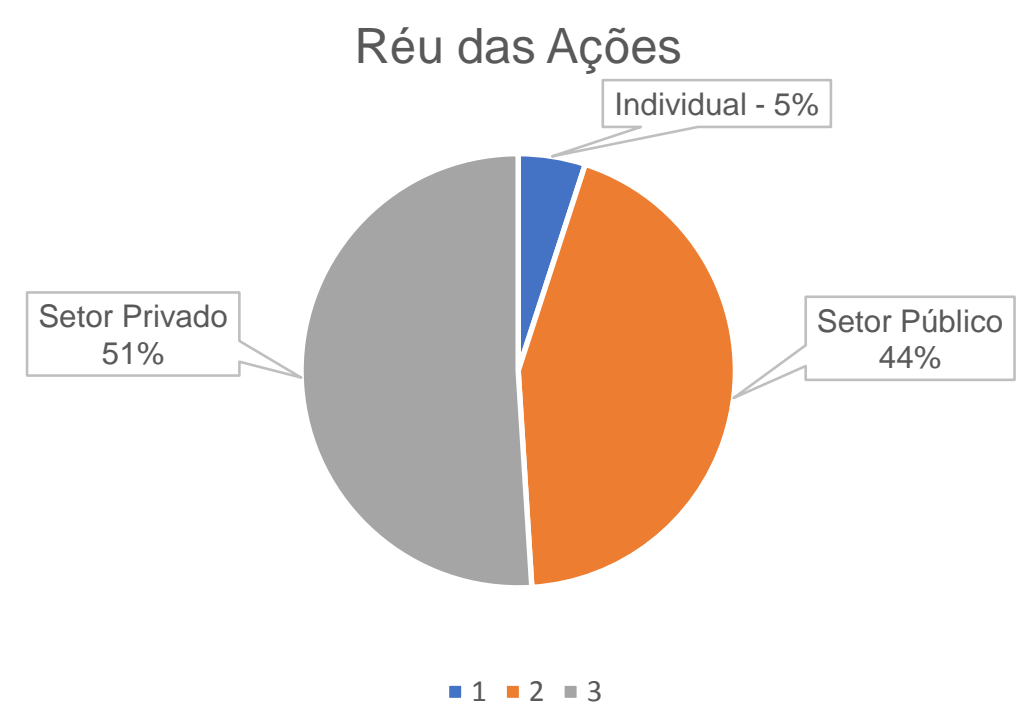

Figura 4 - Identificação do polo passivo das ações judiciais sobre erro médico no TJDFT no período entre 2013 e 2015. (Fonte: TJDFT)

O setor privado teve o maior aporte de processos por erro médico no Distrito Federal. Tais ações foram movidas contra a pessoa jurídica, seja clínica ou hospital, sendo que o médico individualmente foi processado em $5 \%$ das ações analisadas. A opção por processar a pessoa jurídica empregadora do profissional da medicina é uma forma de garantir uma indenização mais robusta, visto que as empresas de saúde detêm um ganho bem maior que a do profissional, isoladamente.

É certo que, uma vez condenada, a empresa terá que mover ação regressiva contra o seu empregado, profissional médico, para ver-se ressarcido dos custos do processo, honorários advocatícios e pagamento da indenização.

Os processos por erro médico movidos contra pessoas jurídicas de direito público, o Sistema Único de Saúde-SUS, do Distrito Federal somam 44\%. Nestes casos, responde o processo a Fazenda Pública que pode ser a União ou o próprio Distrito Federal, posto que os hospitais são vinculados à Secretaria de Saúde. A jurisprudência brasileira tem entendido que a União não poderá responder por erros médicos cometidos em nosocômios pertencentes ao SUS, nos estados e municípios. Nesse particular, os tribunais não reconhecem a solidariedade tão propalada na prestação de serviços de saúde para a indenização por erro médico. 
Sendo o Estado sujeito de direito, e pessoa jurídica de direito público, também deve se submeter aos ditames legais, ainda que por ele impostos. Ademais, a responsabilidade do Estado está implícita na própria noção de Estado de Direito, "a responsabilidade estatal é simples corolário da submissão do Poder Público ao Direito" (12).

A responsabilidade civil médica é um ramo do gênero responsabilidade civil. Todas as pessoas - físicas ou jurídicas - estão abrangidas pela legislação da responsabilidade civil, sendo necessário identificarmos as peculiaridades que envolvem a atividade médica.

A responsabilidade civil subjetiva se caracteriza pela verificação de culpa no dever de indenizar enquanto a responsabilidade civil objetiva tem a característica de dispensar a culpabilidade. É uma responsabilidade sem culpa, onde, para haver a indenização, não é necessário demonstrar que a culpa do agente causador do dano. A responsabilidade do médico é subjetiva, ou seja, segue a teoria da culpa. Sendo assim o profissional de saúde somente será obrigado a indenizar se restar provada a sua culpa no resultado danoso.

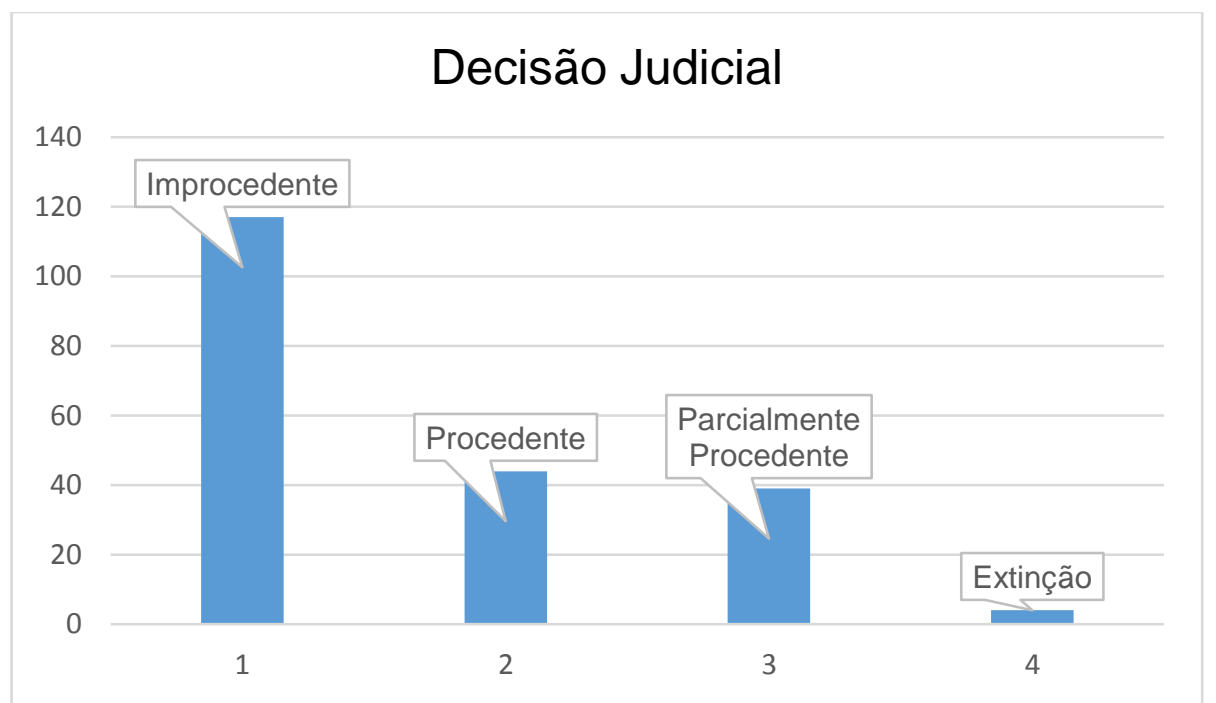

Figura 5 Resultado das decisões nas ações sobre erro médico analisadas no TFDFT, no período entre 2013-2015 (Fonte: TJDFT)

A maioria dos processos analisados foram negados (57\%) o que demonstra uma certa dificuldade em comprovar o evento adverso como dano ou o fato das indenizações serem desproporcionais a gravidade do fato. Apenas $22 \%$ das ações analisadas tiveram decisão final procedente, dando-se o ganho de causa ao paciente- 
autor. As ações parcialmente procedentes tiveram 19\% do total analisado e apenas $2 \%$ foram extintos sem o julgamento.

Contrariando os achados de Svider et. al. (13) que analisou vereditos de processos referentes a eventos adversos em procedimento cirúrgico de carótida onde os desfechos dos casos foram resolvidos a favor do arguido em $67,5 \%$ dos casos e resultaram em pagamento de indenizações $32,4 \%$ dos casos e $8,1 \%$ de acordos extrajudiciais.

\section{Conclusão}

A responsabilidade médica é um fenômeno inseparável do cuidado em saúde. Percebemos que os cidadãos tendem a buscar soluções extrajudiciais com a finalidade de ressarcimento dos danos sofridos nos sistemas de saúde enquanto os legisladores tendem a reconhecer os pleitos como forma de melhorar o sistema e aumentar a segurança dos pacientes.

Os conselhos de classe costumam tratar o erro médico como falta ética e os processos tramitam sob sigilo fazendo a sociedade desconhecer o alcance do problema, ao contrário do que é percebido nos tribunais onde os erros médicos costumam ser traduzidos em processos judiciais que tramitam pela justiça comum ou juizados especiais. A pressão legal da prática médica vem a moldar as atitudes e as práticas de saúde nos serviços, motivado pelas repercussões legais e pelas consequências econômicas da gestão. Isto é o reflexo de uma sociedade em que a afirmação de direitos e a ideia de ter sofrido uma lesão compensável é interpretada como a responsabilidade de um bom profissional ou de um bom serviço de saúde seja ele público ou privado.

O médico não deve ser interpretado como o único responsável e causador do dano, é necessário que todas as partes envolvidas estejam conscientes das mudanças que merecem ser implementadas e que já foram discutidas pela Organização Mundial de Saúde como a melhoria nos mecanismos de comunicação médico-paciente, sistema de notificação de eventos adversos rápido e eficaz e a criação de protocolos de procedimentos, com a implantação dessas pequenas melhorias muitos dos processos não chegariam a justiça. 
Espera-se que este trabalho venha a demonstrar a real dimensão do problema e venha a auxiliar na tomada de decisões no enfrentamento da questão do erro médico. Erros são inerentes a condição humana mesmo em profissionais extremamente capacitados, porém reconhecer o problema talvez seja o primeiro passo a ser tomado para o enfrentamento da questão e isto não depende de um parecer de colegiado ou da sentença de um juiz.

\section{Bibliografia}

1. Fujita R, Santos I. Denúncias por erro médico em Goiás. Revista da Associação Médica Brasileira. 1992; vol. 55 n.3, p.283-289.

2. Carvalho M De, Vieira A a. Erro médico em pacientes hospitalizados. Jornal de Pediatria (Rio J) [Internet]. 2002; 78:261-8. Available from: http://dx.doi.org/10.1016/j.bjorl.2015.12.002

3. Weingart SN, Wilson RM, Gibberd RW, Harrison B. Epidemiology of medical error. BMJ. 2000;320(7237):774-7.

4. Grober ED, Bohnen JMA. Defining medical error. Vol. 48, Canadian Journal of Surgery. 2005. p. 39-44.

5. Jornal o Estado de São Paulo. Em 4 anos o número de processos por erro médico cresce $160 \%$. Available from: http://saude.estadao.com.br/noticias/geral,em4-anos-numero-de-processos-por-erro-medico-cresce-140-no-stj-imp-,1655442.

6. Jornal A Tribuna. Processos Judiciais registram alta de $1.600 \%$. Available from: http://www.tribunapr.com.br/noticias/parana/processos-judiciais-contra-medicosregistram-alta-de-1-600/.

7. Makary M, Daniel M. Medical Error - the third leading cause of death in the US. Br Med J. 2016;353:i2139.

8. Brasil. Lei № 9.099, de 26 de Setembro de 1995 [Internet]. BRASIL; 1995. Available from: http://www.planalto.gov.br/ccivil_03/leis/L9099.htm

9. Yamauti K, Zerbini T. A oftalmologia no tribunal: avaliação das sentenças judiciais no âmbito do Tribunal de Justiça do Estado de São Paulo. Saúde, Ética \& 
Justiça [Internet]. 2014 Dec 5 [cited 2017 Feb 1];19(2):78. Available from: http://www.revistas.usp.br/sej/article/view/100095

10. Jena AB, Chandra A, Lakdawalla D, Seabury S, C K, FA S, et al. Outcomes of Medical Malpractice Litigation Against US Physicians. Arch Intern Med [Internet]. 2012 Jun 11 [cited 2017 Jan 12];172(11):3291-7. Available from: http://archinte.jamanetwork.com/article.aspx?doi=10.1001/archinternmed.2012.1416 11. Koeche LG, Censi I, Bortoluzzi MC B EL. Prevalência do erro médico entre as especialidades médicas nos processos julgados pelo Conselho Regional de Medicina do Estado de Santa Catarina. Arq Catarinenses Med [Internet]. 2013;42(4):45-53. Available from: http://www.acm.org.br/revista/pdf/artigos/1257.pdf

12. Mello, Celso Antônio Bandeira de. Curso de direito administrativo. 1150 p.

13. Svider PF, Vidal G-P, Zumba O, Mauro AC, Haser PB, Graham A, et al. Adverse events in carotid endarterectomy from a medicolegal perspective. Vasc Endovascular Surg. 2014;48(5-6):425-9. 


\title{
Artigo 3: Análise Idiossincrática dos Discursos proferidos nas decisões judiciais sobre Erro Médico no TJDFT: um estudo qualitativo.
}

\section{Análise Idiossincrática dos Discursos proferidos nas decisões judiciais sobre Erro Médico no TJDFT: um estudo qualitativo.}

\author{
Talita Gomes \\ Maria Célia Delduque
}

Resumo:

Sabendo que as relação médico-paciente insatisfatória decorrente de erro médico são responsáveis por grande parte das denúncias feitas nos conselhos de classe e das demandas pecuniárias junto aos tribunais de justiça. É necessário reconhecer a importância e conhecer os fatores relacionados aos erros médicos para a formulação de medidas no sentido de evitar a má prática profissional. Com o objetivo de conhecer os argumentos utilizados nas decisões judiciais procedentes sobre erro médico que foram julgadas no TJDFT mediante uma metodologia qualitativa realizou-se uma análise idiossincrática do discurso com a finalidade de conhecer pressupostos classificados como: legal, processual e material. Observamos uso diferenciado da legislação para o julgamento de casos de erro médico de forma distinta para o setor público e o setor privado assim como observamos julgados em vista de problemas processuais e erros formais no processo civil. É possível aferir a partir do discurso analisado tanto a negligência, como imperícia e imprudência no trato dos pacientes o que evidencia falhas no sistema de saúde. Constata-se a necessidade de efetivação de ações de saúde e propostas de formação dos profissionais de saúde e do direito mais humanizadas.

Palavras-chave: Erro Médico, Judicialização, Análise Qualitativa, Saúde Pública

\section{Abstract:}

Knowingly that unsuccessful relationship between patient-doctor relate to most of the complaints made though health councils and damage restitution claims in the courts of justice. It is necessary to knowledge the importance and the factors associated to medical errors to promote measures in order to avoid professional malpractice. In order to understand the arguments used in sentences regarding medical error that were pronounced in the TJDFT this research made a qualitative analysis through an idiosyncratic reading of the sentences conducted with the purpose of understanding assumptions classified as: legal, procedural and material. We observed differentiated uses of legislation for the lawsuits regarding medical error in a different way for the public sector and the private sector; we also observed the outcome of the complaints due to procedure and formal errors in civil proceedings. It is possible to estimate from the complaints problems such as negligence, malpractice and presumption in the treatment of the patients, which demonstrates failures in the health system. There is 
a need for health actions and proposals of health professionals and law practitioners training with a more humanized manner.

Key-words: Medical Error, Judicialization, Qualitative Analysis, Public Health

\section{Introdução}

Os erros médicos, quase sempre, causam danos e sofrimento aos pacientes, o que, aliado a uma relação médico-paciente insatisfatória, é responsável por grande parte das denúncias feitas nos Conselhos Regionais de Medicina (CRM) (BITENCOURT et. al., 2007). Segundo Chehuen Neto et. al. (2011), erro médico é o dano provocado no paciente pela ação ou omissão do médico, no exercício da profissão, e sem a intenção de cometê-lo. Há três possibilidades de suscitar o dano e alcançar o erro: imprudência, imperícia e negligência. A negligência, consiste em não fazer o que deveria ser feito; a imprudência consiste em fazer o que não deveria ser feito e a imperícia em fazer mal o que deveria ser bem feito.

Os Conselhos Regionais de Medicina são autarquias federais consideradas especiais e cuja finalidade é proteger a sociedade dos maus médicos (FUJITA; SANTOS, 1992). Deslizes cometidos por profissionais de outras áreas podem não acarretar maiores consequências, mas os erros dos médicos frequentemente provocam resultados indesejados e, muitas vezes, sequelas irreversíveis (RENATA GROU VOLPE et. al., 2014). Reconhecer a importância e conhecer os fatores relacionados aos erros médicos é fundamental para formular medidas no sentido de evitar a má prática profissional (RIBEIRO; JULIO, 2011).

Vem ocorrendo no Brasil e no mundo aumento nas demandas judiciais na área cível e na esfera administrativa por parte de advogados que buscam indenizações e na atuação dos conselhos de medicina na abertura de processos éticos profissionais (CORDERO et. al., 2010).

A prevenção de erros deve basear-se na busca de causas reais, que geralmente incluem erros no sistema de organização e implementação do serviço. Erros devem ser aceitos como evidência de falha no sistema, e encarados como oportunidade de revisão do processo e aprimoramento da assistência prestada ao paciente (CARVALHO; VIEIRA, 2002).

A segurança do paciente, uma importante dimensão da qualidade em saúde, se tornou foco de atenção a partir do relatório apresentado pelo Instituto de Medicina - To err is human -, que apontou a alta frequência de eventos adversos resultantes 
do cuidado hospitalar, ou seja, incidentes que resultavam em dano para o paciente, e que mais da metade dos casos eram ocasionados por erros médicos (LINDA T. KOHN; JANET M.; CORRIGAN M., 1999).

Ao tratar o erro médico como uma conduta antiética os processos tramitam junto sob sigilo junto aos Conselhos de Medicina, o que acaba fazendo a sociedade desconhecer a gravidade problema. Ao revés, nos tribunais, os erros médicos costumam ser traduzidos em processos judiciais de caráter público que tramitam em Varas Civis e Varas Criminais e acabam sendo de conhecimento público e de livre acesso.

Segundo Bonetti et. al. (2016) a negligência médica envolve danos, lesões ou morte podendo ser atribuído ao comportamento negligente por um médico ou de outros profissionais de saúde. Muitas vezes pacientes e familiares que acreditam ter sido vítimas de negligência médica recorrem contra os prestadores de cuidados de saúde. Isto tem um forte impacto em termos de custos e os reembolsos, e leva médicos, profissionais de saúde e organizações de saúde a aderirem políticas de seguro de responsabilidade civil para compensar seus riscos.

Ao contrário do apontado por Makary; Daniel (2016), erros médicos são apontados como a terceira maior causa de morte nos Estados Unidos num estudo que analisa os dados de mortalidade no país por oito anos, onde constataram que mais de 250 mil mortes por ano são atribuídas a erros assim como na Itália, o número anual de processos que alegam negligência médica tem aumentado ao longo dos últimos anos para todas as tipologias de reivindicações como: lesão corporal, lesões no momento do nascimento, morte e outros danos materiais segundo Bonetti et al. (2016).

Segundo Cordero et. al. (2010), em 7 anos, o número de médicos denunciados no Conselho Regional de Medicina do Estado de São Paulo (CREMESP) aumentou em 75\%. De 2.023 médicos denunciados em 2000, o número subiu para 3.569 em 2006, o que demonstra que no Brasil os processos contra médicos também atingem níveis expressivos.

Para Rodríguez; Riva e Serratosa (2011) a responsabilidade médica é um fenômeno inseparável dos cuidados de saúde, sendo assim uma lesão, uma incapacitação, ou mesmo o óbito do paciente proveniente de tratamento médico pode ser considerada um crime (HENRIQUE; MARTINS, 1998). 
Os processos judiciais têm interesse público e estão disponíveis para consulta, seja na internet, em forma sintética, seja nos cartórios dos Fóruns, para vistas dos solicitantes. Este caráter público do processo judicial faz com que seja possível o acesso aos dados referentes a toda a sorte de assunto, incluído os erros médicos. Com o objetivo de conhecer os argumentos utilizados nas decisões judiciais procedentes sobre erro médico que foram julgadas no TJDFT, entre os anos de 2013 e 2015 é que foi realizado pesquisa, cujos resultados são discutidos neste artigo.

\section{Metodologia}

Foi realizada uma pesquisa jurisprudencial, com o erro médico como objeto material. Tratou-se de uma pesquisa exploratória, analítico-descritiva de base qualitativa, cuja unidade de consulta foi o processo judicial contendo Apelações Cíveis e/ou Apelações Criminais julgadas em segunda instância no TJDFT.

Foi consultada a base jurisprudencial do referido tribunal, utilizando-se para a seleção das ações o descritor "erro médico".

Os princípios que nortearam a pesquisa qualitativa se situam nas correntes cujos resultados provêm de uma visão extraída a partir do discurso do próprio sujeito pesquisado, ou seja, o julgador dos casos sobre erro médico colocados sob seu julgamento.

Para as análises dos argumentos utilizados pelos julgadores em suas decisões, optou-se em utilizar o Método da Análise do Discurso por sua técnica de Análise Idiossincrática (MAEDA; POLLAK; MARTINS, 2009), que representa o ato de extrair da fala do sujeito, unidades significativas que explicitam a consciência que este momento tem do fenômeno. O discurso, nesta proposta, está delimitado ao descrito como argumentos provenientes da transcrição dos acórdãos analisados.

Optou-se em selecionar apenas as decisões procedentes, a fim de conhecerIhes o discurso a partir de 3 pressupostos: legal, processual e material.

Por pressuposto legal entende-se todo o arco normativo elencado pelo julgador em sua decisão, isso possibilita conhecer as regras jurídicas utilizadas para as decisões. Por pressuposto processual entende-se os entendimentos jurídicos que possam ter alterado a normal tramitação do processo, tais como indeferimento de provas, pedido de perícia etc. Por fim, o pressuposto material, entendido neste 
trabalho como aquele que diz respeito diretamente ao mérito da causa, os argumentos fáticos trazidos aos autos que embasaram a decisão.

Minayo (2010) defende que a análise do discurso pode ser realizada por um conjunto de abordagens interdisciplinares, e tem seu marco inicial com Michael Pêcheux na década de 1960, onde seu objetivo é realizar uma reflexão da apreensão dos significados. Assim é que se compreende que a materialidade específica da ideologia é o discurso. E a materialidade do discurso é a língua que constituiu a relação língua-discurso-ideologia. Complementando a isso Pêcheaux (1975) afirma que não há discurso sem sujeito, como não há sujeito sem ideologia: o indivíduo é interpelado como sujeito pela ideologia e é assim que a língua faz sentido.

O conceito de discurso é elaborado exatamente como meio de contemplar a articulação entre o objeto língua e os processos ideológicos de constituição de sentido pela reconstrução dos processos discursivos

\section{Resultados e Discussão}

A partir do levantamento das decisões judiciais proferidas, no TJDFT, utilizando os termos "erro médico" juntos no campo disponibilizado para pesquisa específica. no período de 01/01/2013 e 01/01/2016, verificou-se um universo de 427 processos nos anos entre 2013 e 2015. Em vista este resultado, 204 demandas foram classificadas PROCEDENTES e utilizadas nesta análise. Foi feito um levantamento de dados online dos acórdãos em segunda instância, através de pesquisa jurisprudencial disponível no site do Tribunal de Justiça do Distrito Federal e Territórios (TJDFT) no período de 01/01/2013 e 01/01/2016, utilizando os termos "erro médico" juntos no campo disponibilizado para pesquisa específica.

Foram desconsideradas as ações julgadas improcedentes porque o resultado da ação judicial de algum modo já sinaliza o discurso adotado pelos julgadores para dar provimento a um pedido, a contrário sendo dos julgados procedentes.

As vítimas por erro médico podem recorrer ao Poder Judiciário com ações em âmbito penal, cível e ainda pela via da ação disciplinar junto ao conselho profissional em busca de medidas disciplinares contra o prestador de cuidados de saúde. Pode ainda haver a conciliação em que as partes, vítima e médico, venham a acordar a eventual reparação dos danos havidos, sendo que a conciliação implica na renúncia ao direito de queixa ou representação junto ao Judiciário (art. 74 , § único, da Lei 9.099/95). 
Os processos analisados no TJDFT, em segunda instância, consubstanciados em demandas sobre erro médico foram julgados pelas Turmas Cíveis $\left(1^{\underline{a}}, 2^{a}, 3^{a}, 4^{a}, 5^{a}\right.$ e 6 ${ }^{\underline{a}}$ Turma Cível) como também pelos Juizados Especiais Cível e/ou Criminal ( $1^{\mathrm{a}}$ e $2^{\mathrm{a}}$ Câmara Cível e pela $2^{\mathrm{a}}$ Turma Criminal). Tal difusão no julgamento das ações movidas

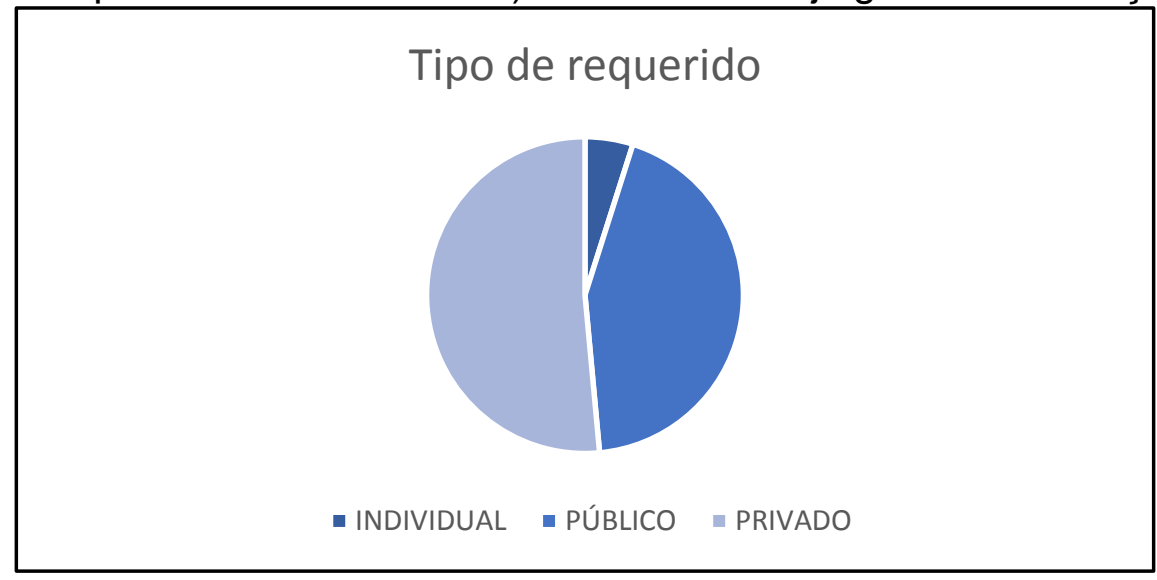

pelos pacientes acabam por ter grande representatividade do tribunal, podendo-se afirmar que a análise das decisões proferidas pelas turmas e câmaras têm relevante representação de todo o tribunal estudado.

Figura 1 Tipos de requeridos nos processos entre 2013-2015 no TJDFT sobre erro médico. (Fonte: TJDFT)

Resta informar que a maioria das demandas por erro médico foram em desfavor do ente jurídico privado (51\%), ou sejam, hospitais e clínicas operantes no âmbito do Distrito Federal. O ente público, representado pelo SUS-DF, por seus hospitais da rede pública e conveniadas foram o segundo tipo mais comum encontrado na pesquisa (44\%). Com pouca expressão, foram localizados processos judiciais contra pessoas físicas representando os profissionais médicos (5\%).

Esta "pressão legal" nada mais é que o reflexo de uma sociedade em que a afirmação de direitos e a ideia de ter recebido uma lesão compensável é interpretada como a prática de saúde de um sistema público. Portanto, a responsabilidade criminal é definida como a responsabilidade pessoal de ser "bom profissional", enquanto a administração em saúde é cobrada a ser um "bom serviço de saúde" seja ela público ou privado (RODRÍGUEZ HORNILLO; RIVA MORENO; SERRATOSA SÁNCHEZIBARGÜEN, 2011).

Referente as sentenças analisadas observamos que $57 \%$ dos casos foram declarados improcedentes, $44 \%$ declarados procedente, $19 \%$ declarados parcialmente procedente e $2 \%$ dos processos relacionados ao erro médico foram 
extintos sem resolução do mérito. Para fins da análise do discurso, foram selecionadas apenas as decisões procedentes em um total de 44 decisões.

Os achados de Svider et. al. (2014) analisou vereditos de processos referentes a eventos adversos em procedimento cirúrgico de carótida em que os desfechos dos casos foram resolvidos a favor do arguido em $67,5 \%$ dos casos e resultaram em pagamento de indenizações.

Dentre os argumentos encontrados nas sentenças dos processos coletados observa-se que nenhuma Apelação Cível se utilizou da terminologia relacionada a segurança do paciente e a Classificação Internacional de Segurança do Paciente (ICPS - sigla em inglês) da Organização Mundial de Saúde (OMS): "incidente sem danos", "evento adverso" e " segurança do paciente" em contrapartida observou-se que as definições jurídicas de crimes culposos ou dolosos segundo o Código Penal: negligência $(4,9 \%)$, imperícia $(3,3 \%)$ e imprudência $(1,9 \%)$ foram mais utilizadas.

A falta de unificação dos conceitos jurídicos e de segurança do paciente refletem certa deficiência por parte dos médicos relacionado ao conhecimento das leis implicadas na regulamentação de sua profissão, além da necessidade dos profissionais do Direito desenvolverem uma visão multidisciplinar ao conduzirem adequadamente um processo judicial, cercando-se de pessoas habilitadas para fazer julgamentos técnicos como perícias médicas segundo (CHEHUEN NETO et. al., 2011).

Tabela 1 - Análise dos Discursos inseridos nas Decisões Procedentes das Apelações Cíveis e Criminais com a Variável Normativa.

\begin{tabular}{|l|l|l|}
\hline $\begin{array}{l}\text { Discurso na linguagem do } \\
\text { acórdão }\end{array}$ & Unidade significativa & Asserções articuladas \\
\hline $\begin{array}{l}\text { 1) A saúde é direito de todos } \\
\text { e dever do Estado, garantido } \\
\text { mediante políticas sociais e } \\
\text { econômicas que visem à redução } \\
\text { do risco de doença e de outros } \\
\text { agravos }\end{array}$ & Citação ao art.196 CF/88 & O cidadão tem direito a saúde \\
\hline $\begin{array}{l}\text { 2) "[...] do ponto de vista da } \\
\text { execução de políticas públicas } \\
\text { para o fim de tornar efetivos tais } \\
\text { direitos subjetivos constitucionais, } \\
\text { foram previstas as regras dos arts. } \\
\text { 196, 197 e 198 da Constituição } \\
\text { Federal, }\end{array}$ & Citação ao art. 196 CF/88 & O cidadão tem direito à saúde \\
\hline $\begin{array}{l}\text { 3) É o que dispõe o §̧4o do } \\
\text { artigo 14 do CDC, in verbis: }\end{array}$ & $\begin{array}{l}\text { Citação ao Código de Defesa } \\
\text { do Consumidor }\end{array}$ & \\
\hline $\begin{array}{l}\text { 4) "E o que se extrai do } \\
\text { disposto no artigo 186 do Código } \\
\text { Civil: "Aquele que...." }\end{array}$ & $\begin{array}{l}\text { Citação ao Código Civil } \\
\text { Brasileiro }\end{array}$ & $\begin{array}{l}\text { O consumidor tem direito a } \\
\text { prestação de serviços }\end{array}$ \\
\hline
\end{tabular}




\begin{tabular}{|c|c|c|}
\hline $\begin{array}{l}\text { 5) "...a culpa do profissional } \\
\text { responsável pelo procedimento, } \\
\text { conforme a teoria de } \\
\text { responsabilidade subjetiva dos } \\
\text { profissionais liberais abrigada pela } \\
\text { legislação consumerista" }\end{array}$ & $\begin{array}{l}\text { Citação ao Código de Defesa } \\
\text { do Consumidor }\end{array}$ & $\begin{array}{l}\text { O consumidor mantém uma } \\
\text { relação consumerista com o } \\
\text { prestado do serviço de saúde }\end{array}$ \\
\hline $\begin{array}{l}\text { 6) "[...] com o intento de } \\
\text { regulamentação da matéria, a Lei } \\
n^{\circ} 8.080, \text { de } 19 \text { de setembro de } \\
1990 "\end{array}$ & Citação a Lei Federal 8080/90 & O cidadão amparado pela lei \\
\hline $\begin{array}{l}\text { 7)"[...] por outro lado, o Código de } \\
\text { Etica Médica (Resolução CFM no } \\
1.246 / 88 \text {, de 08.01.88, D.O.U } \\
\text { 26.01.88), estabelece os seguintes } \\
\text { preceitos deontológico }\end{array}$ & $\begin{array}{l}\text { Citação ao Código de Ética } \\
\text { Médica }\end{array}$ & $\begin{array}{l}\text { O médico deve prestar } \\
\text { serviços de qualidade }\end{array}$ \\
\hline
\end{tabular}

Fonte: Fragmentos das decisões dos processos do TJDFT

$\mathrm{Na}$ totalidade das decisões procedentes analisadas, quando se deparou com menções à legislação, elas se restringiram à Constituição Federal, a Lei Federal 8080/90, o Código de Defesa do Consumidor, o Código Civil e o Código de Ética Médica.

O que chama a atenção é o uso diferenciado da legislação para o julgamento de casos de erro médico de forma distinta para o setor público e o setor privado. Quando se está julgando o erro médico no setor público, os julgadores se utilizam da Constituição Federal para reforçar o direito à saúde dos pacientes. No entanto, tal normativa não é trazida para a decisão quando se trata de julgar o erro médico no setor privado. Neste, os julgadores elencam o Código de Defesa do Consumidor.

Ora, segundo a Constituição Federal de 1988, o setor privado da saúde atua como complementar ao Sistema Único de Saúde-SUS, devendo, logicamente, que os princípios inerentes ao SUS serem igualmente aplicados no setor privado. Nos discursos analisados percebemos que não há um sistema ÚNICO de saúde e sim duas modalidades de assistências em saúde, uma privada garantida como uma relação de consumo e outra assistência baseada na constituição e outros fatores jurídicos.

Tabela 2 - Análise dos Discursos inseridos nas Decisões Procedentes das Apelações Cíveis e Criminais com a Variável Processual.

\begin{tabular}{|c|c|c|}
\hline $\begin{array}{l}\text { Discurso na linguagem do } \\
\text { acórdão }\end{array}$ & Unidade significativa & Asserções articuladas \\
\hline $\begin{array}{l}\text { 1) No momento } \\
\text { processual oportuno, formulou } \\
\text { pedido de produção de prova } \\
\text { pericial, o qual foi indeferido. }\end{array}$ & Violação do CPC & Prova pericial \\
\hline $\begin{array}{lll}\text { 2) Não logrando } & \text { a } \\
\text { consumidora demonstrar a } & \text { a derência de dano moral } \\
\text { ocorren }\end{array}$ & Nexo Causal não provado & Nexo Causal \\
\hline
\end{tabular}


passível de reparação,

tampouco 0 nexo de

causalidade entre 0 suposto

erro médico e o abalo moral que

aquela alegou sofrer

Fonte: Fragmentos das decisões dos processos do TJDFT

Alguns processos deixaram de ser julgados no mérito em vista de problemas processuais. Admira-se que tais obstáculos à obtenção de justiça e reparação sejam vislumbrados nos processos analisados.

Erros de procedimento geralmente são provocados pelo advogado da parte e até mesmo pelo juiz, o que não é justificável, já que o paciente vítima de um erro médico acaba por ver-se vítima também de erro processual.

As abordagens sobre o erro processual são vastas na literatura jurídica. Os erros que podem ser sanáveis ou insanáveis habitam como certa frequência os processos no Judiciário. No processo civil o erro material é aquele que pode ser perceptível num primeiro olhar. Ex. erro quanto ao nome das partes na sentença, troca de letras. $O$ erro material pode ser corrigido pelo julgador.

O erro material dá-se quando o Juiz ou o Advogado escreve coisa diversa do que queria escrever, quando o teor da sentença ou despacho não coincide com o que o Juiz tinha em mente exarar. Fora dos casos de lapso manifesto por erro material o discurso jurídico fundamentador de facto e de direito da decisão contém o sentido do enquadramento jurídico dado pelo Tribunal. (PEREIRA, 2005)

$O$ erro formal no processo civil pode ser relativizado. Segundo o princípio da instrumentalidade das formas os atos processuais reputam-se válidos quando realizados de outro modo, Ihe preencham a finalidade essencial art. 154 CPC.

Normalmente dizemos erro material aquele proveniente do direito civil, à matéria, direito substancial. Erro formal é aquele decorrente da forma, normalmente decorrente do procedimento, ou do direito processual, direito adjetivo.

Tabela 3 - Análise dos Discursos inseridos nas Decisões Procedentes das Apelações Cíveis e Criminais com a Variável Material (Fática).

\begin{tabular}{|l|l|l|}
\hline $\begin{array}{l}\text { Discurso na linguagem do } \\
\text { acórdão }\end{array}$ & Unidade significativa & Asserções articuladas \\
\hline 1) Constitui ato ilíito indenizável & Demora no atendimento & Negligência \\
pelo Estado, por ato praticado em & & \\
hospital público, consistente na & & \\
demora para realizar parto de & & \\
paciente com a bolsa rota, além de & & \\
não ministrar antibióticos & & \\
necessários para evitar a & & \\
contaminação fetal & \\
\hline
\end{tabular}




\begin{tabular}{|c|c|c|}
\hline $\begin{array}{l}\text { 2) "não Ihe prestou assistência } \\
\text { pós-operatória adequada, a } \\
\text { despeito de ter sido } \\
\text { insistentemente contatado pelos } \\
\text { seus familiares, já que ela } \\
\text { apresentava quadro de fortes } \\
\text { dores." }\end{array}$ & Não prestou assistência & Negligência \\
\hline $\begin{array}{l}\text { 3)"Sustenta que, mesmo depois } \\
\text { dessa segunda cirurgia de revisão } \\
\text { e diante do persistente quadro de } \\
\text { dor o réu continuou a lhe negar } \\
\text { qualquer assistência pós- } \\
\text { operatória" }\end{array}$ & Não prestou assistência & Negligência \\
\hline $\begin{array}{l}\text { 4)" A leitura apurada do diário de } \\
\text { saúde, permite concluir, mesmo } \\
\text { sem auxílio de perícia judicial, que } \\
\text { durante aqueles dias de } \\
\text { internação, a equipe médica } \\
\text { constatou que o quadro de saúde } \\
\text { da autora era grave e decorria da } \\
\text { infecção desde o primeiro } \\
\text { procedimento cirúrgico. }\end{array}$ & Agravamento do quadro & Imprudência \\
\hline $\begin{array}{l}\text { 5)"[...] assevera que, ainda na rede } \\
\text { pública, não conseguiu ser } \\
\text { submetida } \text { à cirurgia } \\
\text { recomendada, ante a dificuldade } \\
\text { de aquisição de material e } \\
\text { anestesia [...]" }\end{array}$ & Falta de material para cirurgia & Negligência \\
\hline $\begin{array}{l}\text { 6) A Autora deu à luz a uma } \\
\text { criança que veio a óbito. Alegam } \\
\text { também que o médico } \\
\text { acompanhou o parto de outras } \\
\text { quatro parturientes ao mesmo } \\
\text { tempo }\end{array}$ & Excesso de trabalho & Imprudência \\
\hline $\begin{array}{l}\text { 7) Menor de } 4 \text { anos descreve o } \\
\text { sofrimento durante quase um mês } \\
\text { de internação, necessidade de } \\
\text { uma segunda cirurgia para } \\
\text { limpeza de órgãos, sequela } \\
\text { estética, vergonha do corpo e } \\
\text { pânico. }\end{array}$ & Muito tempo de internação & Imperícia \\
\hline
\end{tabular}

Fonte: Fragmentos das decisões dos processos do TJDFT

Da análise do discurso contidos nas decisões judiciais em $2^{\circ}$ grau de jurisdição, vê-se que é possível aferir tanto a negligência, como imperícia e imprudência no trato dos pacientes o que evidencia falhas no sistema de saúde.

Ferraz (2006) afirma que o tratamento médico não é ausente de risco e que esses podem ser classificados em leves, moderados ou graves, razão de se tomar um Termo de Responsabilidade do paciente previamente a qualquer procedimento em que envolvem riscos.

Chehuen Neto et. al. (2011) discute a percepção de alunos de Medicina e Direito a respeito de erro médico e afirma que essas modalidades se entrelaçam pela relevância na vida profissional do médico como agente ativo, e a vida do profissional que estuda as implicações legais da prática médica. Devido aos apelos por condutas 
éticas esta discussão ganha importância na graduação devido a necessidade de se formarem profissionais mais bem informados e preparados para as necessidades que emergem na sociedade.

Implica igualmente em erros com consequentes responsabilidades a frágil formação do médico posto que, segundo dados da CREMESC (2015) o Brasil possui cerca de 257 escolas médicas em atividade, o que acaba por transformar o ensino em produto comercializável contribuindo para a proliferação de faculdades e para a queda na qualidade do ensino. Há casos em que são autorizados novos cursos sem o prérequisito do hospital-escola (MORAES, 1998, p. 46).

Dados avaliativos do CREMESP, o desempenho dos estudantes do sexto ano do curso de Medicina das escolas do Estado de São Paulo obteve um índice de reprovação de $61 \%$ (CREMESP, 2009). A educação médica, neste contexto, tem dois papéis, o de informador e o de formador. Enquanto o primeiro tem a função de fornecer ao estudante conhecimentos científicos e de natureza técnica essenciais ao exercício da futura profissão, o segundo é responsável pelo amadurecimento de uma personalidade adulta e equilibrada, capaz de entender a complexa estrutura biopsicossocial do paciente (BITENCOURT et. al., 2007).

A imperícia também pode ser avaliada em relação ao progresso científico à época e ao profissional. O médico desatualizado poderá ser reputado imperito quando o desuso de determinada prática.

Estudos mostram que a maioria dos médicos que respondem por erro está graduada há mais de 10 anos (GOMES, DRUMOND, FRANÇA, 2002, p.15). Segundo Koeche; LG et. al. (2013) o tempo de profissão acima de 10 anos traz ao médico falsa segurança de experiência, tendência ao afastamento dos livros e necessidade de maior aporte financeiro para o crescimento patrimonial, favorecendo sua exposição aos riscos.

\section{Conclusão}

O cuidado em saúde é objeto de investigação científica por vários profissionais de saúde. Erros médicos na prática em saúde ocorre mais frequentemente por causas organizacionais e técnicas como a má formação profissional. É importante notar que os atos jurídicos relacionados a saúde exigem que os profissionais de saúde em seu 
trabalho forneçam um certo padrão de conhecimento, competência e cuidados na prestação do cuidado médico.

Ao analisar as sentenças proferidas pelo TJDFT constata-se a necessidade de efetivação de ações de saúde mais humanizadas, e propostas de formação do profissional da saúde, que contemple aspectos inerentes as relações entre o profissional e seus pares, as relações entre os pacientes e os familiares, e a humanização dos serviços de saúde. Uma boa relação médico-paciente é a melhor maneira de prevenir denúncias e processos contra o médico, contudo com o excesso de escolas médicas em atividades aumentam as oportunidades de ocorrência de erros decorrentes de uma formação precária e um sistema de saúde ausente de mecanismos de enfrentamento da ocorrência de eventos adversos.

Aos magistrados, também se faz necessário a capacitação de forma a auxiliar no julgamento dos pleitos, contribuindo para o enfrentamento racional da questão do erro médico, fomentado em conceitos técnicos e não apenas de base jurídica. Encorajando juristas mais comprometidos com a prática médica e menos sujeitos a elementos processuais.

\section{Bibliografia}

BITENCOURT, A. G. V. et al. Análise do erro médico em processos ético-profissionais: implicações na educação médica. Revista Brasileira de Educação Médica, v. 31, n. 3, p. 223-228, 2007.

BONETTI, M. et al. An Analysis of the Number of Medical Malpractice Claims and Their Amounts. PloS one, v. 11, n. 4, p. e0153362, 2016.

CARVALHO, M. DE; VIEIRA, A. A. Erro médico em pacientes hospitalizados. Jornal de Pediatria, v. 78, p. 261-268, 2002.

CHEHUEN NETO, J. A. et al. Erro médico: a perspectiva de estudantes de medicina e direito. Revista Brasileira de Educação Médica, v. 35, n. 1, p. 5-12, mar. 2011.

CONSELHO DE MEDICINA DO ESTADO DE SÃO PAULO (CREMESP). Especialidades Médicas. Disponível em: http://www.cremesp.org.br. [Acesso em 30.1.2017]. 
CONSELHO FEDERAL DE MEDICINA (CFM) divulga dados sobre concentração de médicos no Brasil. CREMESC. Disponível em: http://www.cremesc.org.br. [Acesso em 30.1.2017]

CORDERO, J. A. et al. Natureza e Especialidades Envolvidas nas Denúncias Sobre Erros Médicos que Originaram Processos Ético-Profissionais no Conselho Regional de Medicina do. Ciênc. Biol. Saúde, v. 12, n. 2, p. 27-30, 2014.

FERRAZ, E. M. Complicação ou erro médico? Revista do Colégio Brasileiro de Cirurgiões, v. 33, n. 4, p. 205-206, ago. 2006.

FUJITA, R.; SANTOS, I. Denúncias por erro médico em Goiás. Revista da Associação Médica Brasileira, vol. 55, n. 3, p. 283-289, 1992.

GOMES, JCM; DRUMOND, JGF; FRANÇA, GV. Erro Médico. Rio de Janeiro: Guanabara Koogan, 2002.

HENRIQUE, J.; MARTINS, S. A RESPONSABILIDADE PENAL POR ERRO MÉDICO. Revista Jurídica da FURB, v. 3, p. 51-64, 1998.

KOECHE LG, CENSI I, BORTOLUZZI MC, B. EL. Prevalência do erro médico entre as especialidades médicas nos processos julgados pelo Conselho Regional de Medicina do Estado de Santa Catarina. Arquivos Catarinenses de Medicina, v. 42, n. 4, p. 45-53, 2013.

LINDA T. KOHN, JANET M. CORRIGAN, AND M. S. D. To Err Is Human. Building a Safer Health System, Volume 6. Washington, D.C.: National Academies Press, 1999. v. 2

MAEDA, A. M. C.; POLLAK, D. F.; MARTINS, M. A. V. A compreensão do residente médico em reumatologia no atendimento aos pacientes com fibromialgia. Revista Brasileira de Educação Médica, v. 33, n. 3, p. 393-404, set. 2009.

MAKARY, M.; DANIEL, M. Medical Error - the third leading cause of death in the US. British Medical Journal, v. 353, p. i2139, 2016.

MINAYO, MCS (org.). Pesquisa social: teoria, método e criatividade. Petrópolis: Vozes, 2010.

MORAES, IN. Erro médico e a Lei. São Paulo: LEJUS, 1998. 
PÊCHEUX e FUCHS (1975). A propósito da Análise Automática do Discurso.

PEREIRA, J. T. R. "Erro material" - em que consiste? Disponível em: $<$ https://www.verbojuridico.net/doutrina/artigos/oadvogado_57.html>. Acesso em: 1 fev. 2017.

RENATA GROU VOLPE, C. et. al. Medication errors in a public hospital in Brazil. British journal of nursing (Mark Allen Publishing), v. 23, n. 11, p. 552, 553-9, 2014.

RIBEIRO, W. C.; JULIO, R. S. Reflexões sobre erro e educação médica em Minas Gerais. Revista Brasileira de Educação Médica, v. 35, n. 2, p. 263-267, jun. 2011.

RODRÍGUEZ HORNILLO, M.; RIVA MORENO, C. D. LA; SERRATOSA SÁNCHEZIBARGÜEN, A. Responsabilidad sanitaria: responsabilidad personal del médico vs. responsabilidad del sistema sanitario. Cuadernos de Medicina Forense, v. 17, n. 2, p. 59-66, 2011.

SVIDER, P. F. et. al. Adverse events in carotid endarterectomy from a medicolegal perspective. Vascular and endovascular surgery, v. 48, n. 5-6, p. 425-429, 2014. 


\section{CONSIDERAÇÕES FINAIS}

O conhecimento sobre a gestão da saúde é a capacidade dos indivíduos de obter, interpretar e entender as informações e serviços básicos de saúde necessários para tomar decisões adequadas para o enfrentamento das demandas e problemáticas da área da saúde e na gestão do sistema. Este conhecimento une educação a saúde e também requer que líderes e autoridades estejam cientes sobre os determinantes de comportamentos sociais, econômicos e ambientais relacionados ao contexto em questão. Pesquisas e trabalhos relacionados ao tema erro médico desempenham um papel importante na conscientização sobre a segurança do paciente e são essenciais para compreender a magnitude e as causas dos efeitos adversos do cuidado em saúde e, portanto, para o desenvolvimento de soluções adequadas.

Do trabalho de revisão da literatura, concluiu-se que no Brasil o estudo do tema do erro médico ainda está muito centrado na área da Enfermagem enquanto no exterior há uma ampla discussão que envolve diversas áreas da saúde, o que reforça que o problema é desencadeado por múltiplos fatores e que merece a atenção de diferentes profissionais. Houve no decorrer de todo este trabalho uma grande dificuldade em obter informações científicas na literatura brasileira relacionada ao tema do erro médico nos tribunais. Em vista do crescente número de ações judiciais sobre o tema, sugere-se que trabalhos de pesquisa devem ser fomentados por meio de editais de pesquisa pelos conhecidos órgãos de fomento.

A judicialização dos casos de erro médico no Tribunal de Justiça do Distrito Federal e Territórios demonstrou que os autores/pacientes estão buscando o Judiciário para obter essencialmente ressarcimento em pecúnia pelos danos materiais e morais sofridos, pouco havendo em punição criminal ao profissional.

Ao tempo que algumas tendências internacionais também se refletem na conjuntura brasileira, exemplo este, nos Estados Unidos onde as indenizações por erros médicos são de valores altíssimos fazendo com que os profissionais ao inaugurar a vida profissional busquem o seguro de suas práticas para fazer face às possíveis indenizações futuras. No Brasil, essa prática ainda está acanhada, limitando-se os julgadores em condenar apenas o ressarcimento dos danos materiais com baixa expressão aos danos morais. 
As especialidades de maior envolvimento com prática inseguras como ginecologia e obstetrícia e procedimentos cirúrgicos se assemelham as literaturas encontradas e demonstram que as evidências bem-sucedidas e as orientações dos organismos internacionais de referência ao tema merecem ser analisadas e incorporadas ao contexto brasileiro.

É necessária uma visão sistêmica do erro na prática médica no lugar da visão meramente individualizada que enfoca na falha do profissional e medidas punitivas, censuras e humilhação. É necessário um mecanismo de prevenção de tais erros compreendendo-se que o profissional é parte de um todo e que o erro é falha de um sistema oportunizando a revisão dos processos de trabalho e promovendo mecanismos de prevenção.

O entendimento da magistratura frente a análise dos pleitos relacionados a má prática do cuidado ao paciente demonstra que há uma disparidade entre o que se considera serviços de saúde pública e privados. É necessário que julgadores tenham uma visão ampliada do assunto pois a judicialização do erro médico pode interferir na gestão dos sistemas de saúde.

Mas não se duvida que o erro médico sendo tratado nos tribunais brasileiros tendem a ser de conhecimento público posto que os processos tramitam publicamente podendo qualquer pessoa fazer uso da pesquisa na internet. Os processos que tramitam nos conselhos de Medicina costumam não ter a mesma publicização. Este trabalho reflete um panorama ainda subdimensionado frente as dificuldades e entraves da gestão dos sistemas de saúde porém não menos importante de serem discutidos pela academia. 


\section{BIBLIOGRAFIA}

AGUIAR JÚNIOR, Ruy Rosado de. Responsabilidade Civil do Médico. Direito e medicina: aspectos jurídicos da Medicina, Belo Horizonte, B.H., 2000. p. 133-180.

ALLISON GM, WEIGEL B, HOLCROFT C. Does electronic medication reconciliation at hospital discharge decrease prescription medication errors? International Journal Of Health Care Quality Assurance. v.28, n.6, p. 564-573, 2012.

ATOOF F, ESHRAGHIAN MR, MAHMOODI M, MOHAMMAD K, RANGRAZ JEDDI F, ABOOTALEBI F. Patients and Public Involvement in Patient Safety and Treatment Process in Hospitals Affiliated to Kashan University of Medical Sciences, Iran, 2013. Nursing And Midwifery Studies, vol. 4, n. 2, 2015.

BARINI, ORESTES. Medicina baseada em evidências. Revista da Associação Médica Brasileira, v. 47, n. 4, p. 294-294, 2001.

BITENCOURT AGV, NEVES NMBC, NEVES FBCS, BRASIL ISP DE S, SANTOS LSC DOS. Análise do erro médico em processos ético-profissionais: implicações na educação médica. Revista Brasileira de Educação Médica, vol. 31, n. 3, p. 223228, 2007.

BOHOMOL, Elena; CUNHA, Isabel Cristina Kowal Olm. Teaching patient safety in the medical undergraduate program at the Universidade Federal de São Paulo. Einstein (São Paulo), São Paulo, v. 13, n. 1, p. 7-13, Mar. 2015.

BONETTI M, CIRILLO P, MUSILE Tanzi P, TRINCHERO E. An Analysis of the Number of Medical Malpractice Claims and Their Amounts. PLoS ONE. v. 11, n. 4. 2016

BONRATH EM, GORDON LE, GRANTCHAROV TP. Characterising "near miss" events in complex laparoscopic surgery through video analysis. BMJ Quality \& Safety; v.24, n.8, p. 516-21, 2015.

BRASIL. Constituição da República Federativa do Brasil. Brasília, DF: Senado Federal: Centro Gráfico, 1988.

. Código Penal, Decreto-Lei n 2.848 de 7 de dezembro de 1940. Disponível em: http://www.planalto.gov.br/ccivil_03/decreto-lei/del2848compilado.htm

. Código Civil, Decreto-Lei $n^{\circ} 10.406$, de 10 de janeiro de 2002. Disponível em: http://www.planalto.gov.br/ccivil_03/leis/2002/L10406.htm

. Lei $n^{\circ}$. 8.080, de 19 de setembro de 1990. Brasília: DF. 1990. Disponível em: https://www.planalto.gov.br/ccivil_03/LEIS/L8080.htm

Lei $\mathrm{n}^{\circ}$ 9.099, de 26 de setembro de 1995. Disponível em: http://www.planalto.gov.br/ccivil_03/leis/L9099.htm

. Ministério da Saúde. Portaria MS/GM n529 de $1^{\circ}$ de abril de 2013. Institui o Programa Nacional de Segurança do Paciente (PNSP). 2013. 
Ministério da Saúde. Agência Nacional de Vigilância Sanitária. Resolução RDC № 36, de 25 de julho de 2013. Institui ações para a segurança do paciente em serviços de saúde e dá outras providências. 2013.

BOBBIO, N. A era dos direitos. Rio de Janeiro: Campus, 1992.

Teoria do ordenamento jurídico. 4. ed. Brasília: Editora Universidade de Brasília, 1994.

BUBALO J, WARDEN BA, WIEGEL JJ, NISHIDA T, HANDEL E, SVOBODA LM. Does applying technology throughout the medication use process improve patient safety with antineoplastics? Journal of oncology pharmacy practice: official publication of the International Society of Oncology Pharmacy Practitioners, v. 20, n. 6, p. 445-460, 2014.

CABELLO CM, BAIR WB, LAMORE SD, LEY S, ALEXANDRA S, AZIMIAN S, National Institutes of Health Public Access. v. 46, n. 2, p.220-231, 2010.

CAINE K, TIERNEY WM. Point and Counterpoint: Patient Control of Access to Data in Their Electronic Health Records. Journal of General Internal Medicine, v. 30, n. 1, p.38-41, 2015.

CAMPOS, R. A. DE C.; CAMARGO, R. A. E.; NEVES, L. R. The judicialization of the medical act. Brazilian journal of otorhinolaryngology, v. 82, n. 1, p. 1-2, jan. 2016.

CARAYON P, XIE A, KIANFAR S. Human factors and ergonomics as a patient safety practice. BMJ Quality \& Safety, v. 23, n. 3, p. 196-205, 2014.

CARVALHO, M. DE; VIEIRA, A. A. Erro médico em pacientes hospitalizados. Jornal de Pediatria, v. 78, p. 261-268, 2002.

CASTEL, E. S.; GINSBURG LR, ZAHEER S, TAMIM H. Understanding nurses' and physicians' fear of repercussions for reporting errors: clinician characteristics, organization demographics, or leadership factors? BMC Health Services Research, v. 15, p. 326, 2015.

CHEHUEN NETO, JA, SIRIMARCO MT, FIGUEIREDO NSV, BARBOSA TN, SILVEIRA TG. Erro médico: a perspectiva de estudantes de medicina e direito. Revista Brasileira de Educação Médica, Rio de Janeiro, v. 35, n. 1, p. 5-12, 2011

CHO, I. LEE JH, CHOI SK, CHOI JW, HWANG H, BATES DW. Acceptability and feasibility of the Leapfrog computerized physician order entry evaluation tool for hospitals outside the United States. International Journal of Medical Informatics, v. 84, n. 9, p. 694-701, 2014.

CONSELHO DE MEDICINA DO ESTADO DE SÃO PAULO (CREMESP). Especialidades Médicas. Disponível em: http://www.cremesp.org.br. [Acesso em 30.1.2017].

CONSELHO FEDERAL DE MEDICINA (CFM) divulga dados sobre concentração de médicos no Brasil. CREMESC. Disponível em: http://www.cremesc.org.br. [Acesso em 30.1.2017] 
SILVA JAC, BRITO MVH, BRITO NB, GONÇALVES RS, FONSECA SNS, OLIVEIRA AJB. Natureza e Especialidades envolvidas nas Denúncias Sobre Erros Médicos que Originaram Processos Ético-Profissionais no Conselho Regional de Medicina do. Ciência e Biologia em Saúde, v. 12, n. 2, p. 27-30, 2014.

CUSHING AM, KER JS, KINNERSLEY P, MCKEOWN P, SILVERMAN J, PATTERSON J. Patient safety and communication: A new assessment for doctors trained in countries where language differs from that of the host country: Results of a pilot using a domain-based assessment. Patient Education and Counseling, v. 95, n. 3, p. 332-339, 2014.

DE PAIVA MCM DA S, POPIM RC, MELLEIRO MM, TRONCHIM DMR, LIMA SAM, JULIANI CMCM. The reasons of the nursing staff to notify adverse events. Revista latino-americana de enfermagem, v. 22, n. 5, p. 747-54, 2014.

DINIZ SG, SALGADO H DE O, ANDREZZO HF DE A, DE CARVALHO PGC, CARVALHO PCA, AGUIAR C DE A.. Violência obstétrica como questão para a saúde pública no brasil: origens, definições, tipologia, impactos sobre a saúde materna, e propostas para sua prevenção. Journal of Human Growth and Development, v. 25, n. 3, p. 377-82, 2015.

DUARTE, SCM; QUEIROZ, ABA; BUSCHER, A; STIPP, MAC.. Human error in daily intensive nursing care. Revista latino-americana de enfermagem, v. 23, n. 6, p. 1074-1081, 2015.

DUDAS, R. A., \& BARONE, M. A. Can medical students identify a potentially serious acetaminophen dosing error in a simulated encounter? A case control study. BMC Medical Education, v.15, n.13, p. 288, 2015.

EIBLING D. We're Not There Yet. Otolaryngology-Head and Neck Surgery. v. 150, n. 5, p. 785-786, 2014.

FERRAZ, E. M. Complicação ou erro médico? Revista do Colégio Brasileiro de Cirurgiões, v. 33, n. 4, p. 205-206, 2006.

FERREIRA R, MARQUES A, MENDES A, DA SILVA JA. Rheumatology telephone advice line - experience of a Portuguese department. Acta Reumatológica Portuguesa. v. 40, n. 2, p.163-168, 2015.

FUJITA, R.; SANTOS, I. Denúncias por erro médico em Goiás. Revista da Associação Médica Brasileira, vol. 55, n. 3, p. 283-289, 1992.

GHOBRIAL, GM, HAMADE YJ, BENDOK BR, HARROP JS. Technology and simulation to improve patient safety. Neurosurgery Clinics of North America, v. 26, n. 2, p. 239-243, 2015.

GINSBURG, LR, TREGUNNO D, NORTON PG, MITCHELL JI, HOWLEY H. "Not another safety culture survey": using the Canadian patient safety climate survey (CanPSCS) to measure provider perceptions of PSC across health settings. BMJ Quality \& Safety, v. 23, n. 2, p. 162-70, 2014. 
GOMES, JCM; DRUMOND, JGF; FRANÇA, GV. Erro Médico. 3 ed. Rio de Janeiro: Guanabara Koogan, 2002.

GOULART, B. N. G. DE; CHIARI, B. M. Humanização das práticas do profissional de saúde: contribuições para reflexão. Ciência \& Saúde Coletiva, v. 15, n. 1, p. 255268, jan. 2010.

GROBER ED, BOHNEN JMA. Defining medical error. Canadian Journal of Surgery. v. 48, n.1, p. 39-44, 2005.

HARRIS JD, STAHELI G, LECLERE L, ANDERSONE D, MCCORMICK F. What Effects Have Resident Work-hour Changes Had on Education, Quality of Life, and Safety? A Systematic Review. Clinical Orthopaedics and Related Research, v. 473, n. 5, p. 1600-1608, 2015.

HENRIQUE, J.; MARTINS, S. A responsabilidade penal por erro médico. Revista Jurídica da FURB, v. 3, p. 51-64, 1998.

HRON, JD, MANZI S, DIONNE R, CHIANG VW, BROSTOFF M, ALTAVILLA SA. Electronic medication reconciliation and medication errors. International Journal for Quality in Health Care, v. 27, n. 4, p. 314-319, 2015.

JEFFS, L., HAYES C, SMITH O, MAMDANI M, NISENBAUM R, BELL CM. The effect of an organizational network for patient safety on safety event reporting. Evaluation \& The Health Professions, v. 37, n. 3, p. 366-378, 2014.

JENA AB, CHANDRA A, LAKDAWALLA D, SEABURY S, C K, FA S. Outcomes of Medical Malpractice Litigation Against US Physicians. Archives of Internal Medicine v.172, n.11, p: 3291-3297.

JORNAL A TRIBUNA. Curitiba. Processos Judiciais registram alta de $1.600 \%$. Disponível em: http://www.tribunapr.com.br/noticias/parana/processos-judiciaiscontra-medicos-registram-alta-de-1-600/.

JORNAL O ESTADO DE SÃO PAULO. São Paulo. Em 4 anos o número de processos por erro médico cresce 160\%. Disponível em: http://saude.estadao.com.br/noticias/geral,em-4-anos-numero-de-processos-porerro-medico-cresce-140-no-stj-imp-,1655442.

JULIO FABBRINI MIRABETE, R. N. F. Manual de direito penal. 32. ed. São Paulo: Atlas, 2015.

KFOURI NETO, M. Responsabilidade Civil do médico. 5a ed. São Paulo: Revista dos Tribunais, 2003.

KOECHE LG, CENSI I, BORTOLUZZI MC, B. EL. Prevalência do erro médico entre as especialidades médicas nos processos julgados pelo Conselho Regional de Medicina do Estado de Santa Catarina. Arquivos Catarinenses de Medicina, v. 42, n. 4, p. 45-53, 2013.

KROMBACH, JW, EDWARDS WA, MARKS JD, RADKE OC.. Checklists and Other Cognitive Aids For Emergency And Routine Anesthesia Care - A Survey on the 
Perception of Anesthesia Providers From a Large Academic US Institution.

Anesthesiology And Pain Medicine, v. 5, n. 4, 2015.

LESTER H, TRITTER JQ. Medical error: a discussion of the medical construction of error and suggestions for reforms of medical education to decrease error. Medical Education. v.35, n.9, p.855-861, 2001.

LI, Q. MELTON K, LINGREN T, KIRKENDALL ES, HALL E, ZHAI H. Phenotyping for patient safety: algorithm development for electronic health record based automated adverse event and medical error detection in neonatal intensive care. Journal of the American Medical Informatics Association: JAMIA, p. 776-784, 2014.

LINDA T. KOHN; JANET M.; CORRIGAN, M.S.D. To Err Is Human. Building a Safer Health System, Volume 6. Washington, D.C.: National Academies Press, v. 2, 1999.

LIPSHUTZ AKM, CALDWELL JE, ROBINOWITZ DL, GROPPER M. An analysis of near misses identified by anesthesia providers in the intensive care unit. BMC Anesthesiology. v.15, n.1, p.93, 2015.

MAEDA, A. M. C.; POLLAK, D. F.; MARTINS, M. A. V. A compreensão do residente médico em reumatologia no atendimento aos pacientes com fibromialgia. Revista Brasileira de Educação Médica, v. 33, n. 3, p. 393-404, 2009.

MAKARY, M.; DANIEL, M. Medical Error - The third leading cause of death in the US. British Medical Journal, v. 353, p. 2139, 2016.

MARCHON SG, MENDES JUNIOR WV, PAVÃO ALB. Characteristics of adverse events in primary health care in Brazil. Cadernos de Saúde Pública.v.31, n.11, p. 2313-2330, 2015.

MARINHO S, RUÃO T, LOPES F, FERNANDES L. O erro médico na imprensa portuguesa: Quando os pacientes fazem parte da notícia. Saúde e Sociedade. v.24, n.4, p.1362-1376, 2015.

MASIC, I.; IZETBEGOVIC, S. The role of medical staff in providing patients rights. Medical archives, v. 68, n. 1, p. 61-64, 2014.

MASKENS, C. DOWNIE H, WENDT A, LIMA A, MERKLEY L, LIN Y. Hospital-based transfusion error tracking from 2005 to 2010: Identifying the key errors threatening patient transfusion safety. Transfusion, v. 54, n. 1, p. 66-73, 2014.

MCCRORY, B.; LAGRANGE, C. A.; HALLBECK, M. Quality and safety of minimally invasive surgery: past, present, and future. Biomedical Engineering And Computational Biology, v. 6, p. 1-11, 2014.

MELLO, CAB de. Curso De Direito Administrativo. 32. ed. São Paulo, Malheiros, 2015.

MELLO, J. F. DE; BARBOSA, S. DE F. F. Cultura de segurança do paciente em terapia intensiva: recomendações da enfermagem. Texto \& Contexto, v. 22, n. 4, p. 11241133, 2013. 
MINAYO, MCS (org.). Pesquisa social: teoria, método e criatividade. Petrópolis: Vozes, 2010.

MONTGOMERY J. Conscientious objection: Personal and professional ethics in the public square. Medical Law Review. v.23, n.2, p.200-220, 2015.

MORAES, IRANY NOVAH. Erro médico e a Lei. São Paulo: LEJUS, 1998. Erro médico e a justiça. 5a ed. São Paulo: Revista dos

Tribunais, 2003.

MORAES, N. C. DE. Erro médico: aspectos jurídicos. Revista Brasileira de Cirurgia Cardiovascular, v. 11, n. 2, p. 55-59, 1996.

MORAES, M. C. B. Danos à Pessoa Humana; Uma Leitura Civil Constitucional dos Danos Morais. Rio de Janeiro: Renovar, 2003.

MOURA, Caio Roberto Souto. Responsabilidade Civil e sua evolução em direção ao risco no novo Código Civil. Escola Superior da Magistratura Federal no Rio Grande do Sul, ESMAFE-RS.

NASCIMENTO, N. B. DO; TRAVASSOS, C. M. DE R. O erro médico e a violação às normas e prescrições em saúde: uma discussão teórica na área de segurança do paciente. Physis: Revista de Saúde Coletiva, v. 20, n. 2, p. 625-651, 2010.

TOMAZONI, A.; ROCHA, P.K.; KUSAHARA, D. M.; SOUZA, A.I.J; MACEDO, T.R. Avaliação da cultura de segurança do paciente em terapia intensiva neonatal. Texto \& Contexto. v.24, n.1, p.161-169, 2015.

NOLAND, C. M.; CARMACK, H. J. Narrativizing nursing students' experiences with medical errors during clinicals. Qualitative Health Research, v. 25, n. 10, p. 14231434, 2015.

NUNES, F. BARROS L, AZEVEDO R, PAIVA S. Patient safety: how nursing is contributing to the issue? Revista de Pesquisa: Cuidado é Fundamental Online, v. 6, n. 2, p. 841-847, 2014.

OLIVEIRA, R. M. LEITÃO, I.M.T.A; SILVA, L.M.S.; FIGUEIREDO, S.V.; SAMPAIO, R.L.; GOMDIN, M.M. Estratégias para promover segurança do paciente: da identificação dos riscos às práticas baseadas em evidências. Escola. Anna Nery. v.18, n.1, p.122-129, 2014.

PAESE F, SASSO GTMD. Cultura da segurança do paciente na atenção primária à saúde. Texto \& Contexto. v.22, n.2, p.302-310, 2013.

PARANAGUÁ, TTDB,BEZERRA ALQ, DOS SANTOS ALM, SILVA AEBDC. Prevalence and factors associated with incidents related to medication in surgical patients. Revista da Escola de Enfermagem, v. 48, n. 1, p. 41-47, 2014.

PÊCHEUX e FUCHS (1975). A propósito da Análise Automática do Discurso.

PEREIRA, JOEL TIMÓTEO RAMOS. "Erro material" - em que consiste? Disponível em: https://www.verbojuridico.net/doutrina/artigos/oadvogado_57.html. Acesso em: 1 fev. 2017. 
PERREGAARD, H. ARONSON JK, DALHOFF K, HELLEBEK A. Medication errors detected in non-traditional databases: Types of errors in methotrexate dosing as listed in four different Danish registers. European Journal of Clinical Pharmacology, v. 71, n. 11, p. 1375-1379, 2015.

POLISENA J, GAGLIARDI A, CLIFFORD T. How can we improve the recognition, reporting and resolution of medical device-related incidents in hospitals? A qualitative study of physicians and registered nurses. BMC Health Services Research. v.15, p.220, 2015.

RATWANI RM, FONG A. "Connecting the dots": leveraging visual analytics to make sense of patient safety event reports. Journal of the American Medical Informatics Association : JAMIA. v.22, n.2, p. 312-317, 2015.

RAVEESH, B. N.; NAYAK, R. B.; KUMBAR, S. F. Preventing medico-legal issues in clinical practice. Annals of Indian Academy of Neurology, v. 19, n. 1, p. S15-S20, 2016.

REIS, C. T.; MARTINS, M.; LAGUARDIA, J. A segurança do paciente como dimensão da qualidade do cuidado de saúde: um olhar sobre a literatura. Ciência \& Saúde Coletiva, v. 18, n. 7, p. 2029-2036, 2013.

VOLPE, R.G.; MOURA PINHO, D.L., MORATO S.M., KARNIKOWSKI G.O.. Medication errors in a public hospital in Brazil. British Journal Of Nursing , v. 23, n. 11, p. 552, 2014.

REZNEK MA, KOTKOWSKI KA, ARCE MW, JEPSON ZK, BIRD SB, DARLING CE. Patient safety incident capture resulting from incident reports: a comparative observational analysis. BMC Emergency Medicine. v.15, n.1, p.6, 2015.

RIBEIRO, W. C.; JULIO, R. S. Reflexões sobre erro e educação médica em Minas Gerais. Revista Brasileira de Educação Médica, v. 35, n. 2, p. 263-267, jun. 2011.

RODRÍGUEZ HORNILLO, M.; RIVA MORENO, C. D. LA; SERRATOSA SÁNCHEZIBARGÜEN, A. Responsabilidad sanitaria: responsabilidad personal del médico vs. responsabilidad del sistema sanitario. Cuadernos de Medicina Forense, v. 17, n. 2, p. 59-66, 2011.

RUDDY, R. M. CHAMBERLAIN JM, MAHAJAN P V, FUNAI T, O'CONNELL KJ, BLUMBERG S.. Near misses and unsafe conditions reported in a Pediatric Emergency Research Network. BMJ Open, v. 5, n. 9, p. e007541, 2015.

SALVADOR, PTC DE O, MARTINS CCF, ALVES KYA, COSTA TD DA, SANTOS VEP.. Analysis of Youtube Videos About Adverse Health Events. REME: Revista Mineira de Enfermagem, v. 18, n. 4, p. 830-837, 2014.

SINGH, H.; MEYER, A. N. D.; THOMAS, E. J. The frequency of diagnostic errors in outpatient care: estimations from three large observational studies involving US adult populations. BMJ Quality \& Safety. v.23, n.9, p.727-731, 2014. 
SINGH, H.; SITTIG, D. F. Advancing the science of measurement of diagnostic errors in healthcare: the Safer Dx framework. BMJ Quality \& Safety, v. 24, n. 2, p. 103-110, 2015.

SOUTHWICK, F. S.; CRANLEY, N. M.; HALLISY, J. A. A patient-initiated voluntary online survey of adverse medical events: the perspective of 696 injured patients and families. BMJ Quality \& Safety. p.1-10, 2015.

SVIDER, PF, VIDAL G-P, ZUMBA O, MAURO AC, HASER PB, GRAHAM A.. Adverse events in carotid endarterectomy from a medicolegal perspective. Vascular and endovascular surgery, v. 48, n. 5-6, p. 425-429, 2014.

TAMBLYN, R. POISSANT L, HUANG A, WINSLADE N, ROCHEFORT CM, MORAGA T.. Estimating the information gap between emergency department records of community medication compared to on-line access to the community-based pharmacy records. Journal of the American Medical Informatics Association, v. 21, p. 391398, 2014.

TREADWELL, J. R.; LUCAS, S.; TSOU, A. Y. Surgical checklists: a systematic review of impacts and implementation. BMJ Quality \& Safety, v. 23, n. 4, p. 299-318, 2014.

UY, R. C. Y.; KURY, F. P.; FONTELO, P. A. The State and Trends of Barcode, RFID, Biometric and Pharmacy Automation Technologies in US Hospitals. AMIA . Annual Symposium proceedings / AMIA Symposium, v. 2015, p. 1242-51, 2015.

WEINGART SN, WILSON RM, GIBBERD RW, HARRISON B. Epidemiology of medical error. BMJ Quality \& Safety. v.320,n.7237,p.774-777, 2000.

YAMAUTI K, ZERBINI T. A oftalmologia no tribunal: avaliação das sentenças judiciais no âmbito do Tribunal de Justiça do Estado de São Paulo. Saúde, Ética \& Justiça. v.19, n.2, p.78, 2014

YU, H.; HU Z; ZHANG X; LI B; ZHOU S. How to overcome violence against healthcare professionals, reduce medical disputes and ensure patient safety. Pakistan Journal of Medical Sciences, v. 31, n. 1, p. 4-8, 2014.

ZIV A, BEN-DAVID S, ZIV M. Simulation Based Medical Education: an opportunity to learn from errors. Journal Of Family \& Community Medicine. v. 27, n.3, p. 193-199, 2010. 


\section{ANEXO I}

Quadro 1 - Títulos dos artigos sobre erro médico e cuidados com pacientes em língua portuguesa encontrado nas bases BVS, LILACS e MEDLINE - 2014-2015, tipo de estudo, área de pesquisa e palavras-chave.

\begin{tabular}{|c|c|c|c|}
\hline Título & Metodologia de estudo & Área & Palavras-chave \\
\hline $\begin{array}{l}\text { 1.Análise de vídeos do YouTube sobre eventos } \\
\text { adversos em saúde.(10) }\end{array}$ & $\begin{array}{l}\text { Pesquisa exploratória com abordagem } \\
\text { quantitativa, }\end{array}$ & Enfermagem & $\begin{array}{c}\text { Segurança do Paciente; Erros Médicos; } \\
\text { Qualidade da Assistência à Saúde; Cuidados } \\
\text { de Enfermagem. }\end{array}$ \\
\hline $\begin{array}{l}\text { 2.Avaliação da cultura de segurança do paciente em } \\
\text { terapia intensiva neonatal.(11) }\end{array}$ & Estudo quantitativo, tipo survey, & Enfermagem & $\begin{array}{l}\text { Segurança do paciente. Cultura } \\
\text { organizacional. Enfermagem neonatal. } \\
\text { Unidades de Terapia Intensiva Neonatal. }\end{array}$ \\
\hline $\begin{array}{l}\text { 3.Características dos eventos adversos na atenção } \\
\text { primária à saúde no Brasil.(12) }\end{array}$ & $\begin{array}{l}\text { Estudo observacional, descritivo, } \\
\text { prospectivo }\end{array}$ & Saúde pública & $\begin{array}{c}\text { Segurança do Paciente; Avaliação em Saúde; } \\
\text { Atenção Primária à Saúde }\end{array}$ \\
\hline $\begin{array}{l}\text { 4.Identificação da criança na pediatria: Percepções } \\
\text { dos profissionais de Enfermagem.(13) }\end{array}$ & $\begin{array}{c}\text { Pesquisa descritiva exploratória de } \\
\text { natureza qualitativa }\end{array}$ & Enfermagem & $\begin{array}{c}\text { Segurança do paciente. Sistemas de } \\
\text { identificação de pacientes. Enfermagem } \\
\text { pediátrica. Criança hospitalizada. }\end{array}$ \\
\hline $\begin{array}{l}\text { 5.Motivos da equipe de enfermagem para a } \\
\text { notificação de eventos adversos.(14) }\end{array}$ & $\begin{array}{c}\text { Estudo qualitativo da fenomenologia de } \\
\text { Alfred Schutz com abordagem }\end{array}$ & Enfermagem & $\begin{array}{l}\text { Segurança; Controle de Riscos; Erros } \\
\text { Médicos, Enfermagem; Pesquisa Qualitativa. }\end{array}$ \\
\hline
\end{tabular}




\begin{tabular}{|c|c|c|c|}
\hline & $\begin{array}{c}\text { sistemática dos aspectos sociais da ação } \\
\text { humana. }\end{array}$ & & \\
\hline $\begin{array}{l}\text { 6.O erro médico na imprensa portuguesa: quando os } \\
\text { pacientes fazem parte da notícia.(15) }\end{array}$ & $\begin{array}{l}\text { Pesquisa de amostragem não } \\
\text { probabilística por casos típicos }\end{array}$ & $\begin{array}{c}\text { Comunicação } \\
\text { social }\end{array}$ & $\begin{array}{l}\text { Erro Médico; Pacientes; Saúde; Jornalismo; } \\
\text { Imprensa; Portugal. }\end{array}$ \\
\hline $\begin{array}{l}\text { 7.Prevalência e fatores associados aos incidentes } \\
\text { relacionados à medicação em pacientes } \\
\text { cirúrgicos(16) }\end{array}$ & Estudo de corte transversal, & Enfermagem & $\begin{array}{c}\text { Erros de medicação, Segurança do paciente, } \\
\text { Enfermagem, Gestão em saúde }\end{array}$ \\
\hline $\begin{array}{l}\text { 8.Segurança do paciente: como a enfermagem vem } \\
\text { contribuindo para a questão?(17) }\end{array}$ & Revisão integrativa & Enfermagem & $\begin{array}{c}\text { Enfermagem, Segurança do paciente, Doença } \\
\text { iatrogênica, Erros médicos. }\end{array}$ \\
\hline
\end{tabular}




\section{ANEXO II}

Quadro 2 - Títulos dos artigos sobre erro médico e cuidados com pacientes em língua inglesa encontrado nas bases BVS, LILACS e MEDLINE 2014-2015, tipo de estudo, área de pesquisa e palavras-chave.

\begin{tabular}{|c|c|c|c|}
\hline Título & Metodologia de estudo & Área & Palavras-chave \\
\hline $\begin{array}{l}\text { 1.A patient-initiated voluntary online survey of adverse } \\
\text { medical events: the perspective of } 696 \text { injured patients and } \\
\text { families.(19) }\end{array}$ & Voluntary survey & $\begin{array}{l}\text { Behavioral Science And } \\
\text { Community Health, }\end{array}$ & -- \\
\hline $\begin{array}{l}\text { 2.Acceptability and feasibility of the Leapfrog computerized } \\
\text { physician order entry evaluation tool for hospitals outside } \\
\text { the United States.(20) }\end{array}$ & Cross-sectional study & $\begin{array}{l}\text { Nursing, Medicine, } \\
\text { Biomedical Engineering }\end{array}$ & $\begin{array}{l}\text { Computerized physician order entry, } \\
\text { Medication safety, Decision support, } \\
\text { Prescribing Quality }\end{array}$ \\
\hline $\begin{array}{l}\text { 3.Advancing the science of measurement of diagnostic } \\
\text { errors in healthcare: the Safer Dx framework.(21) }\end{array}$ & $\begin{array}{c}\text { Discription paper on a } \\
\text { system-wide safety } \\
\text { measurement, monitoring } \\
\text { and improvement of } \\
\text { diagnostic framework }\end{array}$ & Health Services & diagnostics framework \\
\hline
\end{tabular}




\begin{tabular}{|c|c|c|c|}
\hline $\begin{array}{l}\text { 4.Adverse events in carotid endarterectomy from a } \\
\text { medicolegal perspective( } 22) \text {. }\end{array}$ & $\begin{array}{l}\text { Research on federal and state } \\
\text { court records database }\end{array}$ & Surgery, Law & $\begin{array}{c}\text { carotid endarterectomy, negligence, } \\
\text { liability, medicolegal, malpractice, } \\
\text { litigation }\end{array}$ \\
\hline $\begin{array}{l}\text { 5.An analysis of near misses identified by anesthesia } \\
\text { providers in the intensive care unit.(23) }\end{array}$ & Retrospective analysis & Anesthesiology & $\begin{array}{l}\text { Incident reporting, Adverse event, } \\
\text { Near miss, Critical care, Critical care } \\
\text { anesthesiology, Airway management }\end{array}$ \\
\hline $\begin{array}{l}\text { 6. Can medical students identify a potentially serious } \\
\text { acetaminophen dosing error in a simulated encounter? a case } \\
\text { control study.(24) }\end{array}$ & Case-control study, & Pediatrics & -- \\
\hline $\begin{array}{l}\text { 8. Characterising the complexity of medication safety using } \\
\text { a human factors approach: an observational study in two } \\
\text { intensive care units.(26) }\end{array}$ & $\begin{array}{l}\text { Evaluating study of the } \\
\text { impact of an electronic } \\
\text { health record }\end{array}$ & $\begin{array}{l}\text { Medicine, Industrial And } \\
\text { System Engineering, } \\
\text { Nursing, Health Services }\end{array}$ & $\begin{array}{l}\text { medication safety; medication errors; } \\
\text { adverse drug events; intensive care } \\
\text { unit; human factors engineering }\end{array}$ \\
\hline
\end{tabular}




\begin{tabular}{|c|c|c|c|}
\hline $\begin{array}{l}\text { 9. Checklists and Other Cognitive Aids For Emergency And } \\
\text { Routine Anesthesia Care-A Survey on the Perception of } \\
\text { Anesthesia Providers From a Large Academic US } \\
\text { Institution.(27) }\end{array}$ & Survey & Anesthesiology & $\begin{array}{l}\text { Checklist; Quality of Health Care; } \\
\text { Patient Safety; Medical Errors }\end{array}$ \\
\hline $\begin{array}{l}\text { 10.Connecting the dots': leveraging visual analytics to make } \\
\text { sense of patient safety event reports.(28) }\end{array}$ & Case report & $\begin{array}{l}\text { Human Factors In } \\
\text { Healthcare }\end{array}$ & $\begin{array}{l}\text { patient safety; medical error; error } \\
\text { reporting; visualization; human factors }\end{array}$ \\
\hline $\begin{array}{l}\text { 11.Conscientious objection: personal and professional ethics } \\
\text { in the public square.(29) }\end{array}$ & Review & Medical Law & $\begin{array}{l}\text { Abortion, Conscientious objection, } \\
\text { Personal beliefs, Professional ethics, } \\
\text { Professional discretion, Social contract }\end{array}$ \\
\hline $\begin{array}{l}\text { 12.Does applying technology throughout the medication use } \\
\text { process improve patient safety with antineoplastics?(30) }\end{array}$ & Review & Pharmacy & $\begin{array}{l}\text { Technology, chemotherapy errors, } \\
\text { patient safety }\end{array}$ \\
\hline $\begin{array}{l}\text { 13.Does electronic medication reconciliation at hospital } \\
\text { discharge decrease prescription medication errors?(31) }\end{array}$ & Research paper & Medicine, Healthcare & $\begin{array}{c}\text { Patient safety, Drug errors, } \\
\text { Information management and } \\
\text { technology, Medical records, Quality } \\
\text { improvement, Outpatient intravenous } \\
\text { antibiotic therapy }\end{array}$ \\
\hline
\end{tabular}




\begin{tabular}{|c|c|c|c|}
\hline $\begin{array}{l}\text { 14.Electronic medication reconciliation and medication } \\
\text { errors.(32) }\end{array}$ & Research paper & $\begin{array}{c}\text { Medicine, Pharmacy, } \\
\text { Healthcare }\end{array}$ & $\begin{array}{l}\text { medical errors, patient safety, adverse } \\
\text { events, patient safety, quality } \\
\text { improvement, quality management, } \\
\text { children, specific populations, hospital } \\
\text { care, setting of care }\end{array}$ \\
\hline $\begin{array}{l}\text { 15.Estimating the information gap between emergency } \\
\text { department records of community medication compared to } \\
\text { on-line access to the community-based pharmacy } \\
\text { records(33). }\end{array}$ & Prospective cohort research & $\begin{array}{l}\text { Medicine, Rehabilitative } \\
\text { Science, Health } \\
\text { Informatics }\end{array}$ & -- \\
\hline $\begin{array}{l}\text { 16.Hospital-based transfusion error tracking from } 2005 \text { to } \\
\text { 2010: identifying the key errors threatening patient } \\
\text { transfusion safety.(34) }\end{array}$ & Research paper & $\begin{array}{l}\text { Laboratory Medicine, } \\
\text { Clinical Pathology, } \\
\text { Medicine }\end{array}$ & -- \\
\hline $\begin{array}{l}\text { 17. How can we improve the recognition, reporting and } \\
\text { resolution of medical device-related incidents in hospitals? } \\
\text { A qualitative study of physicians and registered nurses.(35) }\end{array}$ & $\begin{array}{l}\text { Qualitative research - semi- } \\
\text { structured telephone } \\
\text { interviews }\end{array}$ & $\begin{array}{c}\text { Epidemiology, } \\
\text { Community Medicine }\end{array}$ & -- \\
\hline
\end{tabular}




\begin{tabular}{|c|c|c|c|}
\hline $\begin{array}{l}\text { 18.How to overcome violence against Healthcare } \\
\text { professionals, reduce medical disputes and ensure patient } \\
\text { safety.(36) }\end{array}$ & Multidisciplinary research & Health Management & $\begin{array}{l}\text { Medical care research, Quality } \\
\text { improvement, Violence, Quality of } \\
\text { health care, Medical insurance. }\end{array}$ \\
\hline $\begin{array}{l}\text { 19.Human factors and ergonomics as a patient safety } \\
\text { practice.(37) }\end{array}$ & Systematic review & $\begin{array}{l}\text { Quality And Productivity } \\
\text { Improvement, }\end{array}$ & $\begin{array}{l}\text { ergonomics; human factors, } \\
\text { technology; human error, patient } \\
\text { safety; system resilience }\end{array}$ \\
\hline $\begin{array}{l}\text { 20.Medication errors detected in non-traditional databases: } \\
\text { types of errors in methotrexate dosing as listed in four } \\
\text { different Danish registers.(38) }\end{array}$ & Database research & Pharmacoepidemiology & $\begin{array}{c}\text { Methotrexate, Medication errors, } \\
\text { Pharmacovigilance databases }\end{array}$ \\
\hline $\begin{array}{l}\text { 21.Narrativizing Nursing Students' Experiences With } \\
\text { Medical Errors During Clinicals.(39) }\end{array}$ & Qualitative interviews & Nursing & $\begin{array}{l}\text { communication; education, } \\
\text { professional; narrative inquiry; } \\
\text { nursing; safety, patient }\end{array}$ \\
\hline $\begin{array}{l}\text { 22.Near misses and unsafe conditions reported in a Pediatric } \\
\text { Emergency Research Network.(40) }\end{array}$ & Observational study & Pediatrics & -- \\
\hline $\begin{array}{l}\text { 23.Not another safety culture survey': using the Canadian } \\
\text { patient safety climate survey (Can-PSCS) to measure } \\
\text { provider perceptions of PSC across health settings.(41) }\end{array}$ & Policy review & $\begin{array}{l}\text { Health Policy, Family } \\
\text { Medicine, Nursing, }\end{array}$ & -- \\
\hline
\end{tabular}




\begin{tabular}{|c|c|c|c|}
\hline $\begin{array}{l}\text { 24.Patient safety and communication: a new assessment for } \\
\text { doctors trained in countries where language differs from that } \\
\text { of the host country: results of a pilot using a domain-based } \\
\text { assessment.(42) }\end{array}$ & $\begin{array}{l}\text { Assessment/pilot test - } \\
\text { (objective structured clinical } \\
\text { examination) }\end{array}$ & Medicine & $\begin{array}{l}\text { Assessment, Clinical communication, } \\
\text { Global healthcare workforce }\end{array}$ \\
\hline $\begin{array}{l}\text { 25.Patient safety incident capture resulting from incident } \\
\text { reports: a comparative observational analysis.(43) }\end{array}$ & Investigation research & Emergency Medicine, & $\begin{array}{c}\text { Incident reporting, Quality } \\
\text { improvement, Patient safety, } \\
\text { Emergency medicine }\end{array}$ \\
\hline $\begin{array}{l}\text { 26.Patients and Public Involvement in Patient Safety and } \\
\text { Treatment Process in Hospitals Affiliated to Kashan } \\
\text { University of Medical Sciences, Iran, 2013(44). }\end{array}$ & Cross-sectional study & $\begin{array}{c}\text { Epidemiology And } \\
\text { Biostatistics, Health } \\
\text { Information Management }\end{array}$ & $\begin{array}{l}\text { Consumer Participation; Patient; } \\
\text { Patient-Centered Care; Decision } \\
\text { Making }\end{array}$ \\
\hline $\begin{array}{l}\text { 27.Phenotyping for patient safety: algorithm development } \\
\text { for electronic health record based automated adverse event } \\
\text { and medical error detection in neonatal intensive care.(45) }\end{array}$ & Research paper & $\begin{array}{l}\text { Biomedical Informatics, } \\
\text { Medicine }\end{array}$ & -- \\
\hline $\begin{array}{l}\text { 28.Point and counterpoint: patient control of access to data } \\
\text { in their electronic health records.(46) }\end{array}$ & Editorial/manuscript & Health Information, & -- \\
\hline
\end{tabular}




\begin{tabular}{|c|c|c|c|}
\hline $\begin{array}{l}\text { 29. Quality and safety of minimally invasive surgery: past, } \\
\text { present, and future.(47) }\end{array}$ & Perspective research & $\begin{array}{c}\text { Biomedical Engineering } \\
\text { And Computational } \\
\text { Biology }\end{array}$ & $\begin{array}{l}\text { human factors and ergonomics, } \\
\text { minimally invasive surgery, patient } \\
\text { safety, health care quality }\end{array}$ \\
\hline $\begin{array}{l}\text { 30.Rheumatology telephone advice line - experience of a } \\
\text { Portuguese department.(48) }\end{array}$ & Survey & Rheumatology & $\begin{array}{l}\text { Telephone helplines; Education; } \\
\text { Nursing;, Rheumatology }\end{array}$ \\
\hline $\begin{array}{l}\text { 31.Surgical checklists: a systematic review of impacts and } \\
\text { implementation.(49) }\end{array}$ & Systematic review & Medicine & $\begin{array}{l}\text { surgical checklist, pacient safety, } \\
\text { adverse events, }\end{array}$ \\
\hline $\begin{array}{l}\text { 32.Teaching patient safety in the medical undergraduate } \\
\text { program at the Universidade Federal de São Paulo.(50) }\end{array}$ & Descriptive study, & Health Education & $\begin{array}{l}\text { Patient safety; Education, medical, } \\
\text { undergraduate; Hospitals, teaching; } \\
\text { Education, medical; Curriculum; } \\
\text { Schools, medical; Faculty }\end{array}$ \\
\hline 33.Technology and simulation to improve patient safety.(51) & Review & Neurological Surgery & $\begin{array}{l}\text { Simulation, Neurosurgery, Surgical } \\
\text { simulator, Resident education, } \\
\text { Neurosurgical simulator }\end{array}$ \\
\hline $\begin{array}{l}\text { 34. The effect of an organizational network for patient safety } \\
\text { on safety event reporting.(52) }\end{array}$ & Time-series analysis & $\begin{array}{l}\text { Medicine, Clinical } \\
\text { Evaluative Sciences }\end{array}$ & $\begin{array}{c}\text { adverse event reporting, safety culture, } \\
\text { organizational network approach }\end{array}$ \\
\hline
\end{tabular}




\begin{tabular}{|c|c|c|c|}
\hline $\begin{array}{l}\text { 35.The frequency of diagnostic errors in outpatient care: } \\
\text { estimations from three large observational studies involving } \\
\text { US adult populations (53). }\end{array}$ & Database research & $\begin{array}{c}\text { Medicine, Health } \\
\text { Services }\end{array}$ & diagnostic errors \\
\hline $\begin{array}{l}\text { 36.The Role of Medical Staff in Providing Patient's Rights } \\
\text { (54) }\end{array}$ & Review & Medicine & $\begin{array}{l}\text { patient's rights, accreditation, } \\
\text { evaluation, education, health care } \\
\text { quality }\end{array}$ \\
\hline $\begin{array}{l}\text { 37.The State and Trends of Barcode, RFID, Biometric and } \\
\text { Pharmacy Automation Technologies in US Hospitals (55). }\end{array}$ & $\begin{array}{l}\text { Retrospective descriptive } \\
\text { analysis of survey data }\end{array}$ & Medicine & -- \\
\hline $\begin{array}{l}\text { 38. Understanding nurses and physicians' fear of } \\
\text { repercussions for reporting errors: clinician characteristics, } \\
\text { organization demographics, or leadership factors? (56) }\end{array}$ & Cross-sectional analysis & Nursing & -- \\
\hline 39. We're not there yet. (57) & Invited commentary & Medicine & $\begin{array}{l}\text { patient safety, medical error, safety, } \\
\text { culture, human error }\end{array}$ \\
\hline $\begin{array}{l}\text { 40. What effects have resident work-hour changes had on } \\
\text { education, quality of life, and safety? A systematic } \\
\text { review(58). }\end{array}$ & Systematic review & Orthopedic Surgery, & -- \\
\hline
\end{tabular}


